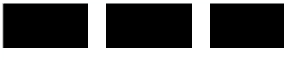 \\ E \\ THE WILLIAM DAVIDSON INSTITUTE \\ AT THE UNIVERSITY OF MICHIGAN
}

\section{Equilibrium Exchange Rates in Transition Economies: Taking Stock of the Issues}

By: Balázs Égert, László Halpern and Ronald MacDonald

William Davidson Institute Working Paper Number 793

October 2005 


\title{
Equilibrium Exchange Rates in Transition Economies: Taking Stock of the Issues
}

\author{
Balázs Égert• László Halpern^ Ronald MacDonald
}

\begin{abstract}
In this paper we present an overview of a number of issues relating to the equilibrium exchange rates of transition economies of the former soviet bloc. In particular, we present a critical overview of the various methods available for calculating equilibrium exchange rates and discuss how useful they are likely to be for the transition economies. Amongst our findings is the result that the trend appreciation usually observed for the exchange rates of these economies is affected by factors other than the usual Balassa-Samuelson effect, such as the behaviour of the real exchange rate of the open sector and regulated prices. We then consider three main sources of uncertainty relating to the implementation of an equilibrium exchange rate model, namely: differences in the theoretical underpinnings; differences in the econometric estimation techniques; and differences relating to the time series and cross-sectional dimensions of the data. The ensuing three-dimensional space of real misalignments is probably a useful tool in determining the direction of a possible misalignment rather than its precise size.
\end{abstract}

JEL: C15, E31, F31, O11, P17.

Keywords: equilibrium exchange rate, Purchasing Power Parity, trend appreciation, Balassa-Samuelson effect, productivity, inflation differential, tradable prices, regulated prices, Fundamental Equilibrium Exchange Rate, Behavioural Equilibrium Exchange Rate, Permanent Equilibrium Exchange Rate, NATREX, CHEER, transitional economies, euro.

Forthcoming in Journal of Economic Surveys.

Oesterreichische Nationalbank; MODEM, University of Paris X-Nanterre and William Davidson Institute. E-mail: balazs.egert@oenb.at and begert@u-paris10.fr

Institute of Economics, Hungarian Academy of Sciences; CEPR, Central European University and William Davidson Institute. Email: halpern@econ.core.hu

- University of Glasgow and CESifo. E-mail: r.macdonald@,socsci.gla.ac.uk

This paper is a substantially revised version of the CEPR Discussion Paper No. 4809. Earlier versions of the paper benefited from comments and suggestions from Enrique Alberola, Mark DeBroeck, Péter Karádi, Kirsten Lommatzsch, Dubravko Mihaljek, Renzo Orsi, Thomas Reininger, Cezary Wójcik and two anonymous referees. The help of national central banks is much appreciated in providing us with the regulated price series used in this paper.

The opinions expressed in this paper do not necessarily represent the views of the Oesterreichische Nationalbank or the European System of Central Banks (ESCB). 


\section{Introduction}

In the last decade, the topics of equilibrium exchange rates and exchange rate misalignment have been the focus of much academic and policy related research. ${ }^{2}$ This is especially the case for the economies of Central and Eastern Europe (CEE), which started their transformation process from planned to market-based economies in the late 1980s and early 1990s. At the start of the transition process, there was considerable interest in the choice of an appropriate exchange rate regime for transition economies and also on the issue of whether their currencies were fairly valued at a given point in time. In particular, the observed trend appreciation of the real exchange rate in some of these countries has raised the issue of whether this reflects adjustment towards equilibrium, due to an initial undervaluation, or whether it corresponds to an equilibrium appreciation. $^{3}$

Concerns of possible overvaluation of CEE exchange rates has been further heightened recently by the high current account deficits that have recently re-emerged in these countries and this has focussed attention again on the issue of equilibrium exchange rates in transition economies. Potential overvaluation should be of great concern for these economies given their high degree of openness, in terms of exports and imports as a proportion of GDP, and because of their export-led economic catching-up process. For countries of the former Soviet Union, such as Russia and Kazakhstan, a key issue is the role of natural resource, in particular the impact of oil price changes on the real exchange rate and the real economy - the so-called Dutch Disease phenomenon.

The fact that three Baltic countries and Slovenia have already joined ERM-II ${ }^{4}$ and are now on the verge of adopting the euro, and that the Czech Republic, Hungary, Poland and Slovakia may join ERM-II in the coming years has given added importance to the issue of what is the correct equilibrium exchange rate for these countries. Getting the rate wrong could have very serious implications for these countries given the degree of catch up that they still have to undergo. Although it is often thought that an overvalued exchange rate would have the greatest deleterious implications, due to its effect on competitiveness, undervaluation may also have a negative economic impact in the context of ERM-II. An undervalued currency may result in an overheating economy fuelled by booming exports, which, in turn, would lead to higher inflation prohibiting the fulfilment of the Maastricht criterion on price stability. So getting the exchange rate right is crucially important for CEE countries.

Other key aspects of transition economics, such as enterprise restructuring and economic growth have already been extensively surveyed (see, for example, Coricelli and Campos, 2002; Djankov and Murrell, 2002; and Kornai, Maskin and Roland, 2003). However, to our knowledge there is no comprehensive survey of equilibrium exchange rate issues for the Central and Eastern European countries and we attempt to redress that imbalance in this paper by presenting an overview of a number of issues relating to the estimation of equilibrium exchange rates for transition economies. In particular, we not only present a critical overview of the various methods available for calculating equilibrium exchange rates, such as Purchasing Power Parity, its trend adjusted variants, the internal-external approach and its variants (the Fundamental Equilibrium Exchange Rate, the Macroeconomic Balance Approach and the NATREX), the Behavioural Equilibrium Exchange Rate, the Permanent Equilibrium Exchange Rate, the capital enhanced equilibrium exchange rate and the New Open Economy Macroeconomic Approach to the determination of the equilibrium exchange rate, but we also examine how they may be linked to each other. We then discuss how the findings of the empirical literature match with theory and address some methodological issues related to the implementation of equilibrium exchange rate estimates for transition economies. Finally, we overview the uncertainties, which make it difficult to derive a point estimate for real misalignments

The outline of the remainder of this paper is as follows. Section 2 presents some stylised facts of real exchange rate behaviour in transition economies. Section 3 gives basic concepts and definitions of the exchange rate. Section 4 discusses the theoretical underpinnings of the leading approaches to calculating and measuring equilibrium exchange rates (where relevant we include empirical evidence from industrialized countries in this overview). Section 5 attempts to link the different approaches. Section 6 addresses some

\footnotetext{
${ }^{2}$ See e.g. Williamson (1994), MacDonald (1995, 2005), Stein $(1995,2002)$ and Driver and Westaway (2004).

${ }^{3}$ If there is initial undervaluation and the real exchange rate did not appreciate, or the equilibrium appreciation exceeded the observed real appreciation, the exchange rate remained undervalued.

${ }^{4}$ Estonia, Lithuania and Slovenia entered ERM-II on June 28, 2004, while Latvia (with Cyprus and Malta) joined the ERM-II on May $1,2005$.
} 
methodological issues of the empirical literature as it relates to CEE countries. Section 7 summarizes the uncertainties related to the computation of equilibrium exchange rates. Finally, Section 8 provides concluding remarks.

\section{Real Exchange Rate Behaviour in Transition Economies: Some Stylised Facts}

In this section we consider some of the stylised facts relating to the exchange rate behaviour of transition economies. Table 1 and Figure 1 show that: (a) the real exchange rate of the transition economies is substantially undervalued in terms of absolute PPP as the real exchange rate in levels is higher than $1^{5}$; and (b) the real exchange rates of the transition economies experienced an appreciation during the transition process. These statements need, however, qualification as there is a great deal of heterogeneity across countries.

The relatively large undervaluation in PPP terms tends to disappear systematically for the CEEC5. Noteworthy is the fact that the Hungarian and Polish currencies started to appreciate from 1990 onwards, while the undervaluation appears to dissipate for the Czech, Slovak and Slovene currencies only from 1992 on. The story for Croatia is very much similar to that for Slovenia, mainly because of their common Yugoslav history. These two countries stand out from the others by having the lowest undervaluation for most of the period analysed here. Although Russia and Ukraine were very close to 1, and Bulgaria even slightly below 1, their currencies became tremendously undervalued by PPP standards by 1992 . While they started to move closer to 1 afterwards, they were the most undervalued in 2002 among the countries reviewed here. For the Baltic countries, data for deviation from absolute PPP is available only for 1999 and 2002, which show that they are more undervalued than the CEE5, but less than countries from South-Eastern Europe (except for Croatia) and of the former Soviet Union.

An ocular analysis of Figure 1 reveals that the real exchange rate appreciated strongly in the early 1990s in the Baltic States but then flattened considerably by now. By contrast, the real exchange rate of the Czech Republic, Hungary, Poland and Slovakia appreciated steadily from 1990 to 2002, with a pronounced appreciation to be observed in 1991 and 1992. The real exchange rate remained pretty stable in Slovenia. Perhaps with the exception of Croatia, the real exchange rate in South-Eastern Europe and the former Soviet Union depreciated to a great extent during the early years of the 1990s, and was followed by large appreciations. A second round of depreciation, much smaller than the initial one, occurred in 1997 in Bulgaria and in the aftermath of the Russian crisis in 1998 in Russia, Ukraine and Kazakhstan.

Table 1. The Real Exchange Rate in Level, 1990 to 2002

\begin{tabular}{|c|c|c|c|c|c|c|c|}
\hline & 1990 & 1991 & 1992 & 1993 & 1996 & 1999 & 2002 \\
\hline \multicolumn{8}{|c|}{ Baltic countries (B-3) } \\
\hline Estonia & --- & --- & --- & --- & --- & 2.33 & 2.18 \\
\hline Latvia & --- & --- & --- & --- & --- & 2.36 & 2.48 \\
\hline Lithuania & --- & --- & --- & --- & --- & 2.58 & 2.45 \\
\hline \multicolumn{8}{|c|}{ Central and Eastern Europe (CEE 5) } \\
\hline Czech Republic & 3.91 & 4.82 & 4.42 & 3.43 & 2.69 & 2.53 & 1.94 \\
\hline Hungary & 3.12 & 2.78 & 2.62 & 2.29 & 2.37 & 2.32 & 1.89 \\
\hline Poland & 4.06 & 2.98 & 2.98 & 2.76 & 2.26 & 2.23 & 1.89 \\
\hline Slovakia & 2.87 & 3.56 & 3.35 & 2.87 & 2.52 & 2.58 & 2.37 \\
\hline Slovenia & 1.43 & 1.82 & 1.88 & 1.74 & 1.45 & 1.42 & 1.42 \\
\hline \multicolumn{8}{|c|}{ South-Eastern Europe (SEE) } \\
\hline Bulgaria & 0.98 & 6.27 & 5.93 & 4.21 & 4.90 & 3.45 & 3.03 \\
\hline Croatia & 1.43 & 1.28 & 2.68 & 2.15 & 1.65 & 1.83 & 1.70 \\
\hline Romania & 3.99 & 4.29 & 6.20 & 4.23 & 4.20 & 3.34 & 2.86 \\
\hline \multicolumn{8}{|c|}{ Former Soviet Union (FSU) } \\
\hline Russia & 1.20 & 1.62 & 16.05 & 6.40 & 2.32 & 4.44 & 3.24 \\
\hline Ukraine & 1.20 & 1.89 & 12.37 & 8.05 & 3.81 & 5.86 & 5.64 \\
\hline
\end{tabular}

\footnotetext{
${ }^{5}$ Throughout the paper, the exchange rate will be defined in this way. Therefore, a rise in the exchange rate implies a depreciation, while a fall indicates an appreciation.
} 
Source: Authors' own calculations based on data obtained from Countries in Transition 2004 (WIIW) and NewCronos (Eurostat) Note: PPP is the domestic to euro area (absolute) price level ratio.

Figure 1. CPI- and PPI-Based Real Exchange Rates Against the Euro Area, 1990/1993-2003 Baltic Countries
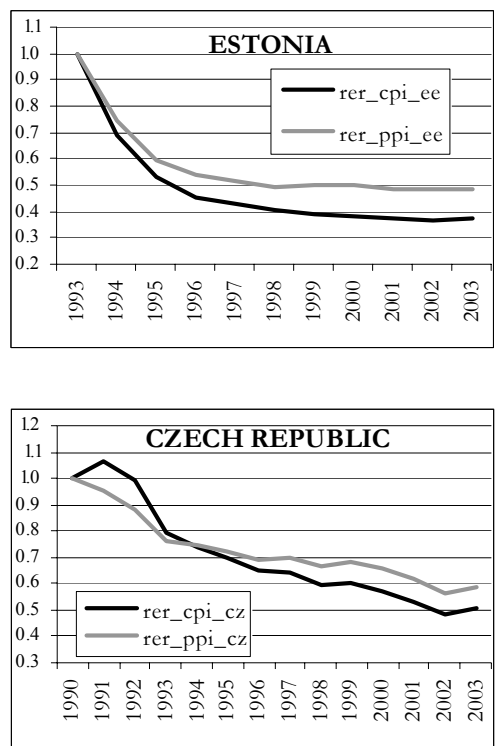

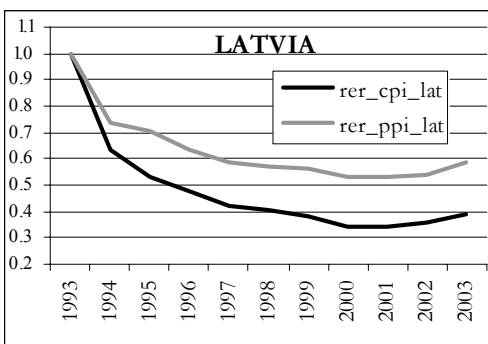

CEE-5

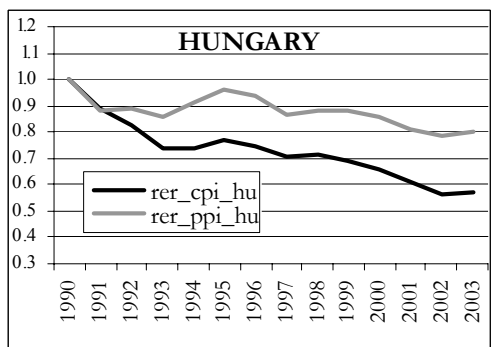

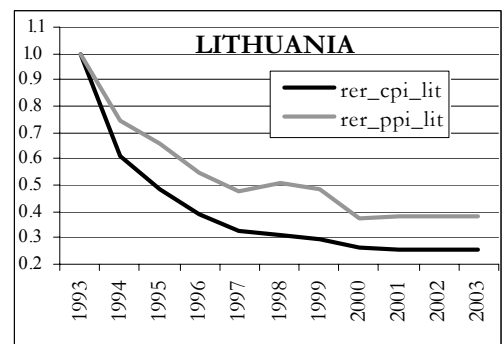

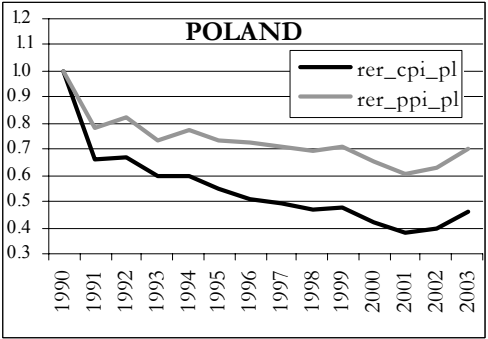

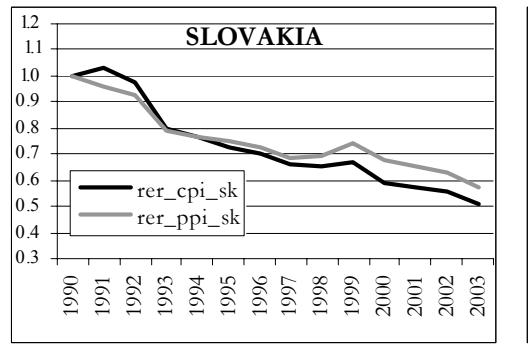

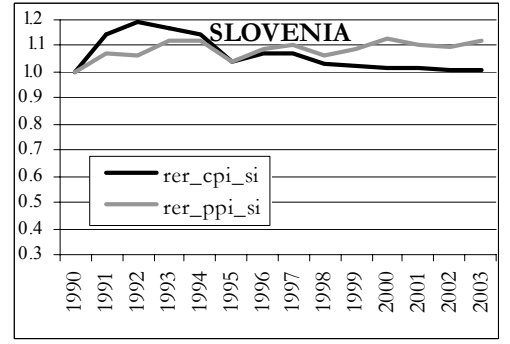

South-Eastern Europe
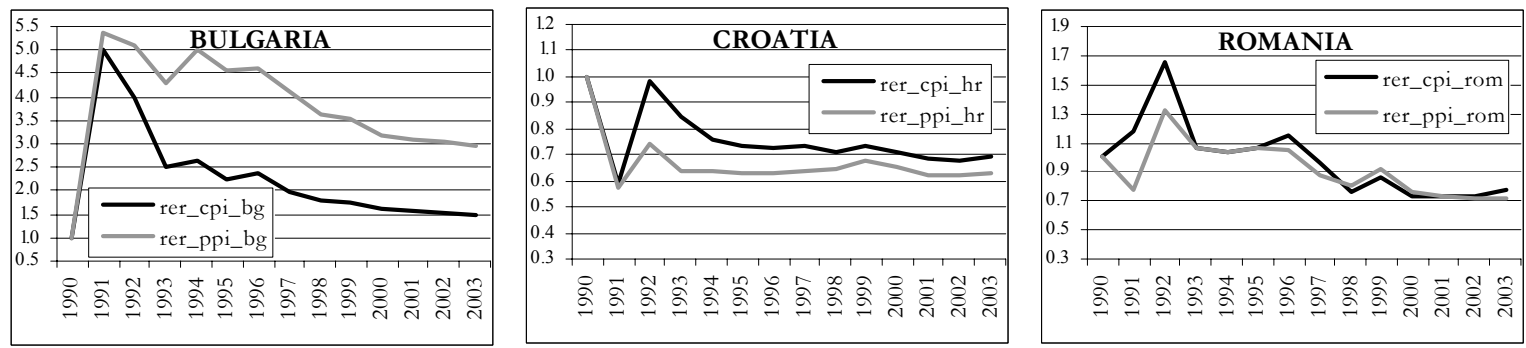

Former Soviet Union (against the USD)
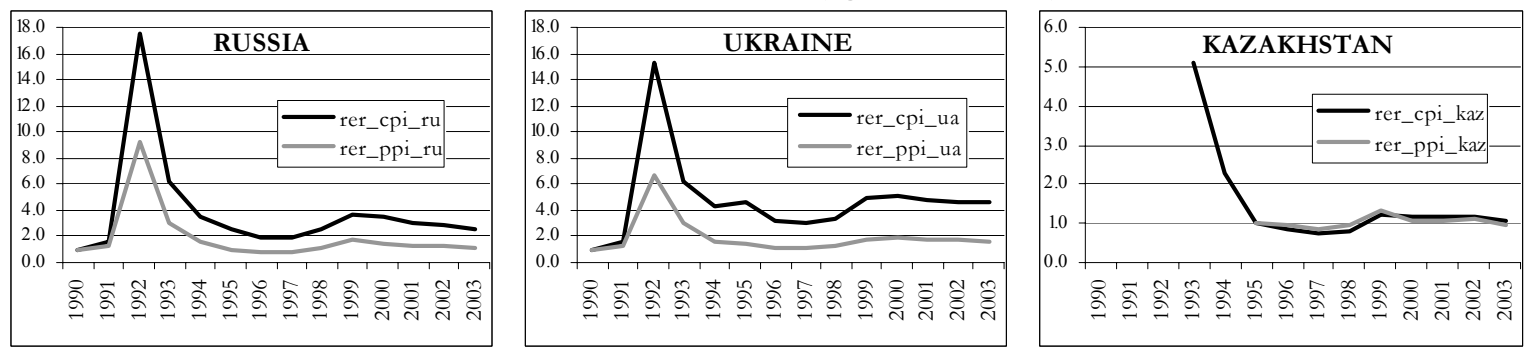

Source: Authors' own calculations based on data obtained from the WIIW Annual Databased (CEEC5), Eurostat (euro area), IFS/IMF and national sources (Baltic States). 


\section{Basic Concepts and Definitions}

The real exchange rate can be defined in a number of ways, two of which are relevant for our discussion in this paper. The first definition, termed the "internal real exchange rate", is the ratio of non-tradable to tradable prices:

$$
Q^{I}=P^{N T} / P^{T}
$$

where $Q^{I}$ is the internal real exchange rate and $P^{N T}$ and $P^{T}$ stand, respectively, for the price level of the non-tradable and tradable sectors.

This definition of the real exchange rate is usually thought to be appropriate for small, open developing countries whose trade consists chiefly of commodities. The internal real exchange rate does not include the nominal exchange rate, as the latter is assumed to be either fixed or to be driven by commodity prices in world markets. This is why estimating the equilibrium "internal real exchange rate" provides little guidance on the equilibrium nominal exchange rate.

By contrast, and of more relevance for our purposes in this paper, is the macroeconomic definition of the real exchange rate, which can also be referred to as the "external real exchange rate," (hereafter, this is simply referred to as the real exchange rate), this is defined as the nominal exchange rate multiplied by the foreign price level, divided by the domestic price level:

$$
Q=\left(E \cdot P^{*}\right) \cdot P^{-1}
$$

or in logarithms:

$$
q=e+p^{*}-p
$$

In this case, the nominal exchange rate $(E)$ is expressed in home currency per unit of foreign currency. ${ }^{6}$ In words, the real exchange rate $(Q)$ is the ratio of the foreign $\left(E P^{*}\right)$ and domestic price $(P)$ levels converted into the same unit of measurement, i.e. domestic currency units. $P$ and $P^{*}$ denote the domestic and foreign price levels. If the variables are expressed in indices, the real exchange rate shows the relative shift which has occurred between the foreign and domestic price levels over a given period of time.

In our discussions of the influence of productivity effects on the real exchange rate it shall prove useful to unravel the real exchange rate given in (2a) into an internal and external component. For example, an analogous representation of the definition of the real exchange rate given in (2a) can also be written for tradable goods as:

$$
q^{T}=e+p^{T^{*}}-p^{T} .
$$

If it is further assumed that the overall price level can be split into tradable and non-tradable prices, which, after transforming variables into logarithms, can be written in the following way: ${ }^{7}$

$$
p=\alpha \cdot p^{T}+(1-\alpha) \cdot p^{N T},
$$

where $\alpha$ stands for the share of tradable goods in the consumer price basket and $(1-\alpha)$ represents the share of non-tradable goods, and an analogous expression is assumed to hold in the foreign country. Using equations (2a), (2b) and (3), the real exchange rate can then be decomposed into three components:

- (A) the nominal exchange rate (e)

- (B) the ratio of foreign to domestic tradable prices $\left(p^{T^{*}}-p^{T}\right)$

- (C) the ratio of the domestic to the foreign relative price of non-tradable goods: $(1-\alpha)\left(p^{N T}-p^{T}\right)-\left(1-\alpha^{*}\right)\left(p^{N T^{*}}-p^{T^{*}}\right)$

\footnotetext{
${ }^{6}$ Throughout the paper, the exchange rate will be defined in this way. Therefore, a rise in the exchange rate implies a depreciation, while a fall indicates an appreciation.

${ }^{7}$ Small letters refer to logarithms hereafter.
} 
$q={\underset{A}{A}}_{A}^{e}+\underbrace{p^{T} *-p^{T}}_{B}-((1-\alpha) \underbrace{(\underbrace{\left.p^{N T}-p^{T}\right)}_{D}-\left(1-\alpha^{*}\right)\left(p^{N T} *-p^{T} *\right)}_{C})$

The first two components, A and B build the real exchange rate for tradable goods, while the third component, $\mathrm{C}$, is the relative price of non-tradables to tradables across countries (sometimes also refereed to as internal relative prices). The so-called internal real exchange rate, D, is part of C. Expression (4) is a useful reference point for the discussion in the next section.

\section{Theoretical Foundations of the Equilibrium Exchange Rate}

A number of alternative methods have been used to calculate an equilibrium exchange rate for CEE countries and we consider the main approaches in this section.

\subsection{Purchasing Power Parity}

There exist several approaches to defining an equilibrium exchange rate. Perhaps the best known of these is purchasing power parity (henceforth PPP), which was formalized and synthesized in a string of papers by Cassel (1916a, b and 1918). PPP indicates that the nominal exchange rate is the domestic price level divided by the foreign price level:

$$
E^{P P P}=P / P^{*} .
$$

PPP is usually taken as a measure of the long-run nominal exchange rate, rather than a concept that holds continuously. Cassel recognised that in the short run, the nominal exchange rate prevailing in the foreign exchange market may deviate from that suggested by PPP due to, for example, non-zero interest differentials and foreign exchange market intervention. In the short-run, therefore, the extent of deviation from PPP might be thought of as an over- or undervaluation of the home currency. This can be illustrated by introducing the following equation: ${ }^{8}$

$$
Q=E / E^{P P P} \text {. }
$$

Therefore, if the actual nominal exchange rate is higher than that determined by PPP ( $E>E^{P P P}$ and $\left.Q>1\right)$, the real and nominal exchange rates are undervalued, whereas in the opposite case they will be overvalued ( $E<E^{P P P}, Q<1$ ). If $E=E^{P P P}$, then the real exchange rate is equal to 1 and, of course, PPP holds (the real exchange rate is fairly valued in PPP terms). ${ }^{9}$

The conjecture underlying PPP is that the Law of One Price (LOOP) holds for every good in the price basket and therefore the second component on the right hand side of (4) is zero. In accordance with the LOOP, a given good should cost the same in the home and foreign country when the price is expressed in the same currency $\left(P_{i}=E \cdot P_{i}^{*}\right)$. This is secured by an international goods arbitrage mechanism, which involves shipping the good from the location where it is cheaper to that where it is more expensive. For this arbitrage process to work perfectly, perfect competition has to prevail in both the home and foreign markets, there must be no trade barriers and capital movements must not be restricted.

There are a number of reasons why PPP might be misleading as a yardstick for assessing equilibrium real exchange rates of which only the most important ones are enumerated here. ${ }^{10}$

Even though the LOOP holds, if the composition and the weights of the price basket differ across countries, PPP is a flawed measurement, as it is akin, say, to comparing apples with oranges and pears. Differences in

\footnotetext{
${ }^{8}$ Note that this formula is sometimes also referred to as the Exchange Rate Deviation Index (ERDI). Q is defined as units of local currency over one unit of foreign currency. 1/Q is the real exchange rate given as units of foreign currency to one unit of domestic currency, and is also labeled as the comparative or relative price level or the exchange rate gap.

${ }^{9}$ The concept of relative PPP, in which the percentage change in the exchange rate is driven by the percentage change in inflation differentials across countries, is much less controversial than absolute PPP and is generally supported empirically.

${ }^{10}$ The failure of PPP in the tradable sector is addressed after we consider the Balassa-Samuelson effect.
} 
the composition of the price basket can come from different consumer and production patterns: consumers may want to consume different goods or varying quantities of the same good and producers can manufacture different goods in different countries. This is likely to be an important issue when using PPP to calculate the equilibrium values of the new member states with their old EU-15 counterparts.

But perhaps most importantly, the presence of non-tradable goods in the price basket will, as suggested by (4), bring about a systematic deviation of the observed exchange rate from the exchange rate implied by PPP. This deviation is expected to be substantial, especially when comparing countries at different stages of economic development. The reason for this is that non-tradable prices in developing countries are far lower than in developed countries.

So it would seem that PPP on its own does not appear to be a very useful construct in explaining the equilibrium exchange rates of transition economies. One popular way of extending PPP is to allow for factors that impart systematic movements in the relative price of non-tradable goods, and perhaps the best known explanation for such systematic deviation is the so-called Balassa-Samuelson effect (B-S effect henceforth), which we now consider.

\subsection{Trend Adjusted Purchasing Power Parity}

In this section we present a discussion of what we refer to as trend adjusted PPP. This variant of PPP essentially allows for deviations of the real exchange rate from unity due to productivity differentials. We first give an overview of the basic Balassa-Samuelson ${ }^{11}$ proposition and then go on to consider extensions and problems with the approach. Since this approach is often thought to have special relevance for transition economies, we devote some time to it here.

\subsubsection{Accounting for Market Non-tradable Prices: The Balassa-Samuelson Effect}

The standard Balassa-Samuelson explanation (see Balassa, 1964; Samuelson, 1964) for the relationship between productivity in the tradable sector relative to that in the non-tradable sector (henceforth referred to as dual productivity) and the price of non-tradable goods relative to that of tradable goods (henceforth referred to as the relative price of non-tradable goods), depends on the following crucial assumptions. The explanation is based on a two sector economy in which both tradable and non-tradable goods are produced. It is assumed that market forces are at work in both sectors. The LOOP is assumed to hold continuously for tradable goods and so prices in this sector are given exogenously. Wages are linked to the level of productivity in the open sector and are equalized across sectors so that the wage level in the closed sector is comparable to that in the open sector. Finally, prices in the sheltered sector depend on wages, i.e. on unit labour costs rather than on the productivity level in this sector. Given these assumptions and in the context of a two-sector neoclassical framework with perfect capital mobility and with the interest rate assumed exogenous, we can obtain the following relationship:

$$
\hat{p}^{N T}-\hat{p}^{T}=\frac{\delta}{\gamma} \hat{a}^{T}-\hat{a}^{N T},
$$

where circumflexes $\left(^{\wedge}\right)$ stand for growth rates, $\delta$ and $\gamma$ denote the share of labour in the sheltered and open sectors, respectively, $\hat{p}^{N T}-\hat{p}^{T}$ represents the growth rate of the relative price of non-tradable goods and $\hat{a}^{T}-\hat{a}^{N T}$ is the growth rate of dual total factor productivity. ${ }^{12}$ Equation (7) could be referred to as the

\footnotetext{
${ }^{11}$ The Balassa-Samuelson effect is sometimes also termed the Harold-Balassa-Samuelson or the Ricardo-Harold-Balassa-Samuelson effect. In this paper, the term Balassa-Samuelson will be used.

12 The supply side of the two sectors is modeled by means of two different, constant-returns-to-scale Cobb-Douglas production functions: $Y^{T}=A^{T}\left(L^{T}\right)^{\gamma}\left(K^{T}\right)^{(1-\gamma)}$ and $Y^{N T}=A^{N T}\left(L^{N T}\right)^{\delta}\left(K^{N T}\right)^{(1-\delta)}$ where $A^{T}, A^{N T}, L^{T}, L^{N T}, K^{T}$ and $K^{N T}$ represent the level of total factor productivity, labor and capital in the open and closed sectors, respectively. Because of profit maximization, interest rates $(i)$ and nominal wages $(w)$ in both sectors equal the marginal products $d Y^{T} / d K^{T}, d Y^{N T} / d K^{N T} d Y^{T} / d L^{T}$ and $d Y^{N T} / d L^{N T}$,respectively:$$
i^{T}=\log (1-\gamma)+a^{T}-\gamma\left(k^{T}-l^{T}\right)
$$ 
internal transmission mechanism of the B-S effect. Note that a decrease in the share of labour in the open sector relative to that in the sheltered sector would lead to a rise in the relative price of non-tradables even without any change in productivities. The transformation of equation (4) into growth rates, combined with equation (7), yields equation (8) as long as the share of tradables in the consumer price basket is the same in the home and foreign economies $\left(\alpha=\alpha^{*}\right)$ :

$$
\hat{q}=\hat{e}+\hat{p}^{T *}-\hat{p}^{T}-(1-\alpha)\left(\left(\frac{\delta}{\gamma} \hat{a}^{T}-\hat{a}^{N T}\right)-\left(\frac{\delta^{*}}{\gamma^{*}} \hat{a}^{T *}-\hat{a}^{N T *}\right)\right),
$$

where the growth rate of the CPI-based real exchange rate equals the rate of growth of the real exchange rate for the open sector, and, most importantly, the difference between the growth rates of dual total factor productivity at home and abroad. So, an increase in the dual productivity differential should lead to a real appreciation of the currency. Rearranging equation (8), as in equation (8'), shows that an increase in the difference between productivity in the home and foreign countries' open sectors causes a real appreciation, whilst an increase in the difference between productivity in the home and foreign countries' closed sectors has the opposite effect. Note that equations (8) and (8') are sometimes labelled as the external transmission mechanism of the B-S effect.

$$
\hat{q}=\hat{e}+\hat{p}^{T *}-\hat{p}^{T}-(1-\alpha)\left(\frac{\delta}{\gamma}\left(\hat{a}^{T}-\hat{a}^{T *}\right)-\left(\hat{a}^{N T} *-\hat{a}^{N T} *\right)\right),
$$

It is also worth noting an analogous relationship to (8), defined in levels (as opposed to growth rates) and on the basis of average labour productivity (instead total factor productivity): ${ }^{13}$

$$
\frac{P^{N T}}{P^{T}}=\frac{\gamma}{\delta} \cdot \frac{Y^{T} / L^{T}}{Y^{N T} / L^{N T}}
$$

where $\mathrm{Y}$ and $\mathrm{L}$ denote output and labour and $Y / L$ is the average labour productivity. Transforming equation (9) into logarithms leads to:

$$
p^{N T}-p^{T}=\text { const }+\left(a^{T}-a^{N T}\right),
$$

where const is a constant term containing $\log (\gamma)$ and $\log (\delta)$. Applying equation (10) to equation (4) gives equation (11), provided $\alpha=\alpha^{*}$ :

$$
q=\text { const }+\left(e+p^{T} *-p^{T}\right)-(1-\alpha)\left(\left(a^{T}-a^{N T}\right)-\left(a^{T} *-a^{N T} *\right)\right),
$$

where the real exchange rate is linked to the difference between dual average labour productivity at home and abroad (henceforth referred to as the dual productivity differential). Note that the constant term now contains $\log (\gamma), \log (\delta), \log \left(\gamma^{*}\right)$ and $\log \left(\delta^{*}\right)$, multiplied by $(1-\alpha)$.

$$
\begin{aligned}
& i^{N T}=\left(p^{N T}-p^{T}\right)+\log (1-\delta)+a^{N T}-\delta\left(k^{N T}-l^{N T}\right) \\
& w^{T}=\log (\gamma)+a^{T}+(1-\gamma)\left(k^{T}-l^{T}\right) \\
& w^{N T}=\left(p^{N T}-p^{T}\right)+\log (\delta)+a^{N T}+(1-\delta)\left(k^{N T}-l^{N T}\right)
\end{aligned}
$$

Equations (3') to (6') are expressed in logarithmic terms. Tradable prices are exogenous because of perfect competition in the open sector. Given that capital is assumed to be fixed in the short run, the first order conditions (FOC) in the open sector determine the capital-labor ratio and the nominal wage. Wage equalization across sectors implies that this wage level is exogenous in the sheltered sector. In turn, the FOC in the sheltered sector give the capital-labor ratio in the sheltered sector and the price of non-tradables relative to that of tradables. To obtain equation (7), equations (3') to (6') are totally differentiated and rearranged (for a step-by-step derivation, see Égert, 2003).

${ }^{13}$ Given that the marginal productivity of labor is equal between the open and closed sectors, equations( $\left.3^{\prime}\right)$ and (4') can be equated based on which the relative price of non-tradables can be expressed as follows: $\frac{P^{N T}}{P^{T}}=\frac{\partial Y^{T} / \partial L^{T}}{\partial Y^{N T} / \partial L^{N T}}$. A well-known feature of Cobb-Douglas production functions is that marginal productivity is proportional to average productivity: $\frac{\partial Y^{T}}{\partial L^{T}}=A^{T} \gamma\left(\frac{K^{T}}{L^{T}}\right)^{(1-\gamma)}=\gamma \frac{Y^{T}}{L^{T}}$ and $\frac{\partial Y^{N T}}{\partial L^{N T}}=A^{N T} \delta\left(\frac{K^{N T}}{L^{N T}}\right)^{(1-\delta)}=\delta \frac{Y^{N T}}{L^{N T}}$, which yields equation (9). 
Such a derivation has two advantages. First, sectoral average labour productivity can be used in its own right and not as a proxy for sectoral total factor productivity. ${ }^{14}$ In addition, the terms $\gamma$ and $\delta$ are incorporated into the constant term. Second, the level relationship makes it possible to use cointegration methods to estimate the long-run relationship between the real exchange rate and the dual productivity differential. ${ }^{15}$

From the model set out above, we can summarize the key propositions of the BS model:

1) Different productivity levels imply, via differences in market-based non-tradable prices, different price levels expressed in the same currency;

2) The real and nominal exchange rates of low-productivity (typically developing) countries seem undervalued in PPP terms;

3) If productivity growth is higher in the open sector compared to the sheltered sector, non-tradable prices, and thus the overall price level, will rise (also referred to as structural inflation);

4) Higher growth of the productivity differential in the home country relative to the foreign country is reflected in faster increases in the price level, leading to a real appreciation of the home currency.

Since PPP is assumed to hold for the open sector, competitiveness is not affected by the real appreciation that results from the productivity imbalance. The last assumption has important implications, particularly we believe for transition economies. In particular, it implies that all of the appreciation of the real exchange rate, deflated by the consumer price index (as a proxy for overall inflation), comes from increases in non-tradable prices, and that this can be fully ascribed to the B-S effect (the appreciation of the CPI-based real exchange rate). By contrast, in the event that PPP is not verified for the open sector and, say, the real exchange rate based on producer prices (as a proxy for tradable prices) also appreciates, the B-S effect can explain only the difference between the CPI- and the PPI-deflated real exchange rate.

It is sometimes argued that there is equivalence between a B-S induced real exchange rate appreciation (with fixed nominal exchange rates) and a real appreciation caused by the nominal exchange rate. Clarifying the nature of this equivalence would seem to be important since often exchange rates are driven by non-price determinants, such as interest rate movements. For example, if some exogenous factor causes the nominal exchange rate to appreciate then, on the basis of the LOOP, there should be a proportionate decrease in the price of tradables, leaving competitiveness unaffected. By contrast, the real exchange rate of the closed sector will appreciate, generating an appreciation of the overall real exchange rate. However, two problems arise with this account: (1) the B-S model does not contain any straightforward mechanism explaining the initial nominal appreciation (i.e. it does not provide a general model of the exchange rate), and (2) if a nominal appreciation occurs for any other reason, because the exchange rate pass-through is usually below one, competitiveness in the open sector would deteriorate (while competitiveness is unaffected if the real exchange rate appreciation is driven by non-tradable inflation).

\subsubsection{Extensions of the Standard Balassa-Samuelson Framework}

The standard simple B-S framework can be extended in at least three directions, and these extensions may be of importance for transition economies. The first extension raises the issue of the failure of the PPP in the tradable sector. The second extension adds demand side factors to the determination of the relative price of non-tradables and, finally, non-market-based non-tradable (regulated and administered) prices can be distinguished from market-based non-tradables referred to in the standard B-S framework.

\subsubsection{The Failure of PPP in the Tradable Sector}

There are a number of potential reasons for the violation of the LOOP in the open sector, such as the absence of perfect competition and the existence of transportation costs. If the LOOP is in fact violated in the open sector it implies that the B-S effect cannot account for the entirety of long-term real exchange rate

\footnotetext{
${ }^{14}$ In equations (7) and (8), total factor productivity can be approximated by average labor productivity, which may, however, be a biased proxy. Labor productivity (LP) can be decomposed into (1) the capital-labor ratio, i.e. capital intensity (CI) and into (2) TFP $(\mathrm{LP}=\mathrm{CI}+\mathrm{TFP})$. Therefore, the level of labor productivity might be systematically higher or lower than TFP, with capital intensity working as a "leverage." In the event that capital intensity changes over time, the evolution of labor productivity will differ from that of TFP. Needless to add that if capital intensity differs across countries, labor productivity as a proxy for TFP will induce an additional bias when productivity developments are compared across countries. Therefore, it would be preferable to use equations (10) and (11) where average labor productivity can be used directly.

${ }^{15}$ A specification in growth rates such as in equations (7) and (8) would imply that the cointegration technique, which is meant to link variables that are non-stationary in levels but stationary in first differences, could not be applied because the growth rates may already render the series stationary.
} 
movements. For instance, Mussa (1986) observed a strong correlation between nominal and real exchange rates for industrialized countries during the post-1973 floating period, implying that overall real exchange rate movements are dominated by changes in the real exchange rate of the open sector. This finding is also documented in Engel (1993, 1999) for the US and, more recently, in Monacelli (2004) for a set of industrialised economies. Canzoneri, Cumby and Diba (1999) provide econometric evidence that PPP cannot be verified for the open sector for a number of OECD countries, especially when the US dollar is used as the numeraire currency.

New Open Economy Macroeconomics (NOEM) models deal with two important aspects of why the real exchange rate in the open sector may drive the overall real exchange rate: (a) home bias and (b) market segmentation which gives a role to pricing-to-market (international price discrimination). These effects can be demonstrated in a simple accounting framework employed, for instance, in Benigno and Thoenissen (2003) and Lee and Tang (2003). Let us decompose tradable prices into a home-produced $\left(p^{H}\right)$ and a foreign-produced component $\left(p^{F}\right.$ ) with $\beta$ and $1-\beta$ representing the respective shares in the price index: $p^{T}=\beta \cdot p^{H}+(1-\beta) \cdot p^{F}$. Benigno and Thoenissen (2003) apply this term to both the home $\left(p^{T}\right)$ and foreign $\left(p^{T^{*}}\right)$ economies and use equation $(2 \mathrm{~b})$ to obtain:

$$
q^{T}=\underbrace{\left(\beta-\beta^{*}\right)\left(p^{F}-p^{H}\right)}_{\text {home bias }}+\underbrace{\beta^{*}\left(e+p^{H^{*}}-p^{H}\right)+\left(1-\beta^{*}\right)\left(e+p^{F^{*}}-p^{F}\right)}_{\text {market segmentation }}
$$

In contrast to the standard B-S framework, which assumes homogenous tradable goods, home consumers may prefer home brands rather than foreign brands, i.e. goods are not perfectly substitutable across countries. This implies that $\beta$ is higher than 0.5 , and this can cause the real exchange rate to deviate from absolute PPP even if the LOOP is verified for individual goods. ${ }^{16}$ Market segmentation introduces a degree of inertia into tradable prices across countries and, for example, allows firms to price to market. ${ }^{17}$

Based on a static general equilibrium model with imperfect substitutability and product variety, à la Dixit and Stiglitz (1977), MacDonald and Ricci (2002) show that productivity in the tradable sector not only impacts positively on the real exchange rate through the B-S effect (via the indirect wage channel) but, if there is a home bias, it also has a direct negative effect on the price of home-produced tradables relative to that abroad leading to a real depreciation. However, if the share of non-tradables in the overall price index is not too small, the B-S effect will dominate the decrease in the price of tradables. Hence, an increase in productivity in the open sector causes the real exchange rate to appreciate. ${ }^{18}$

Benigno and Thoenissen (2003) calibrate a dynamic general equilibrium model for the UK against the euro area, which produces similar results to the model of MacDonald and Ricci (2002). However, in the Benigno and Thoenissen model, an increase in productivity in the open sector yields an overall depreciation of the real exchange rate because its negative impact on the real exchange rate in the open sector (depreciation) outweighs its positive impact on the relative price of non-tradables (appreciation). Világi (2004) in fact argues that international price discrimination has to be included in a dynamic general equilibrium NOEM model, if one does not want the B-S effect-induced real appreciation to be offset by the real depreciation of tradables via the terms of trade channel.

The non-tradable component of tradable prices, which mostly incorporates the costs of distribution services (also called non-tradable processing component), which varies across countries, is a big reason for firms to charge different prices in different countries all things being equal (Corsetti and Dedola, 2004). MacDonald and Ricci (2001) develop a static model to demonstrate the effect of the distribution sector on the real

\footnotetext{
${ }^{16}$ For empirical evidence, see e.g. Haskel and Wolf (2001).

${ }^{17}$ Prices may be sticky in the foreign or in the local currency. If prices are set in the local currency of the target market (local currency pricing, LCP), prices do not adjust to changes in the nominal exchange rate. If prices are set in the firms own currency (producer currency pricing, PCP), there is full pass-through from exchange rate to prices. Indeed, pricing-to-market is needed to lower the exchange rate pass-through.

${ }^{18}$ For a panel composed of 10 OECD countries for the period 1970 to 1992, MacDonald and Ricci find empirical evidence, using panel dynamic OLS, in favor of the model. When wages for tradables are introduced (to control for the indirect B-S effect operating though wages, $\left.q=f\left(a^{T}-a^{T^{*}} ; a^{N T}-a^{N T^{*}} ; w^{T}-w^{T^{*}}\right)\right)$, the sign on the productivity variable in the open sector becomes negative, indicating that an increase in that variable leads to a real depreciation, as predicted by the model.
} 
exchange rate. It can be shown that the real exchange rate depends not only on relative productivity in tradables and non-tradables but also on relative productivity in the distribution sector (D):

$$
q=\phi_{1}\left(a^{T}-a^{T^{*}}\right)-\phi_{2}\left(a^{N T}-a^{N T^{*}}\right)+\phi_{3}\left(a^{D}-a^{D^{*}}\right)
$$

The distribution sector may impact on the real exchange rate through two channels: an increase in the distribution sector's productivity decreases the price of tradables, via their lower non-tradable component and thus leads to a real depreciation, while at the same time, it causes a real appreciation via the wage channel (as in the case of the B-S effect). ${ }^{19}$

\subsubsection{Transition-Specific Factors: The Failure of PPP in the Tradable Sector Initial Undervaluation}

There are two important explanations for the failure of PPP in transition economies, which are closely related to the very nature of economic transformation. The first explanation is related to the initial undervaluation of the transition economies' currencies. Halpern and Wyplosz (1997) put forth that a large initial depreciation of the exchange rate is necessary to eliminate pent-up demand for foreign currency. Such a depreciation may be amplified by the fact that price liberalisation, yielding high inflation, if not hyperinflation, gives another push to switch from domestic currency positions to the foreign currency. In addition to this, a great deal of uncertainty regarding the equilibrium exchange rate motivated policymakers during the late 1980s and early 1990 s to prefer devaluations larger than would have been necessary to correct for external imbalances. ${ }^{20}$ The devaluation of the Polish zloty against the U.S. dollar went, for instance, roughly $20 \%$ below the then prevailing black market rate (Rosati 1994, 1996). There is also anecdotal evidence for the same happening in Croatia in 1991. The ensuing large depreciation of the real exchange rate leads to a large initial undervaluation. As a consequence, the real exchange rate of the open sector (i.e the relative price of traded goods), and consequently, that of the whole economy, tends to appreciate at the onset of the systemic transformation process reflecting an adjustment towards equilibrium. This issue is also related to the stabilisation of hyperinflation in which the exchange rate is used as a nominal anchor. In such a case, policy makers may aim to fix the exchange rate at an undervalued rate (undershooting) so that the real appreciation, which takes place during the post-stabilisation period does not lead to overvaluation and that the credibility of the monetary authorities becomes restored in the meantime, which is seen as a crucial element in controlling inflation in the future (Bruno, 1993).

\section{Trend Appreciation}

Another, and perhaps more important transition-specific factor is the systematic trend appreciation of the open sector's real exchange rate, which is closely related to the transformation process (see Figure 1). At the beginning of transition, both domestic and foreign consumers tend to prefer foreign goods. However, with economic restructuring that entails productivity increases in the tradable sector, the home economy becomes capable of producing a growing number of goods of better quality. This is why the preferences of domestic and foreign consumers shift towards home goods. An increasing reputation and home bias allow higher prices to be set for the goods produced in the home economy both in the foreign and the domestic markets, reflected in positive tradable inflation differentials.

Such an increase in non-price competitiveness can be best captured with labour productivity in the open sector, because technology is mostly imported from abroad via massive foreign direct investment (FDI), which, in turn, is reflected in huge productivity advances in the industrial sector. ${ }^{21}$ Thus, productivity gains could operate not just via non-tradable prices, but also via the tradable price and the nominal exchange rate channels. For example, if rises in tradable prices fuelled by productivity advances are faster in the home

\footnotetext{
${ }^{19}$ MacDonald and Ricci (2001) use the same dataset used in MacDonald and Ricci (2002) to test the empirical validity of the model. The estimation results, based on a specification similar to equation (13), indicate that an increase in productivity of the distribution sector yields a real appreciation, while rising productivity in tradables (non-tradables) results in a standard appreciation (depreciation) of the real exchange rate. It is interesting to note that MacDonald and Ricci (2002) find that the inclusion of the relative wage variable into this kind of set up changes the sign of the coefficient on tradables productivity from positive to negative.

${ }^{20}$ During the late 1980s, the exports of the transition economies collapsed because of the dissolution of Council for Mutual Economic Assistance (CMEA). At the same time, imports rose steadily due to pent-up demand for foreign goods.

${ }^{21}$ Therefore, R\&D expenditures, which is often used as a measure of non-price competitiveness for industrialised countries, is an inappropriate measure for transition economies, since R\&D is mostly produced abroad and is then imported by the transition economies via FDI.
} 
economy than in the foreign economy, the resulting positive inflation differential in tradable prices causes the real exchange rate based on tradable prices to appreciate. Similarly, the appreciation of the nominal exchange rate also leads to an appreciation of the tradable price-based real exchange rate.

Also, an improving export performance based on the aforementioned factors may lead to the appreciation of the nominal exchange rate (Égert and Lommatzsch, 2003). Furthermore, the appreciation of the nominal exchange rate may be due to expected future productivity gains. For example, capital inflows related to productive foreign investment may trigger future productivity gains and an increase in future export revenues that could counterbalance the current deterioration of the current account. Most importantly, this kind of nominal appreciation will be an ex post equilibrium phenomenon only if productivity advances materialize and export revenues actually increase. In the opposite case, in the event that productivity gains do not materialize, an expectations-driven nominal appreciation, viewed ex ante as an equilibrium phenomenon, may lead to an ex post overvaluation of the real exchange rate.

\subsubsection{Demand-Side Factors}

Bergstrand (1991) uses a simple general equilibrium model to demonstrate the importance of other factors, in addition to relative productivity, as determinants of the relative price of non-tradables. In such a framework, the demand for and supply of non-tradable goods (relative to tradable goods) can be solved for the relative price of non-tradables, which yields the following formula:

$$
\hat{p}^{N T}-\hat{p}^{T}=\phi_{1} \cdot\left(\hat{a}^{T}-\hat{a}^{N T}\right)+\phi_{2} \cdot \hat{k}+\phi \cdot \hat{y}
$$

where $\hat{k}$ and $\hat{y}$ are changes in the capital-labour ratio and in per capita income, respectively. The implications of the model are that the relative price determination can be augmented with the capital-labour ratio, as proposed by Bhagwati $(1984)^{22}$, and, perhaps most importantly, demand-side variables, such as government and private consumption. Because of a high income elasticity of demand for non-tradable goods, an increase in dual productivity, accompanied by increasing disposable income per capita, may result, in the long run, in rising consumption, which falls increasingly on non-tradable goods. Thus, demand-side pressure in the sheltered sector yields higher non-tradable prices.

The standard B-S effect rests on a two-sector, two-input, small open economy model. According to Fischer (2004), a three-sector four-input model makes it possible to show that investment demand can also lead to a rise in the price of non-tradable goods.

\subsubsection{Baumol-Bowen and the Role of Regulated Prices in Transition Economies}

As noted in Froot and Rogoff (1994), the Baumol-Bowen effect produces, in general, the historical observation that service prices are likely to rise more than the overall price level because productivity gains in the manufacturing industry put upward pressure on wages in services (as opposed to non-tradables in the B-S framework) via the intersectoral wage spill-over effect. The mechanism behind this "cost disease" is very similar to the one presented in equation $(7)^{23}$. The trend appreciation of the real exchange rate as described in the B-S model is based on sectors and prices which are governed by market forces. Baumol and Bowen (Baumol and Bowen, 1965, 1966, and Baumol, 1996) analyze the case of largely nonprofit sectors, such as health, education or the live performing arts. They argue that "nonprofit organizations (...) earn no pecuniary return on invested capital and they claim to fulfil some social purpose" (Baumol and Bowen, 1965 , p. 497). Put differently, nonprofit organizations have structural financial difficulties because their operating revenues are lower than what would follow from profit maximizing price setting and their expenditures. Because the non-profit sector relies heavily on public (or private) subsidies, it can be viewed as

\footnotetext{
${ }^{22}$ Bhagwati (1984) proposes an alternative explanation to the B-S effect to explain why service prices are lower in less developed countries than in industrialized economies. His argument is not explicitly based on differences between productivity in the open sectors but, rather, on different factor endowments in poor and rich countries. It can be observed from the data that the capital-labor ratio of the tradable sector is higher in rich countries, as compared to poor countries. Provided consumers want to consume the same basket of goods in both rich and the poor economies, Bhagwati demonstrates in a general equilibrium model, that the poor (rich) country will specialize in labor-intensive (capital-intensive) goods. This will result in a lower wage level in the poor country's open sector, which, in turn, determines wages and prices in the sheltered sector. This framework implies that a rise in the capital-labor ratio of the open sector leads to an increase in the relative price of tradables.

${ }^{23}$ For instance, Lojschova (2003), Mihaljek and Klau (2004) and Wagner and Hlouskova (2004) argue that equation (7) represents the Baumol-Bowen effect and that equation (8) shows the B-S effect. This is, to a large extent, a terminological issue (we call it the internal transmission mechanism of the B-S effect)
} 
an administered rather than a market-based sector (as in the B-S framework) ${ }^{24}$. Baumol and Bowen (1966) document that, for instance, the average cost of a single performance at the Royal Shakespeare Theatre in 1963 was 13.6 times higher than the corresponding costs at the Drury and the Covent Garden theatres in London from 1740-75. At the same time, the overall price level in England rose by about $600 \%$. Also, cost increases may be lower than what productivity gains in the open sector would require because the intersectoral wage equalization attenuates this effect. ${ }^{25}$ Furthermore, Baumol and Bowen (1965) state that albeit also on the rise, ticket prices considerably lagged behind soaring costs. To summarize, there are reasons to think that prices in the non-profit sector do not behave in a manner which conforms with the B-S effect.

Administered and regulated prices, ${ }^{26}$ which are composed mainly of services, represent a large component of consumer price indices for transition economies. Table 2 demonstrates the high share of regulated price in the CPI for the Baltic countries, for countries from Central and Eastern Europe and from South-Eastern Europe. Exceptions are Croatia and Kazakhstan. ${ }^{27}$

According to Table 2, not only the real exchange rate of services is undervalued in terms of PPP, as suggested by the B-S model, but also the real exchange rate of different types of goods turns out to be undervalued, albeit to a lesser extent.

For historical reasons, changes in these prices are above-average (in contrast to the Baumol-Bowen effect) and are not related to productivity increases (as opposed to the B-S effect) as shown in Figure 2 for selected transition economies. ${ }^{28}$ Table 3 also evidences that the real exchange of non-market services is the most undervalued in absolute PPP terms compared to other components like tradables or market-based services (which also turn out to be undervalued, albeit to a lesser extent), which suggest the scope for future appreciations coming from regulated prices.

Table 2. The share of administered prices in the CPI

\begin{tabular}{|c|c|c|c|c|c|c|c|c|c|c|c|c|c|c|}
\hline & 1991 & 1992 & 1993 & 1994 & 1995 & 1996 & 1997 & 1998 & 1999 & 2000 & 2001 & 2002 & 2003 & 2004 \\
\hline \multicolumn{15}{|c|}{ Baltic countries } \\
\hline Estonia & $\mathrm{Na}$ & na & na & 21.1 & 18.0 & 24.0 & 24.0 & 25.6 & 25.6 & 25.6 & 28.9 & 28.9 & 24.9 & 26.9 \\
\hline Latvia & $\mathrm{Na}$ & 6.1 & 6.1 & 16.6 & 16.6 & 17.8 & 19.8 & 20.4 & 22.0 & 22.3 & 22.0 & 20.7 & 16.3 & 16.0 \\
\hline Lithuania & $\mathrm{Na}$ & na & na & na & na & $\mathrm{Na}$ & na & 16.9 & 16.2 & 18.1 & 20.4 & 21.5 & 23.5 & 19.8 \\
\hline \multicolumn{15}{|c|}{ Central and Eastern Europe } \\
\hline Czech Rep. & 27.9 & 18.3 & 17.9 & 18.1 & 17.4 & 17.4 & 13.3 & 13.3 & 13.3 & 13.3 & 12.4 & 12.4 & 10.9 & 10.9 \\
\hline Hungary & 11.0 & 10.9 & 10.8 & 11.8 & 12.9 & 12.8 & 15.9 & 17.0 & 18.2 & 18.3 & 18.5 & 18.9 & 19.4 & 17.9 \\
\hline Poland & 11.0 & 14.0 & 10.6 & 12.0 & 12.0 & 11.6 & 10.6 & 10.6 & 9.0 & 2.6 & 1.2 & 1.0 & 1.0 & 1.0 \\
\hline Slovakia & $\mathrm{Na}$ & na & 21.8 & 21.8 & 21.8 & 21.8 & 20.8 & 17.8 & 17.8 & 17.8 & 17.8 & 21.1 & 20.7 & 19.9 \\
\hline Slovenia & $\mathrm{Na}$ & 23.7 & 19.8 & 18.4 & 22.5 & 22.4 & 20.4 & 17.0 & 14.3 & 13.7 & 13.2 & 14.0 & 15.4 & 16.1 \\
\hline \multicolumn{15}{|c|}{ South-Eastern Europe } \\
\hline Bulgaria & 24.0 & 16.0 & 26.0 & 43.0 & 46.0 & 52.0 & 14.4 & 15.8 & 17.2 & 20.0 & 20.6 & 21.3 & 22.0 & 24.7 \\
\hline Croatia & $\mathrm{Na}$ & na & na & na & 6.8 & 6.5 & 3.9 & 3.3 & 3.0 & 5.6 & 0.0 & 0.0 & 0.0 & 0.0 \\
\hline Romania & 47.0 & 29.0 & 20.0 & 18.0 & 18.0 & 18.0 & 7.0 & 7.0 & 8.5 & 10.5 & 13.0 & 20.4 & 21.5 & 22.5 \\
\hline \multicolumn{15}{|c|}{ Former Soviet Union } \\
\hline Russia & $\mathrm{Na}$ & na & na & na & $\mathrm{Na}$ & $\mathrm{Na}$ & na & $\mathrm{Na}$ & na & na & na & na & 13.0 & 9.0 \\
\hline Ukraine & $\mathrm{Na}$ & na & na & na & $\mathrm{Na}$ & $\mathrm{Na}$ & na & $\mathrm{Na}$ & na & na & na & na & na & na \\
\hline Kazahkstan & 10.4 & 2.5 & 2.5 & 2.5 & 0.0 & 0.0 & 0.0 & 0.0 & 0.0 & 0.0 & 0.0 & 0.0 & 0.0 & 0.0 \\
\hline
\end{tabular}

Sources: EBRD Transition Report 2004, 2003, 2002, 2000.

\footnotetext{
${ }^{24}$ The Baumol-Bowen effect assumes that services have close-to-nil productivity advances ("stagnant services”, Baumol, 1996). Hence, it becomes a special case of equation (7) where $\hat{a}^{N T}=0$.

${ }^{25} \mathrm{This}$ is because of "the willingness of those who work in these fields to sacrifice money income for the less material pleasure of their participation in the arts. (Baumol and Bowen, 1965, p. 501.)

${ }^{26}$ The terms administered and regulated prices will be used interchangeably in the remainder of the paper.

${ }^{27}$ Although the figures reported by the EBRD are good to get a grip on this issue, country-specific figures should be taken with caution. For instance, it is hard to believe that the absence of regulated prices in Kazakhstan, a country lagging behind economic restructuring. In addition, data obtained from national sources are different as compared to figures from EBRD, implying that there are open issues regarding classification and definition of regulated prices. For instance, according to national sources, the share of administered prices in the CPI was $22.3 \%$ in Croatia in 2004. ( $0 \%$ in 2003, according to EBRD). Égert (2004) reports lower figures for Estonia as the EBRD do.
} 
Note: The EBRD Transition Report 2000 indicates higher figures from 1993 to 1996 than the 2002, 2003 and 2004 reports (reported here).

Table 3. Level real exchange rates of different groups of goods and services in new EU member states, 2002

\begin{tabular}{|c|cccccc|}
\hline & Durable & Semi-durable & Food & Market services & Non-market services & Property prices \\
\hline & \multicolumn{5}{c}{ EU-15=100\% } \\
CEEC-8 & 1.13 & 1.47 & 1.46 & 1.80 & 2.42 & 2.41 \\
\hline \multicolumn{5}{|l}{ Source: Authors' calculation based on data obtained from NewCronos/Eurostat } \\
\hline
\end{tabular}

Figure 2. The evolution of administered prices and CPI inflation in selected transition economies (Y-o-Y)
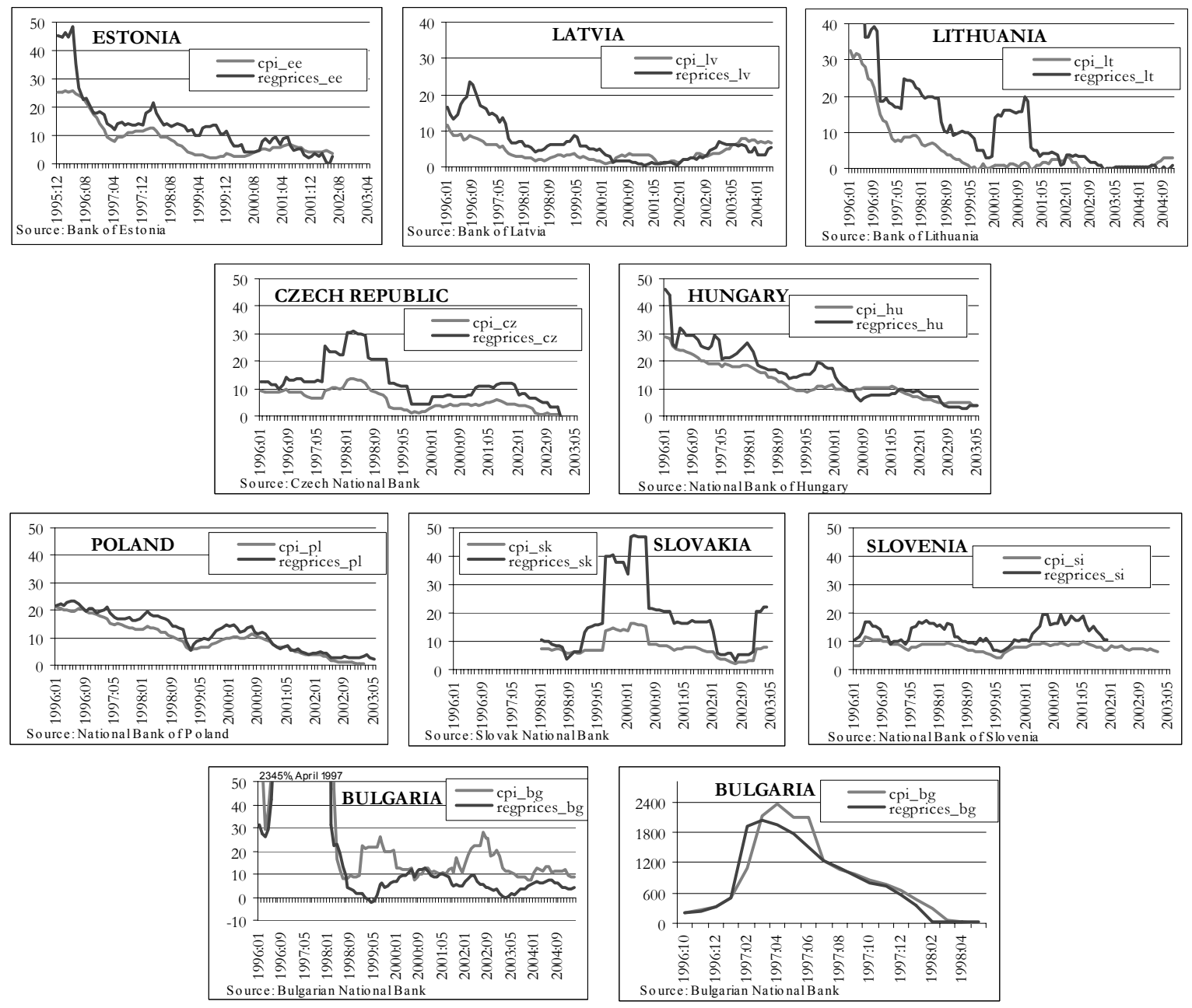

Because regulated items can be inputs for tradable and market non-tradable goods, an increase in regulated prices may affect tradable goods' competitiveness directly and indirectly through the market-based nontradable component of tradable goods.

However, increases in regulated prices may not affect competitiveness and may also partly be viewed as an equilibrium phenomenon, for two reasons.

First, prices of regulated services including public transport, communication, energy and water supply were left largely unchanged during price liberalisation, resulting in high inflation at the outset of the transition process. ${ }^{29}$ Also, in setting the price of regulated items, only operational costs were considered initially

\footnotetext{
${ }^{29}$ Figure 2 shows a more recent episode of hyperinflation for Bulgaria in which regulated prices grew much less, and for almost one year, compared to overall CPI inflation.
} 
because the capital stock of the sectors concerned was inherited from the communist era and because of political considerations. Eventually, capital maintenance costs were also considered to account for wear and tear. However, once general price liberalization was over, the progressive replacement of the capital stock at market prices, partly through privatization, led to huge increases in regulated prices because the cost of capital had to be taken into account as well (see Zavoico, 1995). This was all the more important as the regulated sectors tend to be very capital intensive. It appears that the adjustment of regulated prices is, however, not over yet. First, prices may still be below cost recovery in some cases. Second, governments still provide direct and indirect subsidies, which may be cut because of efforts to consolidate public finances and because of the need to comply with competition rules in the acquis communautaire. Finally, the need for additional capital investment to meet the quality of services required by EU standards may also imply further price increases (Égert, 2003a). To dampen price increases, efficiency can be improved via privatization and market liberalization. In the case of industries where true market competition is not possible, an appropriate price regulatory framework should be implemented, as was the case in England and Wales (Saal and Parker, 2001).

Second, regulated prices may impact on tradable goods that do not enter international competition. Figure 3 summarizes the elements of the trend appreciation of the equilibrium real exchange rate in transition economies.

Figure 3. Elements of the Appreciation of the Equilibrium Real Exchange Rate

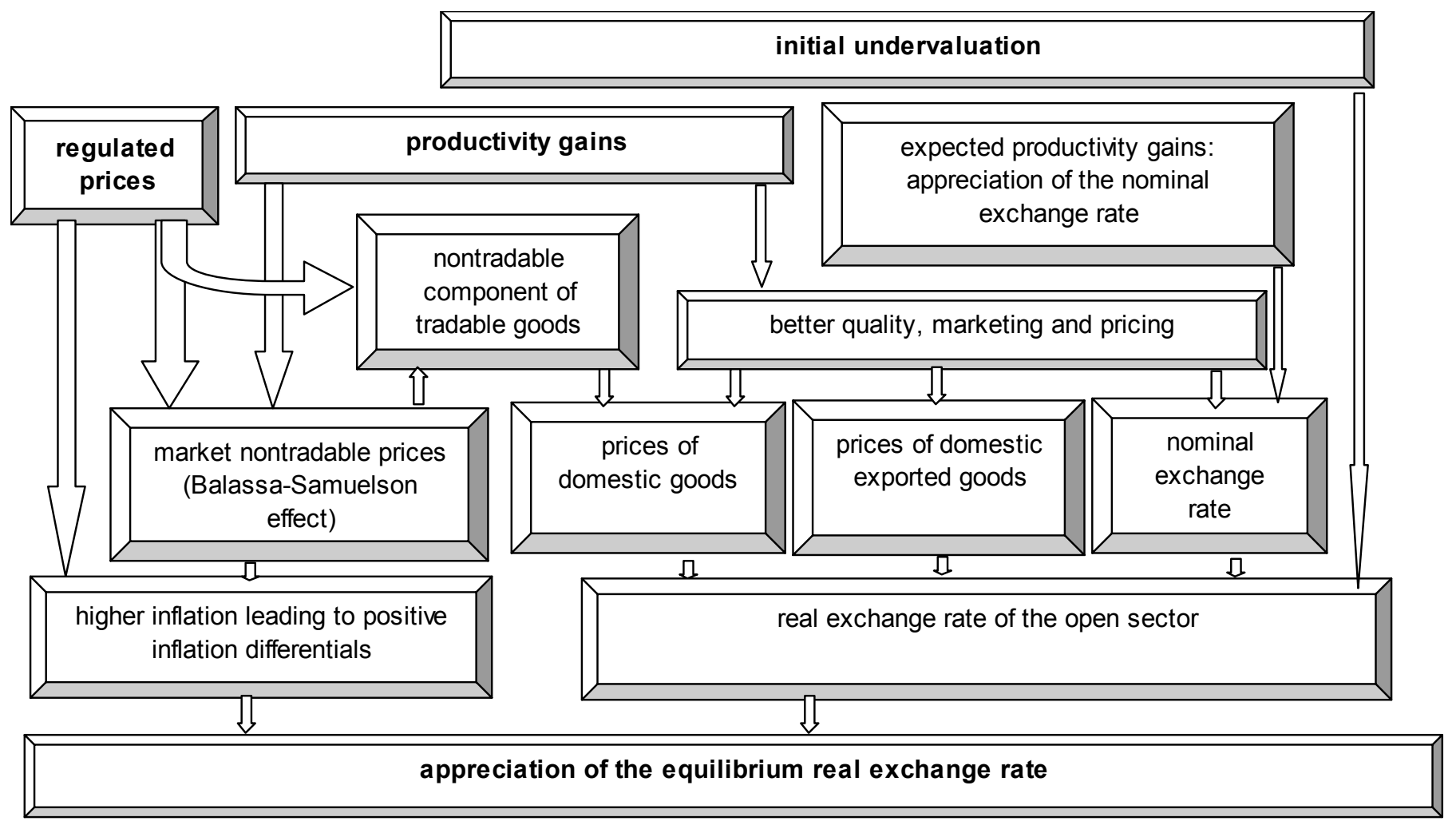

\subsection{The Dutch-Disease Phenomenon}

Besides the aforementioned channels of real exchange rate appreciation, countries rich in natural resources, especially those with economic structures relying heavily on oil production and exports, are usually good candidates for the Dutch Disease (D-D) phenomenon.

According to the D-D phenomenon, an increase in the price of the exported commodity on world markets encourages more investment in the given sector, which in turn increases sectoral output. The need for more labour to produce more output in the commodity sector causes wages to increase, which, if wages tend to equalize across sectors, leads to an increase in wages in other sectors of the economy. As a result, the competitiveness of the non-oil open sector drops, implying a slowdown in exports and, as a consequence, in overall sectoral output. At the same time, because of wage increases, the relative price of nontradables and 
the production of this sector rise. Another implication of increasing commodity prices is the appreciation of the real exchange rate triggered by the inflow of export revenues. Simultaneously, the overall trade balance remains balanced or even in surplus. So, the main implication of the D-D phenomenon for our subject is the appreciation of the real exchange rate if there is an increase in oil prices. Sosunov and Zamulin (2004) apply a general equilibrium model to Russia, and according to the closed-form solution, the only observable variable (besides a number of elasticity and preference parameters), which related to the real exchange rate is the oil price. ${ }^{30}$

\subsection{The Internal-External Balance Approach: The Fundamental Equilibrium Exchange Rate (FEER) and its Variants}

For a small open economy, a straightforward way of defining the equilibrium real exchange rate is in terms of the sustainability of its external balance, i.e. the current account which prevents an explosion, and default, of external debt. The Balassa-Samuelson framework implicitly recognizes the external sustainability issue by stressing that any appreciation of the real exchange rate should go in tandem with appropriate productivity gains, which, in turn, ensures that the competitiveness of exports is maintained. However, it is straightforward to demonstrate that there are factors other than productivity growth, such as the real interest rate, fiscal policy or the determinants of savings and investment, which can play a crucial role in current account and external debt sustainability.

The notion of the external sustainability-based equilibrium real exchange rate was first advocated by Nurkse (1945), and then further elaborated by Artus (1978). In the context of empirical exchange rate issues the concept gained popularity with a series of publications by Williamson $(1985,1994)$. Williamson coined the expression Fundamental Equilibrium Exchange Rate (FEER) for the sustainable external account-based equilibrium real exchange rate. In accordance with Williamson's definition, the FEER is the real effective exchange rate that simultaneously secures internal and external balance for a country, or for a number of countries simultaneously. Internal balance is defined as the non-accelerating inflation rate of unemployment (NAIRU). Put differently, internal balance is reached when the economy functions at full capacity output accompanied by low inflation. External balance is achieved when the balance of payments is in a 'sustainable' position over a medium-term horizon, ensuring external debt sustainability. ${ }^{31}$ The general flavour of the internal-external balance approach may be captured by the following equation:

$$
S(W)-I(X)=C A(\hat{q}, Y)=-K A(Z)
$$

where $S$ denotes national savings, $I$ denotes investment spending, CA and KA are the current account and the capital account and $W, X, Y$ and $Z$ are vectors of variables, to be discussed below, and $q$ is the real exchange rate consistent with internal balance.

When it comes to operationalising the FEER, there are two key issues to be addressed. The first relates to the determinants of potential output growth associated with low inflation. Two main approaches have been adopted in the literature. On the one hand, historical GDP growth can be statistically decomposed into trend

\footnotetext{
${ }^{30}$ The symptoms of the Dutch Disease can be summarized in the following propositions: 1.) The real exchange rate appreciates; 2.) The output and exports of the non-oil (nonbooming) open sector decline; 3.) The production of the nontradable sector increases; and 4.) The trade balance is balanced or is in surplus.

In the flagship paper of the proponents of the D-D phenomenon, Sachs and Werner (1995) find strong empirical evidence in favour of the D-D effect especially in emerging Asian economies and in Sub-Saharan Africa. Nevertheless, in the second half of the 1990s, an increasing number of papers put into question the general validity of the D-D phenomenon and showed that it holds under specific conditions, thus diminishing the policy implication of the findings of Sachs and Warner (1995), according to which countries with abundant natural resources should not exploit their natural resources because this puts at risk their long-term growth. Spilimbergo (1999), for instance, shows that the D-D phenomenon does not seem to work for the cases of Chile and South Africa, countries with abundant natural resources. Gylfason (2002) argues that abundant natural resources may lead to sluggish long-term growth because of (1) ill-defined property rights, imperfect or missing markets and lax legal structures in many developing countries and emerging market economies; (2) the fight for resource rents and the concentration of economic and political power hampering democracy and growth, and (3) too many people getting stuck in low-skill-intensive, natural-resource-based industries. Kronenberg (2004) argues that one of the main reasons for the D-D phenomenon in transition economies is corruption. Papyrakis and Gerlagh (2004) suggest that, when controlling for e.g. corruption, investment, openness and education, abundant natural resources do not decrease (as predicted by the D-D phenomenon) but foster economic growth in the long run.

${ }^{31}$ Bayoumi et al. (1994) define a horizon from four up to six years.
} 
and cyclical components, using, for example, the Hodrick-Prescott (HP) filter or the Beveridge-Nelson decomposition. Alternatively, economic theory can be used to determine the magnitude of potential growth. The second issue to be addressed is that of the sustainability of the current account position. One way of defining current account sustainability is if a current account imbalance is covered, ex ante, by an equal and opposite capital account imbalance and if it stabilizes the external debt-to-GDP ratio at a given level. This is the approach taken by Williamson in his operationalisation of the internal-external balance approach. It remains, though, an open question as to what the optimal level of this ratio is and often a great deal of judgment has to be applied to obtain an appropriate value. A second approach involves viewing the current account in terms of saving and investment balances. According to this approach, labelled the Macroeconomic Balance (MB) approach, econometric models are estimated by regressing the observed current account (saving - investment) onto an array of explanatory variables, such as population growth, the fiscal position or openness etc. Fitted values for the current account are then interpreted as medium-term values of the current account. This is, for example, the approach taken by the IMF in its implementation of the internal-external balance approach (see, for example, Isard et al., 2001).

Given some metric of internal and external balance there are essentially two mechanical ways of estimating a FEER. The first involves taking an estimated macro-econometric model, imposing internal and external balance, and solving for the real exchange rate, which is then classified as the FEER. However, by far the most popular method of generating a FEER involves focussing on an estimated current account equation and setting it equal to a sustainable capital account (see Wren-Lewis (1992)). There are essentially five steps involved in this process:

1) Determination of the targeted current account position;

2) Estimation of the elasticities of the trade account with respect to domestic and foreign output and to the real effective exchange rate $\left(T B=f\left(Y, Y^{*}, R E E R\right)\right)$;

3) Calculation of the change in the real effective exchange rate (REER) that would place domestic and foreign output on their potential path and that would achieve the targeted current account. However, it is hard to achieve these three objectives simultaneously. Therefore, it is normally assumed that internal balance in both the home and foreign economies is achieved without the aid of the real effective exchange rate;

4) Determining the change in the real effective exchange rate that makes the current account, adjusted for internal balances (i.e. the current account that would prevail at potential output), move to its target value. The change in the real effective exchange rate is effectively the total misalignment; and

5) If necessary, calculating the bilateral equilibrium nominal exchange rates from the equilibrium real effective exchange rate.

Šmídková and others (2003) and Buliř and Šmidkova (2005) propose introducing an external debt target into this framework, and this widens the horizon of the standard FEER model from the medium term to the long run. This variant of the FEER, called the Fundamental Real Exchange Rate (FRER), imposes a long-term external debt target to which the actual external debt is required to converge in the long run. The equilibrium exchange rate is the exchange rate that secures the attainment of this target.

Barrell and Wren-Lewis (1989) demonstrate that in calculating the FEER it is very important to allow for revaluation effects through the net foreign asset term ${ }^{32}$, especially if the Marshall-Lerner condition just holds. As Wren-Lewis (1992) emphasises, this implies that the real interest rate has settled at its long-run equilibrium value in the medium-run. Clearly this is a strong assumption, since it places a constraint on monetary policy in the medium-run. Furthermore, Wren-Lewis (1992) notes that the FEER is a 'method of calculation of a real exchange rate which is consistent with medium term macroeconomic equilibrium.' That is to say, the FEER approach does not embody a theory of exchange rate determination. Nonetheless, there is the implicit assumption that the actual real effective exchange rate will converge over time to the FEER. Hence embedded in this approach is a medium-run current account theory of exchange rate determination. That is, it is assumed that a divergence of the actual real rate from the FEER will set in motion forces that will eventually eliminate this divergence, but as the approach characterises only the equilibrium position, the nature of the adjustment forces is left unspecified.

\footnotetext{
${ }^{32}$ However, Gourinchas and Rey (2005) argue that the revaluation effect hinges crucially on the foreign currency denomination of the asset and liability sides.
} 
In addition to the difficulty in measuring a sustainable capital account, the calculation of trade elasticities has often meant that an extra layer of judgement has to be imposed before the FEER can be calculated. This is because the estimated trade elasticity (or elasticities) often turns out to be effectively zero (see Goldstein and Khan (1985)). Furthermore, what has been described by Driver and Westaway (2005) as the 'Achilles heel' of the FEER approach is the hysteresis introduced into the FEER due to interest payments on the net foreign asset term. Bayoumi et al (1994) consider this effect in some detail. To illustrate, assume that in the initial period the current exchange is at the FEER level and internal and external balance obtains. The actual real exchange rate then depreciates in the next period, thereby improving the current balance and improving the country's net foreign asset position. The latter, in turn, implies that in future periods the real exchange rate, consistent with medium-run capital accumulation, will no longer be the FEER; in particular, the FEER needs to appreciate to squeeze out the effects of the net asset accumulation. This hysteresis effect is a necessary consequence of viewing the exchange rate as a medium run concept. Taking a stock measure of equilibrium would of course rule out this kind of effect

Driver and Wren-Lewis (1999) assess the sensitivity of FEER calculations of the US dollar, Japanese yen and German mark to different formulations and assumptions. They find that two key factors impart a considerable amount of uncertainty into FEER type calculations. For example, changes in the assumed value of the sustainable capital account (as a proportion of GDP) of $1 \%$ can produce changes in the value of the FEER of around 5\%. Since such changes in the capital account could easily be due to measurement error, this suggests caution needs to be exercised in interpreting point estimates of the FEER. For example, in using a FEER to define the equilibrium rate with which to lock two currencies together, some sort of confidence interval should be applied to the point estimate (this uncertainty is one of the reasons why Williamson argues that crawling peg arrangements should feature wide exchange rate bands). Driver and Wren-Lewis also show that it is often difficult to produce well-defined estimates of the trade equations, and therefore the underlying trade elasticities, which are so central to the FEER. Inevitably this means that the FEER estimate will be sensitive to the chosen elasticity.

\subsection{The Natural Real Exchange Rate (NATREX)}

The NATural Rate of EXchange (NATREX) was developed by Stein (1994, 1995 and 2002), and is also based on an internal-external balance framework. In contrast to the FEER approach, the NATREX approach distinguishes equilibrium real exchange rates at two horizons, in the medium run and long run. In the medium run, the real exchange rate can be viewed at equilibrium when internal and external balances are achieved simultaneously, very much as in the FEER approach. However, the definition of internal balance is slightly different to that used in the FEER approach, because it is defined in terms of full capacity utilization, rather than in terms of the NAIRU. As in the FEER approach, external balance is synonymous with current account sustainability:

$$
C A-(S-I)=0 \text {. }
$$

That is, the current account corresponds to net exports $(N X)$ minus net income payments/inflows related to foreign debt/assets, i.e. net factor income $(C A=N X-i * F D E B T)$ should be equal to long-term net capital inflows, determined by saving and investment decisions.

Consider now the investment and consumption functions and the determinants of the trade balance that are connected via the national account identity as in equation (19):

$$
\begin{aligned}
& \frac{I}{Y}=f\left(\stackrel{+}{a}, \frac{\vec{K}}{Y}, \stackrel{-}{r}, \stackrel{+}{Q}\right), \\
& \frac{C}{Y}=f\left(\frac{\stackrel{+}{Y}}{Y}, \frac{F D E B T}{Y}, \bar{Z}\right) \text {, } \\
& \frac{N X}{Y}=f\left(\stackrel{+}{Q}, \frac{\bar{D}}{Y}, \frac{\stackrel{+}{D^{*}}}{Y}, \stackrel{+/-}{T O} T\right),
\end{aligned}
$$




$$
\frac{I}{Y}+\frac{C}{Y}+\frac{N X}{Y}=1
$$

where $I$ denotes investment, $C$ denotes consumption (an aggregate of both private and public consumption), $K$ is the capital stock, FDEBT is foreign debt, $N X$ is the trade balance, $D$ and $D^{*}$ represent domestic and foreign demand, respectively, $K$ is the capital stock, $\bar{Z}$ denotes a vector of exogenous variables, the most important of which is the social thrift parameter that stands for the social (private and public) propensity to save and $Y$ represents GDP. The + and - signs above the explanatory variables indicate the hypothetical relationships with respect to the dependent variables. Substituting equation (16) - (18) into the identity (19) and solving it for the real exchange rate $(Q)$ yields the medium-term equilibrium real exchange rate, or NATREX. In practice, equations (16) - (18) are estimated using econometric techniques and the estimated medium-term NATREX is given by applying the estimated parameters to the solution of the system. ${ }^{33}$

In the NATREX model, a change in foreign debt and in the capital stock $(K)$ feeds back into the macroeconomic balance. For instance, an increase in foreign debt resulting from a deteriorating current account position decreases wealth $(K-F D E B T)$, and this leads to a fall in consumption. As a consequence, import demand drops and the real exchange rate depreciates, which, in turn, ameliorates the current account position and decreases foreign debt. This feedback mechanism eventually stabilizes foreign debt.

The value added of the NATREX approach, relative to the FEER, is that it additionally considers the influence of the stock of capital and net foreign debt on the long run exchange rate and it also describes the path of the real exchange rate from the medium-term equilibrium to the long-term equilibrium. In contrast to the medium-term NATREX, which as we have seen, is based on current values of the capital stock and foreign debt, the long-term equilibrium is derived when the stock of capital and the stock of foreign debt are stabilized at their steady-state levels, given respectively in equations (20) and (21):

$$
\begin{aligned}
& \frac{K}{Y}=\frac{1+g}{\delta+g} \cdot \frac{I}{Y}, \\
& \frac{F D E B T}{Y}=\frac{1+g}{g} \cdot \frac{C A}{Y},
\end{aligned}
$$

where $\delta$ denotes the rate of depreciation of the capital stock and $g$ stands for the growth rate of GDP.

To illustrate the difference between the medium- and long-run real exchange rates, Stein (1995) considers two cases: first a decrease in the propensity to save and, second, a rise in productivity. In both cases, the medium-term NATREX appreciates. In the first case, a decrease in savings implies an increase in consumption, and this leads to a worsening of the current account and foreign debt. The resulting capital inflows cause the real exchange rate to appreciate, which restores both internal and external balance. However, in the long-run the real exchange rate depreciates because increased foreign debt causes interest payments to rise. Indeed, the real exchange rate depreciates to improve the trade balance required to service the debt.

As in the savings example, a positive productivity shock also produces a medium run real exchange rate appreciation and this also implies a larger current account deficit and an increase in foreign debt. However in contrast to the propensity to save example, an increase in productivity may result in an appreciation of the long-run real exchange rate, since in addition to foreign debt, the capital stock also rises in the medium term. This, in turn, makes productivity increase further, and the resulting higher GDP growth produces higher savings. Given this development, foreign debt decreases and the real exchange rate appreciates in the long run to counterbalance the improving current account. At the same time, however, the higher capital stock implies higher imports, which may offset some of the appreciation of the real exchange rate.

Its emphasis on productivity and savings as key determinants of the real exchange rate would seem to make the NATREX an important tool for the analysis of transition countries exchange rates. Recent attempts to

\footnotetext{
${ }^{33}$ Equations (16) to (18) are normalized using actual output, which implies that the medium-run NATREX is the exchange rate that brings investment, consumption and net exports such as estimated in equations (16) to (18) in line with observed output (equation (19)). However, if equations (16) to (18) were normalized using potential output, the medium-term NATREX would be given as the exchange rate that equalizes medium-term aggregate demand with potential output (Karádi, 2003).
} 
estimate the structural form of the NATREX model include Detken et al. (2002) for the euro area and Karádi (2003) for Hungary. In contrast to the FEER approach, however, the NATREX is often written as a reduced form relationship, such as in equation (22), and this has been the most popular way of estimating the NATREX:

$$
Q=f\left(a, \frac{K}{Y}, r, \frac{N F A}{Y}\right) .
$$

The way in which the equilibrium measure is recovered in a reduced form NATREX, is similar to the Behavioural Equilibrium Exchange Rate, which we now discuss.

\subsection{The Behavioural Equilibrium Exchange Rate (BEER)}

The BEER approach of Clark and MacDonald (1999) is not based on any specific exchange rate model, and in that sense may be regarded as a very general approach to modelling equilibrium exchange rates. However, it takes as its starting point the proposition that real factors are a key explanation for the slow mean reversion to PPP observed in the data. In contrast to some of the FEER based approaches, discussed above, its specific modus operandi is to produce measures of exchange rate misalignment which are free of any normative elements and one in which the exchange rate relationship is subject to rigorous statistical testing. To illustrate their approach, Clark and MacDonald (1999) take the risk adjusted real interest parity relationship, which has been used by a number of researchers to model equilibrium exchange rates (see, for example, Faruqee (1995) and MacDonald (1998a,b)):

$$
\Delta q_{t+k}^{e}=r_{t, t+k}^{e}-r_{t, t+k}^{*_{e}}+\lambda_{t}
$$

where $\Delta q_{t+k}^{e}$ is the difference between the real exchange rate expected in $t$ for $t+k\left(q_{t, t+k}^{e}\right)$ and the observed real exchange rate in period $\mathrm{t}$ represent the

domestic and foreign ex ante real interest rates and $\lambda_{t}$ is a measure of the risk premium, assumed to be a function of relative bond supplies. Expression (23) may be rearranged as an expression for the real exchange rate as:

$$
q_{t}=q_{t, t+k}^{e}-\left(r_{t, t+k}^{e}-r_{t, t+k}^{* e}\right)-\lambda_{t}
$$

If $q_{t, t+k}^{e}$ is interpreted as the 'long-run', or systematic, component of the real exchange rate, it can be assumed to be the outcome of the expected values of the fundamentals and can be replaced by $\bar{x}_{t, t+k}^{e}$ as in (24)

$$
q_{t}=\bar{x}_{t, t+k}^{e}-\left(r_{t, t+k}^{e}-r_{t, t+k}^{* e}\right)-\lambda_{t} .
$$

where $\lambda_{t}$ is the time-varying risk premium. With rational expectations imposed, (25) can be rewritten as:

$$
q_{t}=\bar{x}_{t}-\left(r_{t}-r_{t}^{*}\right)
$$

In practical terms, the real exchange rate can be written as a function of the long- and medium-term fundamentals $(x)$ and the short-term variables $(\mathrm{z})$ :

$$
q_{t}=q_{t}\left(\bar{x}_{t}, \bar{z}_{t}\right)
$$

The estimation of the BEER essentially proceeds in five stages:

1) Estimating the statistical long-run relationship between the real exchange rate, the fundamentals and shortrun variables, which is tantamount to estimating a reduced form real exchange rate model;

2) Calculating the actual or current misalignment. Short-term variables are set to zero and actual values of fundamentals identified in step 1) are substituted into the estimated relationship. The actual misalignment is taken as the difference between the fitted and the actual value of the real exchange rate;

3) Identifying long-run, or sustainable, values for the fundamentals. This can be achieved either by decomposing the series into permanent and transitory components (for example, using an HP filter or a Beveridge-Nelson decomposition), or using a subjective evaluation of the long-term values is also possible (see Baffes et al., 1999); 
4) Calculating total misalignment. In this case long-term values of fundamentals are substituted into the estimated relationship, relating the real exchange rate to the fundamentals, and short-term variables are again set to zero. Total misalignment is the difference between the fitted and actual value of the real exchange rate when sustainable values of fundamentals are used. Total misalignment depends on the short-term effect and on the departure of fundamentals from their long-term value;

5) Given a value for the equilibrium real exchange rate the nominal equilibrium exchange rate can also be deduced. $^{34}$

\subsection{The Permanent Equilibrium Exchange Rate (PEER)}

\subsubsection{Decomposition of the Real Exchange Rate}

The so-called permanent equilibrium exchange rate (PEER) model is based on decomposing a real exchange rate into its permanent $\left(q_{t}^{P}\right)$ and transitory $\left(q_{t}^{T}\right)$ components:

$$
q_{t}=q_{t}^{P}+q_{t}^{T}
$$

The permanent component is then taken to be the measure of equilibrium. In the literature, a number of alternatives have been proposed for extracting the permanent component from an economic series. Perhaps the best known is the univariate and multivariate decompositions of Beveridge-Nelson. Huizinga (1987) was the first to plot the permanent component derived from a univariate BN decomposition against the actual real rate and then make inferences about the extent of over- or undervaluation of particular currencies. Cumby and Huizinga (1990) use multivariate B-N decomposition (MBN) for the same purpose. Clarida and Gali (1994) show that the univariate and multivariate decompositions give very different measures of misalignment, in the sense that the two measures can give conflicting signals.

Clarida and Gali (1994) use an SVAR approach to extract demand and supply shocks (taken to be the permanent components of the real exchange rate) and nominal shocks (taken to be the transitory components) of real exchange rates. They then construct figures to show the importance of the three shocks on the real exchange rates of the US dollar bilateral rates of the Canadian dollar, German mark, Japanese yen and UK pound. MacDonald and Swagel (2000) apply the Clarida-Gali method to the real effective exchange rates of the German mark, Japanese yen, UK pound and US dollar (and also the bilateral US dollar exchange rates of the German mark, pound sterling and Japanese yen). They interpret the cyclical, or business cycle, component as the sum of the demand and nominal shocks and netting this out from the actual real exchange rate, produce an alternative measure of the permanent (i.e. supply side) component of the real exchange rate. Detken et al. (2002), augment the basic Clarida-Gali model to include a relative employment term, the difference in the ratio of government consumption over GDP and the long-term interest differential.

\subsubsection{Decomposition of the Cointegrating Vector}

Clark and MacDonald (2000) also propose using the permanent component calculated from a VAR system and interpret this as measure of equilibrium, which is referred to as the Permanent Equilibrium Exchange Rate (or PEER). In contrast to the studies that use SVARs, the PEER does not rely on Blanchard-Quah style restrictions but it does require the existence of cointegration amongst the variables entering the VAR and relies on the decomposition of Granger and Gonzalo (1995).

Clark and MacDonald (2000) interpret the PEER as one way of calibrating a BEER. For example as an alternative to steps three and four of the BEER approach, discussed in the last section, is a single step that consists in decomposing the fitted estimated long-term relationship into permanent and transitory components using the Gonzalo-Granger method. This version of the BEER is usually referred to as the Permanent Equilibrium Exchange Rate (PEER).

\footnotetext{
${ }^{34}$ Note that this is a highly simplified approach to deducing the nominal equilibrium exchange rate because it does not account for the dynamic effects of a nominal adjustment. A sizeable change in the nominal exchange rate that would correct for real misalignments in period t may move the real exchange rate away from equilibrium because of the nominal adjustment's effects on domestic (and foreign) prices. Such an effect could be considered by examining nominal exchange rate pass-through (Darvas, 2001) or by using a structural model of the economy.
} 


\subsection{UIP and PPP: Capital Enhanced Measures of the Equilibrium Exchange Rate - CHEERS}

In this section we consider the so-called capital enhanced equilibrium exchange rate, or CHEERs (see MacDonald (2004)), approach to defining an equilibrium exchange rate. The main advantage of this approach is that it is highly tractable and can be used to provide reasonable measures of equilibrium exchange rates for both developed and transition economies in the absence of the kind of data needed to implement some of the other approaches. In the academic literature the approach has been popularised by Juselius (1991, 1995), Johansen and Juselius (1992), MacDonald and Marsh (1997, 1999) and Juselius and MacDonald (2000). The approach captures the basic Casselian view of PPP that an exchange rate may be away from its PPP determined rate because of non-zero interest differentials. Unlike the pure form of Casselian PPP, in which non-zero interest differentials only have a transitory impact on the real exchange rate, here the interest rates can have a medium run, or business cycle, effect. The essential proposition of this approach is that the long-term persistence in the real exchange rate is mirrored in the interest differential. Since the approach requires only a limited menu of variables it has been argued to be potentially useful for transition economies where data limitations are often severe. We consider the CHEERs approach firstly from a statistical perspective and then from an economic perspective.

Since interest differentials are usually empirically found to be I(1) processes (see for example, Juselius and MacDonald (2000)) some combination of an appropriate interest differential and the real exchange rate may cointegrate down to a stationary process:

$$
\left[e_{t}+\beta_{1}\left(p_{t}^{*}-p_{t}\right)+\beta_{2}\left(i_{t}-i_{t}^{*}\right)\right] \sim I(0)
$$

The CHEERs approach, therefore, involves exploiting the following vector:

$$
x_{t}^{\prime}=\left[e_{t}, p_{t}, p_{t}^{*}, i_{t}, i_{t}^{*}\right] \text {. }
$$

As a measure of the equilibrium exchange rate, CHEERs is clearly a 'medium-run' concept in the sense that it does not impose stock-flow consistency. This may be seen as a disadvantage of the approach for assessment purposes. However, it may, nevertheless, provide a useful measure of equilibrium in circumstances where data on net foreign asset positions and other fundamentals are not available.

\subsection{The New Open Economy Macroeconomics Approach to Equilibrium Exchange Rates.}

Obstfeld and Rogoff (2001) have shown how the New Open Economy Macroeconomic (NOEM) approach may be used to address misalignment issues. Although this approach has so far not been widely used for assessment purposes, the fact that only a very small amount of information is required to produce a measure of exchange rate misalignment would seem to make it ideally suited for the current group of new EU member states. In illustrating the approach we follow the example in Obstfeld and Rogoff (2001). The latter was set up to show how much the US exchange rate would have to move in 2001 in order to restore balance on the US current account.

The key element in the new open economy (NOEM) class of model is that the optimising behaviour of consumers has implications for the current account which, in turn, has implications for exchange rates. The approach has more in common with the FEER based approach than the other approaches considered in this paper, since it does not produce a measure of the equilibrium exchange rate. Rather it asks the question: how much would the exchange rate have to move to reduce a current account imbalance to zero given an assumption of internal balance?

Consumers are assumed to have a CES Utility function of the form:

$$
\left[\gamma C^{T^{\frac{\theta-1}{\theta}}}+(1-\gamma) C^{N T^{\frac{\theta-1}{\theta}}}\right]^{\frac{\theta}{\theta-1}}
$$

where $\theta$ is price elasticity. When $\theta=1$, (31) simplifies to the simple $\log$ form: 


$$
\gamma \log C^{T}+(1-\gamma) \log C^{N T}
$$

The domestic production of both tradables and non-tradables is assumed exogenous at $Y^{T}$ and $Y^{N T}$, respectively, and so the consumption of non-tradable goods must match the production of non-tradable goods, that is $C^{T}=Y^{N T}$. However, the existence of international trade means that the consumer's consumption of the tradable good is not tied to production - $C^{T} \neq Y^{N T}$

If prices are assumed fully flexible then it follows that the relative price of non-tradable to tradable goods $p=P^{N T} / P^{T}$ - is determined in the following way.

$$
p=\frac{1-\gamma^{1 / \theta}}{\gamma} C^{T} / Y^{N T^{1 / \theta}}
$$

and it follows that the exact CPI, in terms of the tradable good, is:

$$
P=\left[\gamma+(1-\gamma) p^{1-\theta}\right]^{\frac{1}{1-\theta}}
$$

Given the above set up, calculation of the required exchange rate change - real and nominal - to remove a current account imbalance hinges on having numerical values for $\theta$ and $C^{T} / Y^{N}$. For the parameter $\theta$, Ostry and Reinhart (1992) have reported point estimates of around 1 for short to medium run horizons, although the figure is likely to be higher in the long-run. An estimate of $C^{T} / Y^{N}$ may be obtained from the current account ratio:

$$
\frac{C A}{Y}=\frac{Y_{T}-C_{T}-i D}{Y}
$$

where Y (GDP) and D (net external debt) are expressed in terms of tradable goods ${ }^{35}$. The impact of the rise in the relative price of tradable goods ( $\mathrm{p}$ falls) on the CPI depends on the central bank's price stabilisation policy. If the Fed tries to stabilise the CPI then with $\mathrm{Y}^{\mathrm{NT}}=75 \%$ and $\mathrm{Y}^{\mathrm{T}}=25 \%$ a $12 \%$ rise in tradable prices would be required and a $4 \%$ fall in non-tradable prices. Since $\mathrm{P}_{\mathrm{T}}$ is set in world markets this implies a $12 \%$ depreciation of the exchange rate.

The effects of current account changes depend crucially on the underlying assumptions. For example, if the parameter $\theta$ equalled 0.5 , instead of 1 , this would imply a nominal exchange rate depreciation of $24 \%$. Alternatively, a value of $Y^{T} / Y$ of $15 \%$ would imply a $20 \%$ exchange rate depreciation. If the assumption of price flexibility is swapped for one of some price stickiness, this will alter the current account implications for the exchange rate further. For example, if exporters only pass through one-half of any exchange rate change to importers, the Fed would have to let the dollar depreciate by $24 \%$ to stabilise the CPI and the level of employment in the non-tradable sector. With price stickiness of tradable and non-tradable goods, and if imports account for about $1 / 2$ of all tradable consumed, then a US dollar depreciation of between 40 and 50 per cent would be required.

The upshot of the Obstfeld and Rogoff analysis is that there is an important short - long distinction in the effects of the current account on the exchange rate. In the long-run with price flexibility and a higher value of $\theta$, the required exchange rate change would be much smaller than in the short-run where the combination of price stickiness and a relatively small value of $\theta$ would produce a large exchange rate change.

\section{The Connection between Different Approaches}

So far we have presented the major models which have been used to estimate equilibrium real exchange rates in CEE countries. They can be structured as follows: PPP is perhaps of most use in the very long run, i.e. in a

\footnotetext{
${ }^{35}$ Taking the situation of the US in 1991, where a current account deficit as a proportion of GDP of 4.4 per cent existed, Obstfeld and Rogoff assume $\mathrm{Y} / \mathrm{Y}$ is $25 \%$ and $\mathrm{iD} / \mathrm{Y}$ is $1.2 \%$ (which implies an interest rate of $6 \%$ and a GDP to net debt ratio of $20 \%$ ). If for external balance, the ratio of the current account to income, $\mathrm{CA} / \mathrm{Y}$, falls to zero the drop in net imports of tradables would be $16 \%$ (i.e. 4.4/28.2). With prices fully flexible and $\theta$ equal to unity, the relative price of non-tradable to tradable goods, $p$, has to fall by $16 \%$ otherwise there would be an excess supply of non-tradable goods which would conflict with the internal balance assumption.
} 
secular context. The B-S effect, both in levels (PPP adjusted for differences in productivities) and dynamics (convergence towards the PPP level in the event of rapid growth) should provide good guidance in the longrun, although in addition to the non-tradable price channel, a trend appreciation of the tradable price-deflated real exchange rate can, as we have seen, also occurs in the long-run and it is important that this is recognised. The FEER and medium-term NATREX, since they focus on medium-term current account sustainability, should be useful for more immediate exchange rate assessment issues. The long-term NATREX, which considers adjustments of the capital and net foreign debt stocks toward their steady state level, gives further guidance on the evolution of the long-run real exchange rate. The BEER is useful for both medium and longer run assessment issues.

In order to gain a better understanding of the interrelationships between the different equilibrium exchange rate approaches, consider Figure 4, where the grey corridor represents what may be called the PPP zone. For countries at comparable levels of development, the level of the real exchange rate should be equal to 1, i.e. the price levels in the home and foreign countries should be equal when expressed in the same currency unit $\left(\mathrm{EP}^{*}=\mathrm{P}\right.$, that is, absolute PPP holds). Nonetheless, because of differences in, for example, the tax system and wage policies and because of trade barriers and other market imperfections, the equilibrium real exchange rate fluctuates in a band of, say, $\pm \mu$ around 1. Also, differentiated goods allow for pricing-tomarket practices, which may shift the PPP ratio (with the band around it) away from 1, even in the long run.

When countries at different stages of development are considered, the less developed country's real exchange rate is usually undervalued when using the PPP concept and, consequently, it is higher than $1 .{ }^{36}$ But this is an equilibrium undervaluation in PPP terms. At the same time, the real exchange rate is in equilibrium when taking into account the difference in the levels of dual productivity between countries. Point A represents this situation.

In these two cases, the absence of major changes in relative economic development, especially in relative dual productivity levels, would imply no major changes in the level of the equilibrium real exchange rate. However, for industrialized countries PPP has proven difficult to verify, especially when standard time series methods are applied to relatively short time spans of 20 to 30 years. Although the use of secular time series and large panel data sets appears to show that real exchange rates are significantly mean reverting, the typical half-life (i.e. the time needed for the deviation vis-à-vis equilibrium to diminish by half), ranges from three to five years - Rogoff (1996) - and is too slow to be consistent with PPP. However, a more plausible explanation for the PPP puzzle has recently emerged. Using threshold autoregressive (TAR) models, it is possible to show that within a band around equilibrium, such as shown in Figure 4, the real exchange rate exhibits non-stationarity, i.e. it follows a stochastic trend because transaction costs are high enough to prohibit goods arbitrage. However, when the real exchange rate moves beyond a threshold, over which profits to be realized from goods arbitrage exceed transaction costs, the real exchange rate tends to return to the PPP corridor ${ }^{37}$ which may be different for individual countries. Typically, nonlinear adjustments towards the band are found to happen much faster when compared with the typical half-life of three to five years. ${ }^{38}$ Alternatively, Imbs et al. (2002) argue that the three to five years half-life of the rate exchange rate drops to one year, if disaggregated goods-level data is used and if heterogeneity is accounted for appropriately. However, Chen and Engel (2004) show that if a small sample bias is corrected for when estimating the half life, and data measurement issues are addressed, the heterogeneity and aggregation bias does not play a role in explaining the long half-life in Rogoff (1996).

If one country experiences higher economic growth, and especially rapid increases in dual productivity that cause the price level to rise, compared with those in the other countries, its equilibrium real exchange rate appreciates systematically. This reflects a successful catching-up with the other countries if this country starts from a less-developed stage. Alternatively, if it starts from a similar stage of development, it can also grow apart from the rest of the world. In Figure 4, the equilibrium real exchange rate appreciates until it reaches, through points $\mathrm{B}$ and $\mathrm{C}$, the PPP corridor of $1 \pm \mu$. The equilibrium appreciation itself is also a corridor because of transaction costs.

\footnotetext{
${ }^{36}$ The exchange rate is expressed as home currency units over one unit of foreign currency.

${ }^{37}$ The speed with which the real exchange rate returns to the band may be modeled in different ways. The TAR model assumes abrupt adjustment back to the band, whereas smooth transition autoregressive (STAR) and self-exciting threshold autoregressive (SETAR) models allow for smoother adjustment toward the band of inaction.

${ }^{38}$ For an overview, see Sarno and Taylor (2002).
} 
However, it may be that the real exchange rate is not in equilibrium when considering dual productivity levels. For instance, point A' shows the situation of the real exchange rate when it is undervalued, not only in PPP terms, but also when accounting for differences in dual productivity levels. This implies an initial undervaluation of the domestic currency that could call for a quick real appreciation towards levels given by productivity. In contrast, $\mathrm{A}$ " refers to the position in which the real exchange rate can be viewed as overvalued when differences in dual productivity levels are accounted for. As a consequence, the actual real appreciation should be lower than the equilibrium trend appreciation in line with productivity advances so as to compensate for this misalignment and to ensure that the real exchange rate returns to the "equilibrium corridor."

During periods of rapid change in relative economic development levels, the equilibrium real exchange rate may exhibit trending behaviour over a period of 15 to 30 years. For such a period, PPP cannot be used as a yardstick, although it may be indicative in periods over which relative economic performances equalize (Froot and Rogoff, 1994; Froot et al. 1995). But a period of 15 to 30 years is still far too long to interpret the equilibrium real exchange rate for policy purposes and so some other more appropriate measure is required. The FEER approach provides a medium-term definition of the equilibrium real exchange rate which is compatible with current account sustainability. This implies that even during a period of trend appreciation, the equilibrium real exchange rate can depreciate or appreciate compared to the trend because of external imbalances.

Accordingly, not only the observed real exchange rate, but also the equilibrium real exchange rate can fluctuate within the band in the medium run. The reason for this is that productivity increases consider current account developments and net foreign indebtedness only implicitly by referring to competitiveness in the tradable sector. This is possibly not always sufficient to secure current account sustainability in the medium term, and that is why the BEER including these variables, and especially the FEER approaches, can explicitly tackle this issue in the medium run. It may be that, in spite of the fact that the equilibrium real exchange rate appreciates in the longer run, it has to depreciate in the medium run so as to bring back the current account to its long-term value, which ensures a viable path for the foreign debt. 
Figure 4. Trend Appreciation of the Equilibrium Real Exchange Rate

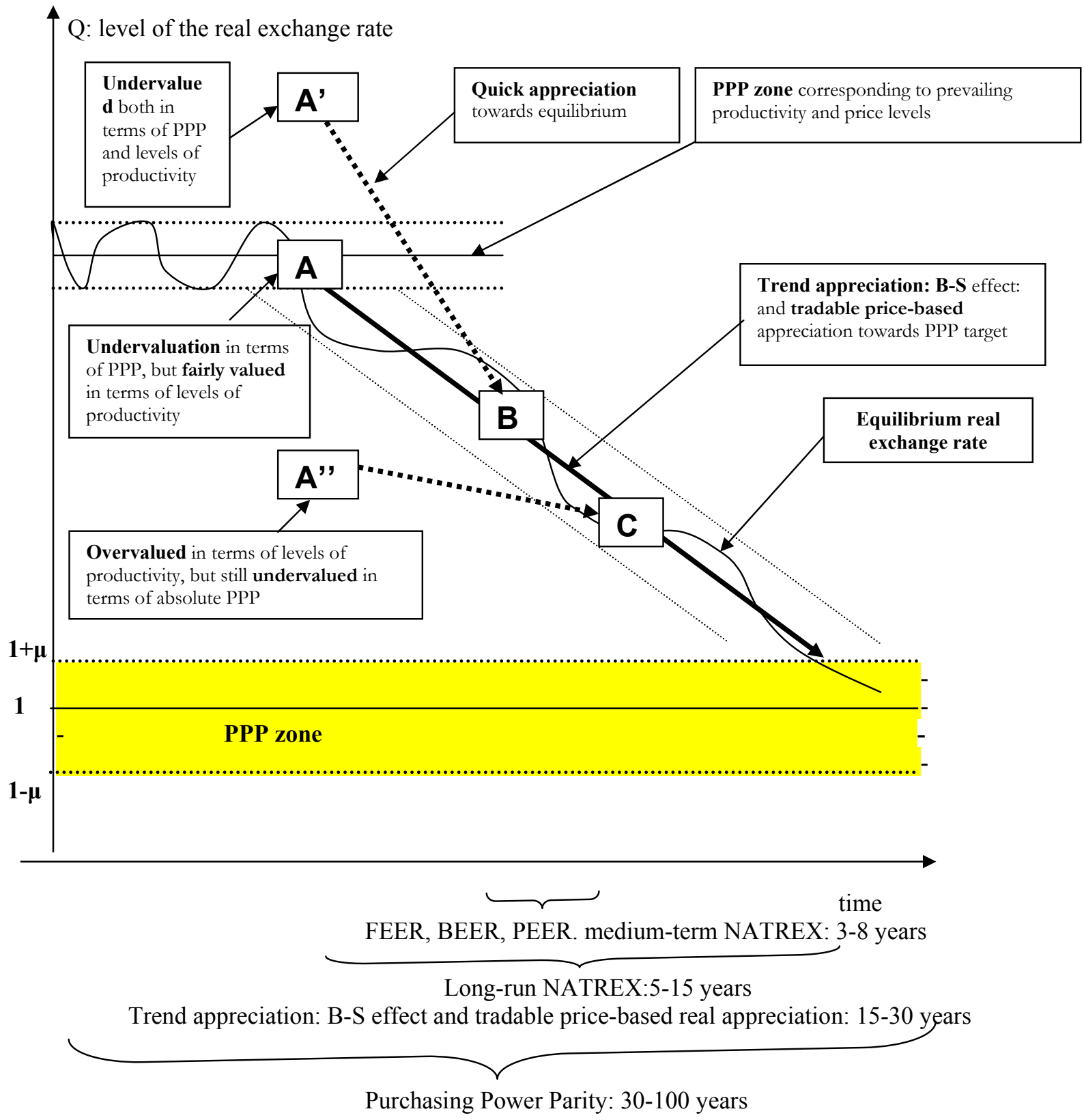

\section{Methodological Considerations in Transition Economies}

We now turn to the issue of the statistical techniques used (displayed in Table 1) to estimate the equilibrium real exchange rate. The first, and simplest, approach used for transition economies involves the calculation of descriptive statistics, for key relationships from the simple B-S model. This consists of computing yearly average growth rates for dual productivity (or the dual productivity differential) and the relative price of nontradables (or the relative price differential). Alternatively, data can be analyzed graphically to determine if the real exchange rate and the relative price differential are in line with the dual productivity differential. 
Table 4. Overview of Major Differences in the Estimation Methods

\begin{tabular}{|c|c|c|c|}
\hline Approach & Estimated Specification & Econometric Methods & Misalignment \\
\hline Simple B-S model & $\begin{array}{l}\left(a^{\mathrm{T}}-a^{\mathrm{NT}}\right) \rightarrow\left(\mathrm{p}^{\mathrm{NT}}-\mathrm{p}^{\mathrm{T}}\right) \\
\left(\mathrm{a}^{\mathrm{T}}-\mathrm{a}^{\mathrm{NT}}\right)-\left(\mathrm{a}^{\mathrm{T} *}-\mathrm{a}^{\mathrm{NT}}\right) \rightarrow\left(\mathrm{p}^{\mathrm{NT}}-\mathrm{p}^{\mathrm{T}}\right)-\left(\mathrm{p}^{\mathrm{NT} *}-\mathrm{p}^{\mathrm{T} *}\right) \\
\left(\mathrm{p}^{\mathrm{NT}}-\mathrm{p}^{\mathrm{T}}\right)-\left(\mathrm{p}^{\mathrm{NT}}-\mathrm{p}^{\mathrm{T} *}\right) \rightarrow \operatorname{RER} \\
\left(\mathrm{a}^{\mathrm{T}}-\mathrm{a}^{\mathrm{NT}}\right)-\left(\mathrm{a}^{\mathrm{T} *}-\mathrm{a}^{\mathrm{NT}}\right) \rightarrow \operatorname{RER}\end{array}$ & $\begin{array}{l}\text { Descriptive statistics } \\
\text { Time series } \\
\text { Panel } \\
\text { Cross-section }\end{array}$ & $\begin{array}{l}\text { None. } \\
\text { Actual }\end{array}$ \\
\hline BEER & $\begin{array}{l}\left(\mathrm{a}^{\mathrm{T}}-\mathrm{a}^{\mathrm{NT}}\right) \rightarrow\left(\mathrm{p}^{\mathrm{NT}}-\mathrm{p}^{\mathrm{T}}\right) \\
\left(a^{T}-a^{N T}\right)-\left(a^{T *}-a^{N T *}\right) \rightarrow R E R \\
\left(a^{T}-a^{T^{*}}\right),\left(a^{N T}-a^{N T *}\right) \rightarrow R E R \\
\left(\mathrm{a}^{\mathrm{T}}-\mathrm{a}^{\mathrm{NT}}\right) \rightarrow \mathrm{RER} \\
\left(\mathrm{p}^{\mathrm{NT}}-\mathrm{p}^{\mathrm{T}}\right)-\left(\mathrm{p}^{\mathrm{NT} *}-\mathrm{p}^{\mathrm{T} *}\right) \rightarrow \mathrm{RER}\end{array}$ & $\begin{array}{l}\text { Time series } \\
\text { Panel: in-sample, out-of-sample }\end{array}$ & $\begin{array}{l}\text { None } \\
\text { Actual } \\
\text { Total }\end{array}$ \\
\hline FEER & $\begin{array}{l}\text { Multi-country model } \\
\text { Single-country model } \\
\text { Full-scale macromodel } \\
\text { Model of foreign trade }\end{array}$ & Structural models -4 steps & Total \\
\hline NATREX & & \begin{tabular}{|l|} 
Single equation \\
Structural model
\end{tabular} & Total \\
\hline
\end{tabular}

More rigorous tests of the simple and extended versions of the B-S model have involved using time series methods, such as the cointegration methods discussed in the BEER section. Another way of estimating the simple and extended B-S model consists of employing panel estimation methods. Since the philosophy underpinning the application of panel methods differs to some extent from the use of time series methods, we describe them in more detail below. The basic idea is that the countries included in the panel should behave relatively similarly in the long-run. This implies that the real exchange rate is assumed to react quite similarly to changes in the fundamentals in every country of the panel. The estimation of the relationship between the real exchange rate and its fundamentals yields average coefficients for the whole panel and if long-term homogeneity holds in the panel, the estimated average coefficients are expected to properly reflect the long-run behaviour of the real exchange rate of individual countries and can thus provide a better estimate than that which would be obtained by purely time series methods.

The equilibrium real exchange rate can be derived from panel estimates in much the same way as it is from a time series analysis: first, the actual misalignment is determined and then, in a second stage, the total misalignment is obtained based on the long-term values of the fundamentals.

A further point worth noting with respect to panel methods relates to in-sample and out-of-sample panel estimates. For the in-sample approach the equilibrium real exchange rate is assessed for the countries included in the sample and for the period used for the estimation. By contrast, out-of-sample estimates involve estimating the link between the real exchange rate and fundamentals for a given set of countries and then computing the equilibrium exchange rate for countries not included in the sample, and/or for a different period, ${ }^{39}$ by substituting the corresponding fundamentals series into the estimated equation.

Regarding the calculation of misalignment, the following patterns emerge from the literature on the CEE countries:

1) Some papers simply do not compute misalignment. The sole aim of these papers is to show the empirical linkage through which the real exchange rate is connected to fundamentals (real exchange rate determination, as in step 1 of the BEER and panel estimations), i.e. to estimate a model of real exchange rate determination.

2) Others calculate only actual misalignment. This is particularly the case when purely time-series or panel estimators are used.

3) Finally, another part of the BEER and panel literatures also aims at identifying total misalignment. In this regard, it should be noted that the FEER approach always produces a measure of total misalignment.

\footnotetext{
${ }^{39}$ E.g. the panel includes countries A, B, C,..., M for 1960-90, and the equilibrium exchange rate is assessed for the case of countries $\mathrm{N}$ and $\mathrm{L}$ for the period 1995-2003.
} 


\section{What Have We Learned from the Literature?}

\subsection{The Trend Appreciation of the Real Exchange Rate}

Perhaps the most widely studied relationship for the exchange rates of CEE countries is the role of productivity in explaining the trend appreciation of these currencies. There are a number of ways in which the influence of productivity on the trend appreciation of the two real exchange rates referred to earlier has been captured. The first approach, of relating productivity differentials to the internal price terms, is used most often when investigating the simple B-S, or trend appreciation model, while the remaining approaches, which feature the overall real exchange rate, can be employed, in principle, to test both the simple B-S framework and the BEER approach.

First, there is a test of the relationship linking dual productivity with the relative price of non-tradable goods for the home country $\left(\left(\mathrm{a}^{\mathrm{T}}-\mathrm{a}^{\mathrm{NT}}\right) \rightarrow\left(\mathrm{p}^{\mathrm{NT}}-\mathrm{p}^{\mathrm{T}}\right)\right)$, where " $a$ " stands for productivity. This can be referred to as the internal transmission mechanism and is a test in the spirit of the Balassa-Samuleson hypothesis. A second and more appropriate test considers the link between the dual productivity differential and the difference in the home and foreign relative price of non-tradable goods (relative price differential henceforth) $\left(\left(a^{\mathrm{T}}-\mathrm{a}^{\mathrm{NT}}\right)-\left(\mathrm{a}^{\mathrm{T} *}-\mathrm{a}^{\mathrm{NT} *}\right) \rightarrow\left(\mathrm{p}^{\mathrm{NT}}-\mathrm{p}^{\mathrm{T}}\right)-\left(\mathrm{p}^{\mathrm{NT} *}-\mathrm{p}^{\mathrm{T} *}\right)\right)$. In this context it is worth noting that usually no distinction is made between market and regulated non-tradable prices, which could produce substantially biased estimates. Two complementary sets of regressions then follow, one in which the real exchange rate is regressed on the home country's dual productivity $\left(\left(\mathrm{a}^{\mathrm{T}}-\mathrm{a}^{\mathrm{NT}}\right) \rightarrow \mathrm{RER}\right)$, a regression which links the dual productivity differential to the real exchange rate $\left(\left(a^{\mathrm{T}}-\mathrm{a}^{\mathrm{NT}}\right)-\left(\mathrm{a}^{\mathrm{T} *}-\mathrm{a}^{\mathrm{NT} *}\right) \rightarrow \mathrm{RER}\right)$. Alternatively, the productivity differential for tradables and the one for non-tradables can be used separately $\left(\left(a^{T}-a^{T^{*}}\right),\left(a^{N T}-a^{N T^{*}}\right) \rightarrow R E R\right)$. In terms of the real exchange rate the regression $\left(\mathrm{p}^{\mathrm{NT}}-\mathrm{p}^{\mathrm{T}}\right)-\left(\mathrm{p}^{\mathrm{NT} *}-\mathrm{p}^{\mathrm{T} *}\right) \rightarrow \mathrm{RER}$ is often considered as an alternative to $\left(\mathrm{a}^{\mathrm{T}}-\mathrm{a}^{\mathrm{NT}}\right)-\left(\mathrm{a}^{\mathrm{T} *}-\mathrm{a}^{\mathrm{NT} *}\right) \rightarrow \mathrm{RER}$, where the relative price differential is taken as a proxy for the dual productivity differential. However, it is important to note that this is not an equivalent relationship because productivity may also impact directly on tradable prices. Furthermore, even if the relationship $\left(p^{N T}-p^{T}\right)-\left(p^{N T *}-p^{T *}\right) \rightarrow R E R$ is found to be significant, it might well be a spurious proxy for the productivity relationship and could, for example, reflect the influence of regulated prices.

\subsubsection{The Role of Market Non-Tradables: The Balassa-Samuelson Effect}

The real exchange rate of the transition economies has experienced strong appreciation from the outset of the transition process, although the extent of the appreciation has been very different across individual countries. It is a widely held view that this appreciation is largely due to the B-S effect and thus has not resulted in an overvaluation of the currencies. A first strand of papers (e.g. Sinn and Reutter, 2000; Rother, 2002; Golinelli and Orsi, 2002; Jazbec, 2002) supports this view (upper part of Table 5). However, another group of papers, listed in the lower part of Table 5, has recently shown that, at best, half of this appreciation can be ascribed to the B-S effect (see e.g. Kovács, 2001, 2002; Flek et al., 2002; Égert, 2002; Égert et al., 2003, Mihaljek and Klau, 2004 and Wagner and Hlouskova, 2004) ${ }^{40}$. A major reason for this finding is that relative PPP does not hold for the open sector, since the PPI-based real exchange rate (used as a proxy for the real exchange rate in the open sector) has also appreciated, though to a lesser extent than the CPI-based real exchange rate. The failure of relative PPP to hold for the open sector does not automatically imply that the B-S effect has little impact on overall real exchange rate movements because the B-S effect is expected to explain the difference between the overall inflation-deflated (CPI) and the tradable price-based (PPI) real exchange rates. ${ }^{41}$ Hence,

\footnotetext{
${ }^{40}$ Interestingly, even the first strand of papers finds a very low inflation differential for the Czech Republic that is attributable to the B-S effect. This is because increases in overall and dual productivity in the Czech Republic were among the lowest in the transition countries. However, another explanation for this outcome may lie in statistical problems: The Czech Statistical Office may have considerably underestimated output in the Czech Republic (Filer and Hanousek, 2000). This is all the more possible as the Czech Republic was the biggest net FDI receiver among the transition economies not only in terms of FDI per capita but also regarding the absolute stock of FDI cumulated from 1991 to 2003, which amounts to nearly USD 42 billion (EBRD, 2003).

${ }^{41}$ When using the CPI and the PPI, this only holds if overall inflation is composed of tradable goods and market-based services, and if the tradable component of the PPI corresponds to that of the CPI.
} 
if the share of market-based non-tradable prices is large enough in the CPI, the gap between the two real exchange rate series may be substantial, allowing the B-S effect to explain potentially a large part of overall real exchange rate movements. The second major reason why he B-S effect play a limited role in real exchange rate determination can be traced back to the low share of market-based non-tradables in the CPI. Indeed the share of market-based non-tradable account for around $20 \%$ of the CPI basket in the Baltic states and in South-Eastern Europe and for 30\% in the CEE-5.

The equilibrium appreciation of the real exchange rate, and thus the underlying inflation differential vis-à-vis Germany and the euro area that can be imputed to the B-S effect, is found to amount to up to $2.0 \%$ in Hungary and Poland and is much lower in the other countries. ${ }^{42}$ In the Czech Republic and Latvia, it is close to zero. ${ }^{43}$

This finding has important implications: for example, the B-S effect, i.e. productivity-driven market service inflation, is likely to be no barrier to meeting the Maastricht criterion on price stability, defined as the average inflation rate (measured in terms of the harmonized CPI) of the three best-performing EU countries in terms of price stability plus $1.5 \%{ }^{44}$

However, this does not mean that the fulfilment of the criterion would pose no problem for tradable price inflation, and especially regulated price inflation may be of importance in this respect. For instance, in addition to the standard B-S framework, Wagner and Hlouskova (2004) use GDP per capita as a demandside variable, along with tradable prices, to generate inflation rates for $8 \mathrm{CEECs}$. Based on data running from 1994 to 2001, they find that using these additional variables gives a medium-term inflation rate in the range from 3\% to $7 \%$. Furthermore, it is interesting to note that 'catching-up' EU countries, such as Greece, Portugal and Spain, recorded very low changes in dual productivity during the 1990s despite above-average economic growth coupled with above-average inflation rates. This may imply that mechanisms other than the B-S effect could be at work and bring about changes in relative price levels.

\footnotetext{
${ }^{42}$ Kovács (2003) argues that the B-S effect is not likely to exceed 2\% per annum even in the longer run. Kozamernik (2003) makes model-based projections and concludes that the yearly inflation rate imputable to the B-S effect would range from $1 \%$ to $1.5 \%$ in Slovenia ( $0.4 \%$ to $0.9 \%$ in terms of an inflation differential vis-à-vis Germany).

${ }^{43}$ One should not forget that these figures are based on past data. One may argue that the maximum value of $2 \%$ can be affected by different future developments. On the one hand, a slowdown in productivity increases in the open sector as transition countries' productivity levels approach EU productivity levels. On the other hand, EU accession may foster productivity growth in the open sector due to the deepening of EU integration. But this may be overcompensated by the fact that productivity gains in the sheltered sector may pick up. Although the share of (market) services in the new EU member states' national and harmonized CPI (20\% to $35 \%)$ is still lower than what we can observe in the EU (40\% to $45 \%)$, it may only increase progressively with higher real income per capita, and would not exacerbate the B-S effect's impact on the CPI.

${ }^{44}$ This is in contrast with the long held view, advocated by Buiter and Grafe (2002) and Szapáry (2003) among others, that new EU member states in Central and Eastern Europe would not be able to fulfill the Maastricht criterion on price stability because of the B-S effect.
} 
Table 5. Average Annual Inflation Differential and the Real Appreciation of the Exchange Rate Implied by the Balassa-Samuelson Effect vis-à-vis Germany or the Euro Area (\%)

\begin{tabular}{|c|c|c|c|c|c|c|c|c|c|c|c|c|c|c|}
\hline & \multicolumn{3}{|c|}{ B-3 } & \multicolumn{5}{|c|}{ CEE-5 } & \multicolumn{3}{|c|}{ SEE } & \multicolumn{2}{|c|}{ FSU } & Panel \\
\hline \multicolumn{15}{|c|}{ Conventional view (high estimates) } \\
\hline (in \%) & $\mathbf{E E}$ & $\mathbf{L V}$ & LT & $\mathbf{C Z}$ & HU & PL & SK & SI & BG & HR & RO & $\mathbf{R U}$ & UA & \\
\hline Backé et al. (2003); a & & & & 0.4 & 4.5 & 9.4 & & 3.5 & & & & & & \\
\hline Golinelli and Orsi (2002); a & & & & 4.1 & 1.9 & 4.9 & & & & & & & & \\
\hline Rosati (2002); a & 2.0 & & & 1.0 & 3.9 & 4.2 & & 2.0 & & & & & & \\
\hline Rother (2000); a & & & & & & & & 2.6 & & & & & & \\
\hline Sinn and Reutter (2001); a & 3.2 & & & 2.7 & 6.7 & 4.0 & & 3.2 & & & & & & \\
\hline Average & 2.6 & & & 2.0 & 4.3 & 5.6 & & 2.8 & & & & & & \\
\hline \multicolumn{15}{|c|}{ New view (low estimates) } \\
\hline Burgess et al. (2003) & 0.4 & 0.4 & 0.5 & & & & & & & & & & & \\
\hline DeBroeck and Sløk & & & & & & & & & & & & & & 1.0 \\
\hline Égert (2002) & & & & 0.2 & 1.4 & 1.9 & -0.7 & -0.5 & & & & & & \\
\hline Égert (2005a) & 0.7 & & & & & & & & & & & & & \\
\hline Égert (2005b) & & & & & & & & & -0.8 & 0.0 & 0.5 & 0.7 & .05 & \\
\hline Égert et al. (2003) & 0.5 & 0.0 & 0.0 & 0.0 & 0.8 & 1.7 & 0.9 & 0.7 & & 0.8 & & & & \\
\hline Felk et al. (2002) & & & & -0.3 & & & & & & & & & & \\
\hline Halpern and Wyplosz (2001); a & & & & & & & & & & & & & & 1.0 \\
\hline Kovács (2001) & & & & & 1.5 & & & & & & & & & \\
\hline Kovács and Simon (1998) & & & & & 1.6 & & & & & & & & & \\
\hline Kovács (2002) & & & & 0.1 & 1.9 & & & & & & & & & \\
\hline Mihaljek and Klau (2004); a & & & & 0.0 & 1.2 & 1.1 & 0.3 & 0.3 & & 0.9 & & & & \\
\hline Wagner and Hlouskova (2004) & -0.1 & 0.1 & 0.6 & 0.2 & 0.7 & 0.7 & -0.2 & 0.5 & & & & & & \\
\hline Žumer (2002) & & & & & & & & 0.7 & & & & & & \\
\hline Average & 0.4 & 0.2 & 0.4 & 0.0 & 1.3 & 1.3 & 0.1 & 0.3 & -0.8 & 0.6 & 0.5 & 0.7 & 0.1 & 1.0 \\
\hline $\begin{array}{l}\text { Average real appreciation } \\
\text { 1993-2002 }\end{array}$ & $\sim 10.0$ & $\sim 10.0$ & $\sim 10.0$ & $\sim 5.0$ & $\sim 3.0$ & $\sim 4.0$ & $\sim 4.0$ & $\sim 1.5$ & $\sim 6.0$ & $\sim 3.0$ & $6.0 \sim$ & $\sim 8.0$ & $\sim 7.0$ & \\
\hline
\end{tabular}

Source: Authors' own calculations based on the original papers

Note: Figures are average annual changes. Furthermore, figures are average figures of the range given in the original paper.

a) $=$ the inflation differential against Germany computed using a Balassa-Samuelson implied inflation rate of $0.35 \%$ for the euro area

/ Germany (Swagel (1999), Lommatzsch and Tober (2003) and Égert et al. (2003) put the size of the B-S effect to 0\% (1990 to $1996)$, to $0.1 \%$ (1995-2002) and to $0.55 \%$ (1995-2000), respectively.)

$\mathrm{EE}=$ Estnia, LV=Latvia, LT=Lithuania, $\mathrm{CZ}=$ Czech Republic, $\mathrm{HU}=$ Hungary, $\mathrm{PL}=$ Poland, $\mathrm{SK}=$ Slovakia, SI=Slovenia, $\mathrm{BG}=\mathrm{Bulgaria}$, $\mathrm{HR}=$ Croatia, $\mathrm{RO}=$ Romania, $\mathrm{RU}=$ Russia, $\mathrm{UA}=$ Ukraine.

As documented in Figure 1, both the CPI-based real exchange rate and the PPI-deflated real exchange rate underwent a certain trend appreciation from the early 1990s onwards in the transition economies and these two real exchange rates moved fairly closely together. This is supported by Cincibuch and Podpiera (2004) who show that sectoral real exchange rates in manufacturing industries experienced strong appreciation from 1997-2004. Clearly, the traditional B-S effect cannot explain the appreciation of the real exchange rate deflated by the PPI (as a proxy for tradable prices) because its impact passes through the non-tradable price channel. Indeed, the B-S effect that posits PPP to hold for tradable goods is meant to explain possible differences between changes in the overall inflation-based (CPI) and the tradable price-deflated (PPI) exchange rates.

This point is demonstrated by Égert et al. (2003), who, for a panel of 9 transition economies, report results for the relationship between different relative price measures on the one hand, and the CPI-based real exchange rate and the PPI-based real exchange rate on the other hand. The fact that both real exchange rates turn out to be cointegrated with the relative price measures is a further piece of evidence that the real appreciation cannot be fully associated with the B-S effect. ${ }^{45}$

There are other possible reasons why the B-S effect may not work. The two crucial assumptions for the internal transmission to function properly are a.) the proportionate relation between productivity and real wages in the open sector and b.) wage equalisation across sectors, which ensures that productivity gains are

\footnotetext{
${ }^{45}$ For the B-S effect to explain the entirety of the real appreciation, the CPI-deflated real exchange rate is expected to be connected with the relative price of non-tradables but no relationship should exist between the real exchange rate of the open sector and relative prices.
} 
transmitted proportionately onto relative prices. However, most empirical studies either do not verify these two basic assumptions or they do so only using descriptive statistics and most simply assume that the assumptions are not violated. There are in fact two ways to incorporate these assumptions directly into the econometric analysis. The first approach, initially proposed by Alberola and Tyrväinen (1998), introduces the wage differential $\left(w^{N T}-w^{T}\right)$ into equation (10), which allows to controling for the impact of sectoral wage differences on inflation and the inflation differential. This is useful if wage equalisation is assumed to fail. This approach is employed by Lojschova (2003) and Wagner and Hlouskova (2004) for the CEECs.

A more explicit approach consists of analysing whether the estimated coefficient between real wages and productivity is equal to 1 . If the coefficient is lower than one, then productivity gains are not fully transmitted to real wages (attenuation effect). If it exceeds 1, productivity increases lead to overproportionate real wage increases, which tend to amplify the B-S effect. The second chain in the transmission from productivity to relative prices is the wage equalisation across sectors. If wages in the closed sector tend to increase more (less) than those in the open sector, we can speak of a second source of amplification (attenuation). For instance, Nenovsky and Dimitrova (2002) argue that the B-S effect might not work in Bulgaria precisely because these assumptions do not hold. Égert (2005b) shows attenuation and amplification effects in the internal transmission mechanism for three South-Eastern European countries, Russia and Ukraine. A careful study of these assumptions for the remaining countries is a task for future research, and it remains to be seen to what extent productivity gains in the open sector are evenly distributed across sub-sectors and are not due to some very specific sectors.

\subsubsection{Non-Market Non-Tradables: The Case of Administered and Regulated Prices}

Notwithstanding the fact that the B-S effect can explain only part of the real appreciation of the transition countries' currencies, the currencies are not necessarily overvalued. Real appreciation induced by an increase in regulated prices of non-tradable goods might also be viewed as an equilibrium phenomenon insofar as increases in regulated prices imply an approach towards the market-based service price level and do not lead to a deterioration in competitiveness. Égert and Lommatzsch (2003), Égert (2005a) and MacDonald and Wójcik (2004) investigated the effects of regulated price increases on the real exchange rate of the transition economies and found that an increase in regulated prices was linked to the real appreciation of the transition economies' currencies. MacDonald and Wójcik (2004) show that the regulated price channel dominates the effect of productivity increases. In contrast, Égert and Lommatzsch (2003) found evidence in favour of the coexistence of the regulated price and productivity channels.

\subsubsection{Initial Undervaluation}

Krajnyák and Zettelmeyer (1998) report a strong undervaluation at the beginning of the transition period, which was observed for all transition economies until 1995 (end of the estimation period). Halpern and Wyplosz (1997) also detect undervaluations for most transition economies. However, they found that the Hungarian forint fairly valued and the Slovene tolar overvalued in 1990. According to results reported in Begg, Halpern and Wyplosz (1999), the Hungarian, Polish and Slovene currencies were not undervalued in 1993 and that undervaluation dissipated by 1997 in all transition economies ${ }^{46}$ except for Bulgaria, the Czech Republic and Slovakia. Using a simple two-variable cross-sectional approach linking the level of the real exchange rate to relative productivity levels as opposed to the large multivariate panel setting (as in Halpern and Wyplosz (1997) and Krjanyák and Zettelmeyer (1998)), DeBroeck and Sløk (2001), Burgess et al. (2003), Randveer and Rell (2002) broadly confirm these results. This means that part of the "excess" appreciation of the actual real exchange rate (the difference between the appreciation of the actual and equilibrium real exchange rate) may have only been a "corrective" convergence towards its equilibrium level. However, there is perhaps some uncertainty around initial undervaluation and its correction, as Coudert and Couharte (2003) and Čihák and Holub (2001, 2003) that besides the Czech Republic and Slovakia, also Hungary and Slovenia might be undervalued towards the end of the 1990s. At the same time, they show that the Polish and some of the Baltic currencies may be already overvalued. It seems that the results of the bivariate cross-sectional estimates depend crucially on the country coverage and the year for which the regressions were run.

\footnotetext{
${ }^{46}$ Three Baltic States, Hungary, Poland, Romania, Russia, Slovenia, Ukraine.
} 


\subsubsection{Trend Appreciation of the Real Exchange Rate of the Open Sector}

If the initial undervaluation was large enough, the correction towards equilibrium should have occurred quickly. This is confirmed, for instance, by Halpern and Wyplosz (1997) and Begg, Halpern and Wyplosz (1999) for Poland. A rapid adjustment towards equilibrium means indeed a collapse of the real exchange rate, which is what we observe for the Baltic countries on Figure $1{ }^{47}$ It is important to note, however, that the initial undervaluation and the resulting adjustment towards equilibrium is only part of the story. Instead, real appreciation in both CPI and PPI terms has turned out to be a continuous process, especially in the CEEC5. Thus, the initial depreciation of the real exchange rates did not make the currencies undervalued but was indeed necessary to withstand the sharp pressure of market forces.

To illustrate this point, Égert and Lommatzsch (2003) reported significant and positive long-term cointegrating vectors between the dual productivity differential and the tradable price-deflated real exchange rate for the Czech Republic, Hungary and Poland and also in panels of up to 9 transition economies. Bitans (2002), Bitans and Tiller (2003) and Vetlov (2003) report similar results for Latvia and Lithuania and Oomes (2005) for Slovakia. The existence of such cointegrating vectors strongly supports the proposition that productivity gains lead to an appreciation through the tradable price channel. Cincibuch and Podpiera (2004) analyze sectoral real exchange rates in the manufacturing industry. By decomposing the real exchange rates into a quality adjustment bias and a pricing-to-market term, they show that the steady real appreciation found in some of the sectors is due to a quality adjustment bias, i.e. an inappropriate adjustment for better quality.

In earlier sections of this paper, we presented NOEM models, which feature home bias and international price discrimination and produce a strong correlation between the nominal and real exchange rates. However, it should be borne in mind that such models cannot produce a trend appreciation of the tradable price-deflated real exchange rate such as has been observed for the CEE economies. Furthermore, Cincibuch and Podpiera (2004) find for three CEE economies that pricing-to-market explains only medium term fluctuations but not the trend appreciation. Égert, Lahrèche-Révil and Lommatzsch (2004) show that productivity increases in the open sector yields a depreciation of the real exchange rate in small open OECD countries, but tend to lead to an appreciation of the open sector's real exchange rate in transition countries and in a group of emerging market economies. This suggests that the real appreciation observed in the open sector is a feature of the catching-up process. However, with the move towards an increasingly flexible exchange rate regime in CEE countries - in, for instance, the Czech Republic, Hungary and Poland - could result in the predictions of the NOEM class of models being more useful for the future developments of exchange rates in these countries.

It is also worth noting that tradable prices also contain market-determined non-tradable components and elements of regulated items. ${ }^{48}$ Thus, part of the appreciation of the PPI-based real exchange rate could be attributed indirectly to the B-S effect and to increases in regulated prices (see Rawdanowicz (2004) for econometric evidence).

A trend increase in disposable income per capita results in an increased demand for non-tradable goods of higher value. Improvements in productivity in the distribution sector may also cause the real exchange rate to appreciate, as advocated in MacDonald and Ricci (2001) and as shown in MacDonald and Wójcik (2004) for selected CEE economies.

\subsubsection{The Dutch-Disease: Evidence from Russia and Kazakhstan}

In the spirit of the Dutch Disease hypothesis, an increase in oil prices should lead to an appreciation of the real exchange rate. Strapafora and Stavrev (2003) find empirical evidence for this using a specification, which includes productivity and real oil prices as explanatory variables at a quarterly frequency. Rautava (2004) largely confirms this result. Égert (2005b) analyzes graphically the four symptoms of the D-D and concludes tentatively that the D-D may be at work for the post-crisis (1998) period. However, based on monthly data, he fails to find strong evidence for a significantly positive relationship between the real

\footnotetext{
${ }^{47}$ In econometric terms, such a collapse can be thought of as an I(2) process. For instance, Égert (2004) finds the Estonian real exchange rate against its Western European counterparts to be an I(2) process for the period 1993-2002.

${ }^{48}$ Adjustments in regulated prices are predominantly increases in non-market-based non-tradable prices. For regulated items partly represent inputs for tradable goods, those adjustments contribute to an increase in tradable prices. For homogeneous goods that eventually enter international competition either because they are exported or because they are subject to import competition, an increase in their non-market and market-based non-tradable component may lead to a loss in competitiveness and thus could not be viewed as an equilibrium phenomenon.
} 
exchange rate and oil prices. These conflicting results may be due to differences in the econometric techniques and/or the data frequency. Kutan and Wyzan (2005) find some support for the Dutch Disease for Kazakhstan based on descriptive statistics and by estimating a real exchange rate equation incorporating oil prices and productivity, in which lagged oil prices turn out to have a significant and positive effect on the real exchange rate. Overall, it is fair to say that the empirical evidence points to oil prices as an important determinant of the real exchange rate in Russia and Kazakhstan.

\subsubsection{Measurement Bias of the "True" Size of the Real Appreciation}

There is a more general problem in calculating the "true" size of a country's exchange rate overvaluation. Inflation measures, usually based on the CPI, are likely to overstate the "true" rate of inflation. The four sources of an upward inflation bias are as follows: (1) consumer substitution, (2) outlet substitution, (3) quality improvements, and (4) new goods bias (Boskin et al., 1996; Gordon, 2000). ${ }^{49}$ Transition economies are even more prone to this bias than well-established market economies. For example, Hanousek and Filer (2001a,b) argue that in the Czech Republic, the bias due to quality changes may reach $50 \%$ of the CPI reported for food and goods and that the bias coming from the other sources are comparable to that measured for the U.S. economy and other industrialized countries. Although estimates are not available for other transition economies and for the PPI, the quality issue may also be very important in this case. Hence, the measured appreciation of the real exchange rate may be larger than the one based on unbiased inflation measures, i.e. the "true" appreciation.

It is also worth noting that real exchange rates for CEE countries based on the CPI are not fully consistent with those in developed economies. For example, the weight attributed to non-tradable goods in the CPI is considerably lower in the transition economies than in their Western counterparts. Using the same weights for tradable and non-tradable goods in the CPI for both the domestic and foreign economies would result in a slightly higher appreciation, which, however, would not compensate for the measurement bias.

\subsection{Estimation Uncertainties}

It is clear that a number of factors may render it difficult to obtain any precise point estimates of the equilibrium exchange rate. In what follows, we shall review these factors.

\subsubsection{Time Series versus Panel Data}

As we have noted, at the onset of the transition process, the real exchange rates of the transition economies may have been undervalued. The presence of such undervaluation could bias time-series and in-sample panel estimates of the equilibrium exchange rate due to the vector of slope coefficients, estimated from a regression of the observed real exchange rate projected onto the fundamentals, differing from the true slope coefficient (Maeso-Fernandez; Osbath and Schnatz, 2004and 2005a,b). This problem appears to be exacerbated in an in-sample panel setting if the initial undervaluations and the adjustment paths towards equilibrium are different across countries. However, at present, there is no paper, which quantifies the size of this bias using actual data. Although the bias might have been considerable when undervaluation was important during the early 1990s, it may be less of an issue with the correction of the initial undervaluation by the mid-1990s for most of the countries.

This problem refers to the issue that BEER models are models of real exchange rate determination because they attempt to connect the observed real exchange rate to fundamentals. Hence, empirically estimated coefficients are interpreted as equilibrium coefficients, which link the unobserved equilibrium exchange rate and the fundamentals (the equilibrium relationship is assumed to equal the empirical long-term relationship).

More generally, there is an apparent trade-off between the use of time series and panel data. At best, time series span slightly more than ten years for transition countries, assuming no structural or smooth changes in the estimated relationships, and thus provide roughly 40 to 50 quarterly observations, which, from a strictly econometric point of view, might be insufficient. Using monthly data would produce more than 120

\footnotetext{
${ }^{49}$ Consumer substitution: changes in consumption patterns towards items with low price increases are not taken into account in the CPI. Outlet substitution: weights attributed in the CPI to different channels of distribution do not coincide with the observed patterns. The excessive weight of expensive traditional outlets at the expense of cheaper hypermarkets causes true CPI inflation to be overstated. Quality improvements: changes in prices due to quality changes are misconceived as price inflation. New goods bias: new goods are introduced into the CPI basket only with a delay.
} 
observations but this would only improve the signal-to-noise ratio. However, panel data sets offer a way of increasing the span of the data and the power of any test based on the panel data set. Typically, three types of panels have been used in the literature: small panels, including 6 to 9 countries; medium-size panels, composed of 20 to 30 countries; and large panels, containing up to 80 or 90 countries. In addition, panels may or may not include the countries under investigation. Small panels are typically in-sample panels - in terms of geographical coverage, whilst medium and large panels can be both in-sample and out-of-sample panels.

Another difference is that time series estimates usually provide small deviations from equilibrium because if the estimated model is of good quality, the fit should capture the observed values of the real exchange rate. ${ }^{50}$ In a panel setting, however, deviations from equilibrium may be larger as the estimated coefficients reflect some kind of average behaviour. These deviations tend, at least for in-sample panels, to average out across the members of the panel.

However, although panel methods may have a number of advantages over either purely cross sectional or time series analysis, a number of issues remain. In general, medium-sized in-sample panel studies use a heterogeneous set of countries. From both an econometric and economic viewpoint, using panel data makes sense if the countries composing the panel are not too much different from one another. ${ }^{51}$ A typical panel data set used by, for example, Coricelli and Jazbec (2001) or in Halpern and Wyplosz (2001) contains countries such as the Czech Republic and Slovenia on the one hand and Mongolia and Kyrgyzstan on the other. Homogeneity may be a double-issue in an out-of-sample approach ${ }^{52}$, because it is important that not only countries included in the panel for which estimations are carried out be similar, but homogeneity should apply between the group of countries for which the real exchange rate equation is assessed, on the one hand, and the group of countries for which those estimations are applied, on the other hand. If this double homogeneity criterion does not hold, it is difficult to interpret a common coefficient obtained for a set of economies which are different (and use it for the derivation of real misalignments).

One way around this problem is to use smaller panels composed of more homogeneous countries (De Broeck and Sløk, 2001; Dobrinszky, 2001) or very large panels (Halpern and Wyplosz, 1997; Krajnyák and Zettelmeyer, 1998). However, the problem raised in the case of time series estimates remains in small panels, i.e. estimates stand for the relationship between the observed real exchange rate, rather than the equilibrium real exchange rate, and a set of other variables. Moreover, in small panels based on annual data, the number of observations might drop significantly. The large panel setting assumes that market economies behave very similarly in the long term, and the estimated coefficients should reflect this long-term average behaviour. Therefore, these estimates could be applied to all countries.

For time series estimates and in-sample panels, it barely matters, whether the data used is in levels or is constructed as cumulated indices ${ }^{53}$ given that the differences will be captured by the constant term. However, for the out-of-sample approach, it makes a huge difference. The out-of-sample approach does not provide a country-specific constant for the countries for which the equilibrium exchange rate is analysed. Hence, constants obtained for the "out-of-sample panel" should be used. ${ }^{54}$ Constant terms obtained on the basis of cumulated indices have no cross-sectional meaning (Kim and Korhonen, 2005). This is why MaesoFernandez, Osbat and Schnatz (2004) use data in levels. In this case, however, a problem arises if the nonestimated "real" constant of a country for which the equilibrium exchange rate is computed lies outside the range of constants provided by the estimations. To circumvent this problem, Maeso-Fernandez, Osbat and Schnatz (2005b) propose regressing the estimated constants on the fundamentals of the countries included in the out-of-sample panel. This regression can then be used to derive constants for transition economies by plugging in the fundamentals of transition economies, even if the constants for transition economies lie outside the range of those obtained for developed economies.

\footnotetext{
${ }^{50}$ The extent of a misalignment derived from the estimates might depend on how well the observed real exchange rate can be modelled using fundamentals.

${ }^{51}$ This also applies to econometric techniques, which allow parameter heterogeneity across the panel members, because ultimately a single coefficient, the mean group estimator, will be employed to the individual countries.

52 The out-of-sample approach consists in estimating a real exchange rate equation for a set of non-transitional countries, and then applies the estimated coefficients and constants to transition countries. Examples are Kim and Korhonen (2002) and MaesoFernandez, Osbat and Schnatz (2004).

${ }^{53}$ Example for data in levels is the real exchange rate in levels (Table 1.). For data in indices, see the real exchange rate series with a year for which it is set to be 1 (Figure 3).

${ }^{54}$ See Maeso-Fernandez, Osbat and Schnatz (2004) for different strategies how these constant terms can be used.
} 
Bearing all these aspects in mind, we may think that time series and different panel estimates apply at different time horizons. For "good" time series estimates, deviations from equilibrium are small and shortlived, therefore, these results refer to a shorter time horizon. A transition-based in-sample panel estimate can be thought of as reflecting the average behaviour of transition economies. Taking the example of an out-ofsample panel which includes industrialised countries, and assuming that transition economies will catch-up with those countries, such an out-of-sample estimate would provide an impression of how the equilibrium exchange rate of the transition countries would look by the time catching-up is accomplished, i.e. in approximately 20 to 30 years. Similarly, very large panels composed of nearly all countries in the world could be viewed as representing the very-long run behaviour of a market economy. Figure 5 gives an overview of the time horizons linked to the time and cross-sectional dimension of the data. This is confirmed by Égert and Halpern (2005): whether or not time series, in-sample or out-of-sample datasets are used for the estimations appears to yield strongly differing real misalignments.

Figure 5. The time horizon and the time and cross-sectional dimension of the data

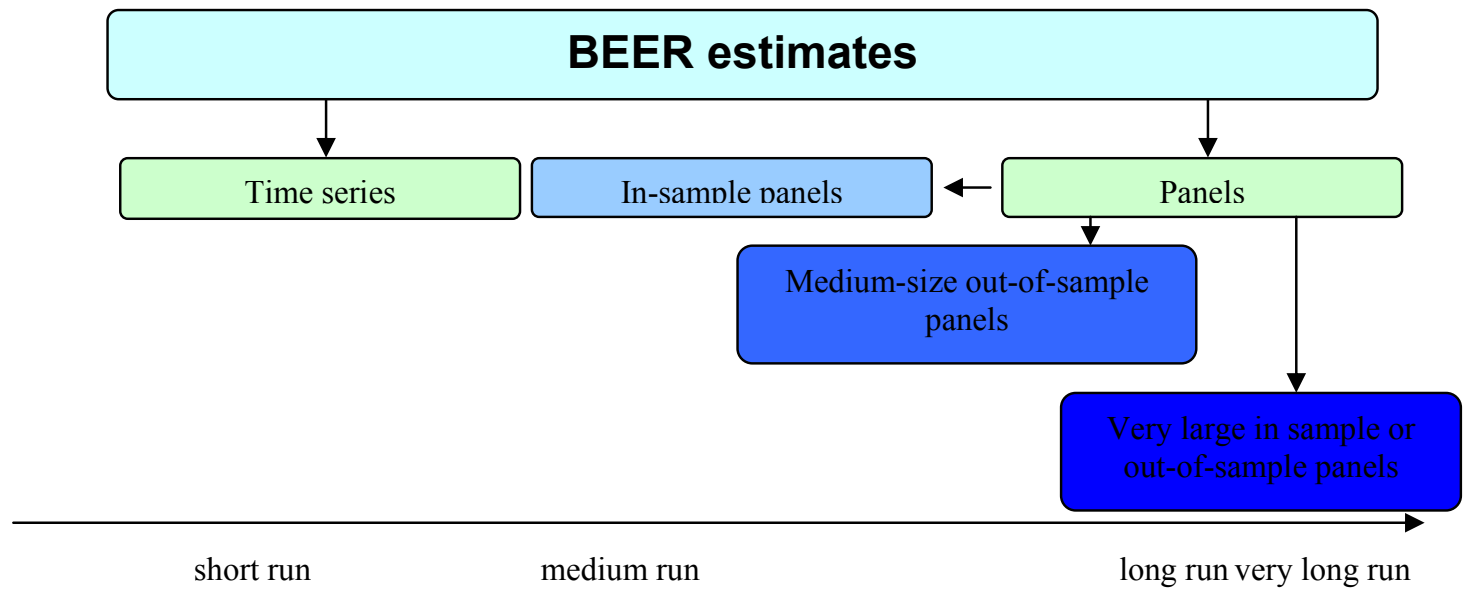

\subsubsection{Econometric Techniques}

A related issue here is how appropriate the estimation methods actually are. Time series studies usually account for the nonstationary nature of the data and employ different cointegration techniques. But some of the panel studies do not consider nonstationarity and do not test for cointegration (see Halpern and Wyplosz, 1997; Coudert, 1999; and Corricelli and Jazbec, 2001; for fixed and random effect OLS and Begg et al., 1999; and Dobrinsky, 2003; for GLS). It is admittedly difficult to test for cointegration when the time series dimension of the panel is limited. However, this issue can be tackled by running the regression in both levels and in first differences (Krajnyák and Zettelmeyer, 1998, and Maurin, 2001) or by applying nonstationary panel techniques: De Broeck and Sløk (2001) and Kim and Korhonen (2005) use PMGE and MGE and take a significant error correction adjustment parameter as evidence for cointegration. Crespo-Cuaresma et al. (2005) use a variety of estimation methods and systematically apply cointegration tests proposed by Kao (1999) to the residuals of the long-term relationships. Following a similar approach, Égert et al. (2003) employ panel cointegration tests developed by Pedroni(1999) ${ }^{55}$ The use of meta-analysis demonstrates that employing alternative econometric techniques results in significantly different misalignments and in significantly different coefficient estimates for BEER studies (Égert and Halpern, 2005).

Wagner and Hlouskova (2004) demonstrate by means of bootstrapping methods that standard critical values of panel cointegration tests may not be valid for small samples when testing for the relationship between the real exchange rate and the inflation differential on the one hand and the dual productivity differential on the other. As a consequence, long-term cointegration relationships detected in the literature may not reflect true long-term relationships. However, Wagner and Hlouskova use a panel of only 8 transition economies and 8 observations on each while most panel studies use quarterly or even monthly data and thus have a time dimension of about 40 to 120 observations per country, which may mitigate the non-cointegration finding.

\footnotetext{
${ }^{55}$ Although MacDonald and Wójcik (2002) use panel dynamic OLS, they do not report panel cointegration tests. Fischer (2002) reports coefficients on the basis of fixed-effect OLS, seemingly unrelated regression and PMGE and carries out Pedroni cointegration tests for the long-term relationship using OLS.
} 
But even some time series studies cannot establish firm cointegration relationships between the real exchange rate and the fundamentals (see Kazaks (2005) for Latvia and Égert and Lommatzsch (2003) for Slovakia and Slovenia).

\subsubsection{Uncertainty Related to the Fundamentals}

Another source of uncertainty when determining the equilibrium exchange rate is the wide range of fundamentals used in the literature (Table 6), and the results often depend on the included fundamentals. The use of different fundamentals may be a result of different theoretical frameworks or may simply reflect ad hoc choices. The fact that for the same country or for comparable panels, long-term relationships can be established, which include a different set of fundamentals, may also indicate that the real exchange rate may be linked to the fundamentals through multiple long-term relationships. ${ }^{56}$

Table 6 reveals that an increase in the dual productivity (differential) always produces an appreciation of the real exchange rate. Terms of trade and the ratio of public consumption to GDP also appear to be positively connected to the real exchange rate, although the evidence on this is less robust. The effects of net foreign assets and openness are much more controversial. For instance, an increase in net foreign assets is shown to produce an appreciation of the real exchange rate in Alonso-Gamo et al. (2002), Lommatzsch and Tober (2004) and Burgess et al. (2003), while Hinnosar et al. (2003) and Rahn (2003) find the opposite effect for Estonia. The finding of Hinnosar et al. (2003) and Rahn(2003) is largely confirmed by Rahn for the Czech Republic, Hungary, Poland and Slovenia, and by Alberola (2003) for Hungary and Poland. In contrast, an increase in net foreign assets turns out to result in a real appreciation of the Czech currency. One reason why the sign on net foreign assets is ambiguous may relate to the shortness of the sample period, such that the real appreciation and net capital inflows occur simultaneously. This may be understood, for instance, in the framework of the NATREX model in which the evolution of net foreign assets is endogenous. If investment rises in the open sector, capital inflows, reflected in a decline in net foreign assets, cause the real exchange rate to appreciate in the medium-run. In the long run, when investment starts working in the open sector, the trade balance improves, resulting in an increase in net foreign assets, and producing an appreciation of the real exchange rate in the second phase.

Égert, Lahrèche-Révil and Lommatzsch (2003) provide a different explanation as to why different studies report different signs on the coefficient on net foreign assets. Countries in the catch-up process may have a negative steady-state net foreign assets position. In other words, in the medium term, they finance their growth via foreign capital. Strong capital inflows appreciate the real exchange rate in this phase. However, once the desired long-term foreign liabilities position is attained, the countries have to start servicing their debt. Thus, for any additional increase in net foreign liabilities, the real exchange rate depreciates. The authors use two panels composed of (1) small, open industrialised OECD countries and (2) transition economies from Central and Eastern Europe. The results indicate that the sign of the net foreign assets variable is positive for the panel of OECD countries. The OECD panel can be thought of as reflecting longrun behaviour of the transition economies. For the panel of transition countries, the sign is negative, which may be taken as the medium-term effect. However, panel results mirror average behaviour of the panel. It may well be the case that some of the transition economies may already be in the long-run regime with a positive sign.

The same kind of controversy holds true for the coefficient on openness. While Braumann (1998), Begg, Halpern and Wyplosz (1999), Beguna (2002) and Csajbók (2003) find that an increase in the openness ratio leads to a real appreciation of the exchange rate, estimates in Avallone and Lahrèche-Révil (1999), De Broeck and Sløk (2001), Bitans (2002), Kim and Korhonen (2005), Vetlov (2002), and Égert and Lommatzsch (2003) show the opposite to be the case. A negative sign (an increase in openness leads to a depreciation of the real exchange rate) reflects the traditional view according to which openness is an indicator of trade liberalization: higher openness is associated with decreasing trade barriers, which raises imports more than exports. The deterioration in the trade balance makes the real exchange rate depreciate. However, an increase in openness can also represent improved supply capacities, which result in higher exports, and this can cause a real appreciation of the exchange rate. Nevertheless, this effect is expected to be captured by the productivity variables.

\footnotetext{
${ }^{56}$ Notice that the uncertainty regarding the fundamentals is still much smaller than, for instance, in growth economics. Durlauf et al. (2005) list about 100 variables used in the growth literature to account for differing cross-country growth rates.
} 
Table 6. Signs of the Estimated Coefficients

\begin{tabular}{|c|c|c|c|c|c|c|c|c|c|c|c|c|}
\hline \multirow[b]{2}{*}{ Time series } & \multirow[t]{2}{*}{ dependent variable } & \multicolumn{11}{|c|}{ explanatory variables } \\
\hline & & PROD & CAPITA & NFA & OPEN & TOT & GOV & PRIV & RIR & INV & FDEBT & REGD \\
\hline Alberola (2003) & REER(CPI) & $+(\mathrm{LP})$ & & $+/-$ & & & & & & & & \\
\hline Alonso-Gamo et al. (2002) & REER(CPI) & $+(\mathrm{CPI} / \mathrm{PPI})$ & & - & & & & & & & & \\
\hline Avallone and Lahrèche-Révil (1999) & $\operatorname{REER}(\mathrm{CPI})$ & & + & & - & + & + & + & & & & \\
\hline Beguna (2002) & $\operatorname{REER}(\mathrm{CPI})$ & & & & + & + & + & & & & & \\
\hline Bitans (2002) & REER(CPI,PPI) EU & $+(\mathrm{LP})$ & & & - & & - & & & & & \\
\hline Bitans and Tillers (2003) & REER(PPI) EU & & + & + & & - & & & & & & \\
\hline Braumann (1998) & REER(CPI, PPI) & $+($ RWAGE $)$ & & & + & & - & & & - & & \\
\hline Burgess et al. (2003) & REER(CPI) & $+(\mathrm{CPI} / \mathrm{PPI})$ & & - & & & & & & & & \\
\hline Csajbók (2003) & REER(CPI) & $+(\mathrm{LP})$ & & + & + & + & + & & + & & & \\
\hline Darvas (2001) & RER (DEM) & $+(\mathrm{LP})$ & & + & & & & & $+/-(1)$ & & & \\
\hline Égert and Lahrèche-Révil (2003) & REER(CPI) & $+(\mathrm{CPI} / \mathrm{PPI})$ & & & & & & & & & & \\
\hline Égert and Lommatzsch (2003) & RER(CPI,PPI) DEM,EUR & $+(\mathrm{LP})$ & & & - & & & & $+/-$ & & $+/-$ & + \\
\hline Filipozzi (2000) & REER(CPI) & $+(\mathrm{LP})$ & & & & & & & & + & & \\
\hline Frait and Komárek (1999) & REER(CPI) & $+($ real GDP $)$ & & & & + & & & & & & \\
\hline Hinnosar et al. (2003) & $\operatorname{REER}(\mathrm{CPI})$ & $+(\mathrm{LP})$ & & + & & + & & & & & & \\
\hline Kazaks (2000) & REER(CPI) & $+(\mathrm{LP})$ & & & - & & & & & & & \\
\hline Lommatzsch and Tober (2004) & REER(PPI) & $+(\mathrm{LP})$ & & - & & & & & + & & & \\
\hline Rahn (2003) & REER(CPI) & $+(\mathrm{CPI} / \mathrm{PPI})$ & & + & & & & & & & & \\
\hline Randveer and Rell (2002) & REER(CPI) & $+(\mathrm{LP})$ & & & & + & & & & & & \\
\hline Rawdanowicz (2003) & RER(CPI) EU & $+(\mathrm{LP})$ & & & & + & & & + & & & \\
\hline Rubaszek (2003a) & REER(PPI) & & & + & & & & & + & & & \\
\hline Vetlov (2002) & REER(PPI) & $+(\mathrm{LP})$ & & & - & & & & - & & & \\
\hline \multicolumn{13}{|l|}{ Panel } \\
\hline Begg et al. (1999) & & & + & & + & & + & & & & & \\
\hline Coricelli and Jazbec (2004) & $\mathrm{P}(\mathrm{t}) / \mathrm{P}(\mathrm{nt})$ & $+(\mathrm{LP})$ & & & & & + & $+(2)$ & & & & \\
\hline Coudert (1999) & RER(CPI) US & $+(\mathrm{CPI} / \mathrm{PPI})$ & & & & & & & & & - & \\
\hline De Broeck and Sløk (2001) & REER(CPI) & $+(\mathrm{LP})$ & & & - & & & & & & & \\
\hline Dobrinsky (2003) & RER(CPI) EU & $+($ TFP $)$ & + & & & & + & & & & & \\
\hline Égert and Lommatzsch (2003) & RER(CPI,PPI) EU & $+(\mathrm{LP})$ & & & + & & & & + & & $+/-$ & + \\
\hline Fischer (2004) & REER(CPI) & $+(\mathrm{LP})$ & & & & - & + & & $+/-$ & & & \\
\hline Halpern and Wyplosz (1997) & RER(CPI) US & $+(\mathrm{GDP} /$ worker $)$ & + & & & & + & & & & & \\
\hline Kim and Korhonen (2005) & REER(CPI); RER(CPI) US & & + & & - & & + & & & + & & \\
\hline Krajnyák and Zettelmeyer (1998) & RER(CPI) US & & + & & & & & & & & & \\
\hline MacDonald and Wójcik (2004) & $\operatorname{REER}(\mathrm{CPI})$ & $+(\mathrm{LP})$ & & $+/-$ & & & & & + & & & $+(3)$ \\
\hline Maurin (2001) & $\operatorname{REER}(\mathrm{CPI})$ & & + & & & & + & & + & & - & \\
\hline
\end{tabular}

Note: $+(-)$ means that an increase (decrease) in the given variables gives rise to an appreciation (depreciation) of the real exchange rate; REER $(\mathrm{CPI})=$ real effective exchange rate based on the CPI; REER(PPI) = real effective exchange rate based on the PPI;

RER(CPI) EU; RER(CPI) EUR; RER(CPI) U.S. = real exchange rate against the EU, the euro and the U.S., respectively; P(t)/P(nt) = the internal real exchange rate.

Explanatory variables: $\mathrm{PROD}=\mathrm{a}$ measure of labour productivity, CAPITA: GDP per capita, OPEN=measure of openness,

TOT=terms of trade, GOV=government consumption over GDP, PRIV=private consumption to GDP, RIR= real interest differential, $\mathrm{FDEBT}=$ foreign debt to GDP, REGD=regulated price differential

(1) the foreign real interest rate

(2) the share of non-tradable consumption in private consumption

(3) regulated prices in the home country

\section{Data and Measurement Uncertainty}

In this section we consider a number of measurement and methodological difficulties connected with the data sets typically used when analysing the exchange rates of CEE countries.

First, because an increase in the dual productivity differential is transmitted into the real exchange rate through the market-based non-tradable inflation, as predicted by the standard B-S effect, and also via multiple channels related to tradable prices, the relative price differential appears to be an extremely poor proxy for the dual productivity differential. In particular, the CPI-to-PPI ratio often used in the literature (see e.g. Coudert,1999; Alonso-Gamo et al., 2002; Burgess et al., 2003; Rahn, 2003) is even more affected by this problem given that the share of non-tradable goods in CPI is very low in the CEECs and because of the presence of regulated prices in the CPI. Égert, Lahrèche-Révil and Lommatzsch (2004) demonstrate this point. If the CPI-to-PPI ratio was an appropriate proxy for productivity, the two variables would then be highly correlated leading to multi-collinearity if used simultaneously. However, both variables turn out to enter the real exchange rate equation with the expected sign and are statistically significant, which basically confirms that they contain a different set of information. ${ }^{57}$

\footnotetext{
${ }^{57}$ In the case of multi-collineary, one of the variables switches sign and becomes insignificant. For the panel of OECD countries, the CPI-to-PPI ratio cancels out the productivity variable in that the latter switches sign but remains significant. This is in line with predictions of the class of NOEM models: the B-S effect, captured through the CPI-to-PPI ratio causes the real exchange rate to
} 
Some authors (Sinn and Reutter, 2001, and Wagner and Hlouskova, 2004) use GDP deflators as a proxy for CPI inflation rates and formulate policy conclusions regarding inflation rates. Although the GDP deflator and the overall CPI behave fairly similarly in transition economies, their components (goods market-based services, regulated prices) exhibit substantial differences. This is why the use of GDP deflators instead of proper inflation series may lead to erroneous conclusions.

Second, in principle, labour productivity is given as output per total hours worked. In practice, however, the output-per-employee ratio is used. If there is a shift in full-time employment towards part-time employment (or vice versa), the number of employees is a poor proxy for total hours worked.

The classification of sectors into open and closed is also surrounded by a great deal of uncertainty: ${ }^{58}$

1.) Different classifications may produce different dual productivity figures. For instance, in Mihaljek and Klau (2004), the open sector includes hotels and restaurants, and transport, storage and communication, which entails larger dual productivity in the Czech Republic than in all the other transition countries. This is in sharp contrast to other studies and with the estimates of the Czech central bank (see Kovács, 2002; Flek et al., 2002). Égert (2003) also shows that results are sensitive to how the open and the closed sectors are defined, and points out that one-size-fits-all techniques are not appropriate (a given sector can be viewed as tradable in one country and as non-tradable in another one). As the B-S model posits PPP to hold in the tradable sector, goods arbitrage - the mechanism ensuring PPP - should be potentially possible in the tradable sector. This, too, might be limited in the case of, for example, tourism or storage ${ }^{59}$, since one cannot buy two nights in a five-star hotel, say, in Tallinn and sell them in Berlin or in Paris.

2) Agriculture has also proven difficult to classify as either a traded or non traded sector, with some researchers considering it as tradable while others do not. For instance, Fischer (2004) argues that half of the appreciation brought about by productivity gains can be attributed to productivity gains in agriculture. This is very questionable and is akin to saying that agriculture has a bellwether role during the catching-up process.

There is a more general statistical problem. Data definitions differ between individual transition economies and EU countries, in spite of ongoing data harmonization. In fact, the harmonization process implies changes in data definitions over time. In addition, data revisions occur relatively often in transition economies (the Czech Republic is a recent example), which might cast doubt on estimates derived using pre-revision data. Finally, the same time series for the same country can exhibit differences depending on whether it is drawn from national statistics, from the IMF or from OECD databases (Égert et al., 2003). ${ }^{60}$ Another problem that needs addressing in this context is that the weights used to calculate effective exchange rates are adjusted to changes in foreign trade with a considerable lag and this may bias the estimates and also create a problem when backing out the bilateral equilibrium exchange rate against the euro.

Another tricky issue for the BEER approach is how to measure the long-term values of the underlying fundamentals. One group of papers simply assumes that actual values correspond to long-term values (see Lommatzsch and Tober, 2004) and therefore use a so-called current misalignment. Others employ statistical methods to extract the trend component of the series (Filippozi, 2000; Randveer and Rell, 2002). Finally, model-based fitted values are also useful for this purpose (e.g. Rubaszek, 2003; Égert and Lahrèche-Révil, 2003). More generally, it is often the case that the home country variable is not defined relative to the foreign country (see Jazbec, 2002). As the very concept of the real exchange rate is based on the comparison of the domestic and foreign economies, variables ought to be computed as the ratio of the home country variable to the foreign country variable (see MacDonald, 1998a,b; Clark and MacDonald, 1999).

\footnotetext{
appreciate through the internal real exchange rate, whereas an increase in productivity in the open sector leads to a real depreciation in the open sector's real exchange rate.

${ }^{58}$ For details on how different papers classify sectors, see Égert, Halpern and MacDonald (2004).

${ }^{59}$ One may argue that there is no need for goods arbitrage. It suffices that the given good/service is exported and that it is exposed to international price competition. In the case of tourism, it would mean that hotels in Tallinn, Paris and Berlin would closely monitor each others' prices. However, the trouble with this argument is that prices in tourism are largely determined by local factors such as labor costs and property prices. In addition, tourism is a highly differentiated good and prices may depend largely on preferences. Although one and the same package holiday to Estonia may actually cost the same for both customers in Germany and customers in Austria, there is no straightforward mechanism to equalize the price a customer in Germany, Austria or elsewhere would pay for one package holiday to Tallinn and another package holiday to Paris.

${ }^{60}$ Although the source of both IMF and OECD statistics are national statistical offices, these institutions may make corrections to the data and may update the data with a lag.
} 
The FEER approach cannot escape these kinds of problems either. For example, Coudert and Couharde (2003) use in-sample panel estimates provided by Doisy and Hervé (2003) for seven transition economies and by Bussière, Fratzscher and Müller (2004) for a panel composed of 10 transition economies and about 20 OECD countries to derive the long-term current account along the lines of the Macroeconomic Balance approach, whereas Buissière Csajbók and Kovács (2002) consider the year 2000 as an equilibrium and use values for the current account from that year. Both methods rely heavily upon subjective expert evaluations. It should also be mentioned that the NIGEM model, on the basis of which FEER calculations are performed, has a number of shortcomings. For example, it is a one-sector economy model, and, second, some of the parameters are estimated using the panel of five transition economies (the Czech Republic, Estonia, Hungary, Poland and Slovenia), whilst others are calibrated.

\subsection{The Three-Dimensional Space of Misalignment: Man on the Moon?}

We considered a number of uncertainties surrounding equilibrium exchange rate estimates. The estimation uncertainty relates: to a) the time series and cross-sectional dimension of the data, b.) the econometric technique and the c.) theoretical background yields a three-dimensional space for equilibrium exchange rate estimates and for the underlying misalignment. For BEER estimates, the variety of different fundamentals that may be linked to the real exchange rate adds to the uncertainty. ${ }^{61}$ The three dimensional space, depicted in Figure 6, implies that these estimates may be useful to determine a band of real misalignment, or, worse, only the direction of a possible misalignment rather that any precise figure. When interpreting the "misalignment space", the different time horizons should be borne in mind, as shown earlier, at which, for instance, BEER, FEER and NATREX estimates on the one hand, and time series and different panel estimates, on the other, apply. In their meta-regression analysis, Égert and Halpern (2005) report indeed results according to which the misalignment figures reported in the literature are systematically affected by the use of different theoretical backgrounds.

A look at the literature indicates that we are still very far from such an all encompassing assessment of the equilibrium exchange rate in the transition economies. First, for some countries, there are either no, or just very few estimates available (FSU, SEE). Second, the literature is mostly dominated by time series BEER estimates, and, as Table 7 testifies, empirical applications of the NATREX framework is a real rarity and the number of FEER-based papers is also not particularly high.

Figure 6. The three-dimensional space of equilibrium exchange rates

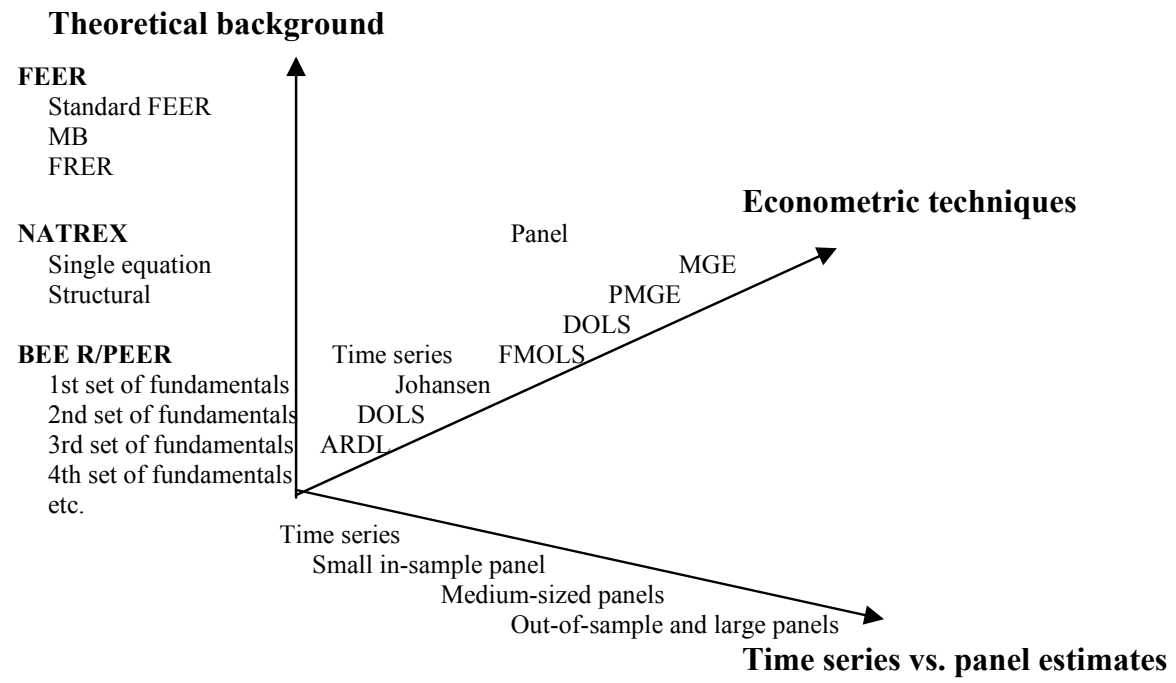

\footnotetext{
${ }^{61}$ In addition, a large number of available estimates refer to the real effective exchange rate. To obtain the equilibrium exchange rate vis-à-vis the euro, reliable information about the equilibrium USD/EUR cross rate is needed. This might also be subject to high uncertainty.
} 
Table 7. Studies reporting real misalignment estimates for transition economies

\begin{tabular}{|c|c|c|c|}
\hline & Countries & Approach & Technique \\
\hline Alberola (2003) & $\mathrm{CZ}, \mathrm{HU}, \mathrm{PL}$ & BEER/PEER & Time series \\
\hline Alonso-Gamo et al. (2002) & $\mathrm{LT}$ & BEER/PEER & Time series \\
\hline Avallone and Lahrèche (1999) & $\mathrm{HU}$ & BEER & Time series \\
\hline Begg et al. (1999) & CEEC5, EE & BEER & Panel \\
\hline Beguna (2002) & LV & BEER & Time series \\
\hline Bitans (2002) & LV & BEER & Time series \\
\hline Bitans and Tillers (2003) & LV & BEER & Time series \\
\hline Braumann (1998) & SK & BEER & Time series \\
\hline Bulir and Smidkova (2004) & CZ, HU, PL, SI & FEER/FRER & -- \\
\hline Burgess et al. (2003) & B3 & BEER/PEER & Time series \\
\hline Cihak and Holub (2001) & CEEC5 & BS & Cross-section \\
\hline Cihak and Holub (2003) & CEEC5, EE & BS & Cross-section \\
\hline Coudert (1999) & $\mathrm{HU}$ & BEER & Panel \\
\hline Coudert and Couharde (2002) & CEEC5, B3 & BS, FEER & Cross-section; --- \\
\hline Csajbók and Kovács (2003) & HU & FEER & --- \\
\hline DeBroeck and Sløk (2001) & CEEC5, B3 & BS & Cross-section \\
\hline Égert and Lahrèche-Révil (2003) & CEEC5 & BEER & Time series \\
\hline Égert and Lommatzsch (2003) & CEEC5 & BEER & Times series, panel \\
\hline Égert (2005b) & SEE, FSU & BEER & Times series, panel \\
\hline Filipozzi (2000) & $\mathrm{EE}$ & BEER & Time series \\
\hline Genorio and Kozamernik & SI & FEER & --- \\
\hline Halpern-Wyplosz (1997) & CEEC5 & BEER & Time series \\
\hline Hinnosar et al (2003) & $\mathrm{EE}$ & BEER & Time series \\
\hline Karádi (2003) & $\mathrm{HU}$ & BEER/NATREX & Time series \\
\hline Kazaks (2000) & LV & BEER & Time series \\
\hline Kazaks (2005) & LV & BEER & Time series \\
\hline Kim and Korhonen (2005) & CEEC5 & BEER & Panel \\
\hline Krajnyák and Zettelmeyer (1998) & $\begin{array}{l}\text { CZ, HU, PL, SK, B3, } \\
\text { FSU }\end{array}$ & BS, BEER & Cross-section, panel \\
\hline Lommatzsch and Tober (2004) & $\mathrm{CZ}, \mathrm{HU}, \mathrm{PL}$ & BEER & Time series \\
\hline Rahn (2003) & CZ, HU, PL, SI, EE & BEER/PEER & Time series \\
\hline Randveer and Rell (2002) & $\mathrm{EE}$ & BS, BEER & Cross-section, time series \\
\hline Rawdanowich (2003) & PL & BEER & Time series \\
\hline Smidkova et al. (2002) & CZ, HU, PL, SI, EE & FEER/FRER & -- \\
\hline Vetlov (2002) & $\mathrm{LT}$ & BEER & Time series \\
\hline Vonnák and Kiss (2003) & $\mathrm{HU}$ & BEER & Time series/Panel \\
\hline
\end{tabular}

Note: BS, BEER, PEER, FEER, NATREX denote the theoretical approaches used in the papers. CEEC5 includes the Czech Republic, Hungary, Poland, Slovakia and Slovenia. B3 is the three Baltic states, i.e. Estonia, Latvia and Lithuania. CZ, HU, PL, SK, SI, EE, LV and LT stand for the Czech Republic, Hungary, Poland, Slovakia, Slovenia, Estonia, Latvia and Lithuania, respectively.

\section{Concluding Remarks}

In this paper we have surveyed the literature on equilibrium exchange rates as it relates to the (former) transition economies in Central and Eastern Europe, South-Eastern Europe and the former Soviet Union. Amongst our findings is the result that the trend appreciation usually observed for the exchange rates of these economies is affected by factors other than the usual Balassa-Samuelson effect, which is probably not an obstacle for meeting the Maastricht criterion on price stability for those countries facing this challenge. We have also agued that the equivalence between a real appreciation driven by market-based non-tradable price inflation and an appreciation caused by a nominal appreciation is more of a fallacy given that the latter is not competitiveness neutral. An important factor in explaining the real exchange rate is the behaviour of the real exchange rate of the open sector (or the relative price of traded goods). In contrast to the industrialized OECD economies' experience with floating exchange rates, pricing-to-market as set out in the class of New Open Economy Macroeconomics models, only explains medium term fluctuations of the real exchange rate for CEE countries. For the latter countries there would appear to be a huge quality adjustment bias and a demand shift towards domestically produced tradable goods as they started producing and exporting goods of higher quality. Also, we have argued that administered/regulated prices and the distribution sector are also important determinants of the trend appreciation of the real exchange rates of CEE countries. There are indications that much of the changes in the real exchange rate may be related to the Dutch-Disease in Russia and in Kazakhstan.

Our literature overview suggests that deriving a precise figure for the equilibrium real exchange rates in general and also for the transition economies is close to mission impossible as there is a great deal of model 
uncertainty related to the theoretical background and to the set of fundamentals chosen. An array of methodological and statistical problems also renders the calculation of an equilibrium exchange rate very complicated. But, of course, similar difficulties are encountered when estimating the equilibrium exchange rate of the euro or the U.S. dollar. According to the European Central Bank (2002), for example, estimates of the equilibrium USD/EUR parity vary considerably within a range of 1.03 to 1.45 . Consistent with this finding is the large degree of uncertainty with regard to the equilibrium value of the euro that Detken et al. (2002) detect when using alternative theoretical models and econometric techniques. A fortiori, therefore, calculations of equilibrium exchange rates for CEE countries should be produced with, perhaps, quite wide confidence bands.

In estimating the equilibrium exchange rate of any given economy, a systematic analysis is needed in terms of alternative economic and econometric specifications and in interpreting the range of the derived real misalignments, the connection of the alternative theoretical and empirical approaches should be borne in mind.

There are promising attempts along the dimension of different theoretical approaches and along the dimension of different econometric techniques. Csajbók (2003), for example, sets a good example by producing estimation results for Hungary based on different theoretical approaches, such as the BEER, FEER, Macroeconomic Balance and NATREX. This is important given no single equilibrium exchange rate approach is problem free. A range of different econometric techniques, but based on one major theoretical approach, are employed in Crespo-Cuaresma, Fidrmuc and MacDonald (2005), Égert and Lommatzsch (2003) and Maeso-Fernandez, Osbat and Schnatz (2004). Yet, we lack, at present, a comprehensive study, which explores all dimensions (theoretical, econometric, time series vs. panel) of the assessment of equilibrium exchange rates for transition, developing and fully developed economies.

\section{References}

Alberola, E. 2003. Real Convergence, External Disequilibria and Equilibrium Exchange Rates in EU Acceding Countries. Banco de España. Mimeo.

Alberola, E. and T. Tyrväinen. 1998. Is There Scope for Inflation Differentials in EMU? Banco de España Working Paper No. 9823.

Alberola, E., S. G. Cervero, H. Lopez and A. Ubide (2002) Quo vadis Euro? The European Journal of Finance, 8, 352370.

Alberola, E., S. G. Cervero, H. Lopez and A. Ubide. 1999. Global Equilibrium Exchange Rates: Euro, Dollar, "Ins," "Outs," and Other Major Currencies in a Panel Cointegration Framework. IMF Working Paper No. 175.

Alonso-Gamo, P., S. Fabrizio, V. Kramarenko and Q. Wang. 2002. Lithuania: History and Future of the Currency Board Arrangement. IMF Working Paper No. 127.

Artus, J. 1978. Methods of assessing the long-run equilibrium value of an exchange rate. Journal of International Economics 8. 277-299.

Avallone, N. and A. Lahrèche-Révil. 1999. Le taux de change réel d'équilibre dans les pays en transition: le cas de la Hongrie. TEAM. University of Paris I - Sorbonne. Cahiers blancs no. 91.

Backé, P., J. Fidrmuc, T. Reininger and F. Schardax. 2003. Price dynamics in Central and Eastern European EU Accession Countries. Emerging Markets Finance and Trade 39(3). 42-78.

Baffes, J., I. A. Elbadawi and S. A. O'Connell. 1999. Single Equation of the Equilibrium Real Exchange Rate. In: Hinkle, L. and P. Montiel (eds.). Estimating Equilibrium Exchange Rates in Developing Countries. Washington D.C.: World Bank.

Balassa, B. 1964. The Purchasing-Power-Parity Doctrine: A Reappraisal. Journal of Political Economy 72(6). 584-596.

Barrell, R. and S. Wren-Lewis (1989). Fundamental Equilibrium Exchange Rates for the G7", CEPR Discussion Paper. 323.

Baumol, W.J. 1996. Children of Performing Arts, the Economic Dilemma: The Climbing Costs of Health Care and Education. Journal of Cultural Economics. 20. 183-206.

Baumol, W.J. and W.G. Bowen. 1965. On the Performing Arts: The Anatomy of Their Economic Problems. American Economic Review. 55(1/2). 495-502.

Baumol, W.J. and W.G. Bowen. 1966. Performing Arts: The Economic Dilemma. New York: Twentieth Century Fund. 
Bayoumi, T., P. Clark, S. Symansky and M. Taylor. 1994. The Robustness of Equilibrium Exchange Rate Calculations of Alternative Assumptions and Methodologies. In: Williamson, J. (ed.). Estimating Equilibrium Exchange Rates. Washington D.C.: Institute for International Economics. 19-60.

Begg, D., Halpern, L. and Ch. Wyplosz. 1999. Monetary and Exchange Rate Policies, EMU and Central and Eastern Europe. Forum Report on the Economic Policy Initiative 5. London: CEPR and New York, Prague: EastWest Institute.

Beguna, A. 2002. Competitiveness and the Equilibrium Exchange Rate in Latvia. EuroFaculty Working Paper in Economics 16. August. Riga: University of Latvia and EuroFaculty.

Benigno, G. and C. Thoenissen. 2003. Equilibrium Exchange Rates and Capital and Supply Side Performance. Economic Journal. 113(486). 103-124.

Bergstrand, J. H. 1991. Structural Determinants of Real Exchange Rates and National Price Levels: Some Empirical Evidence. American Economic Review 81(1). 325-334.

Bhagwati, J. 1984. Why Are Services Cheaper in Poor Countries? Economic Journal. 94(374). 279-286

Bitans, M. 2002. Real Exchange Rate in Latvia: 1994-2001. Bank of Latvia Working Paper.

Bitans, M. and I. Tillers. 2003. Estimates of Equilibrium Exchange Rate in Latvia. Bank of Latvia, mimeo

Boskin, M. J., E.R. Dulberger, R.J. Gordon, Z. Griliches and D.W. Jorgenson. 1996. Toward a More Accurate Measure of the Cost of Living. Final Report to the U.S. Senate Finance Committee from the Advisory Commission to Study the Consumer Price Index.

Braumann, B 1998. Republic of Slovakia: Recent Economic Developments. IMF Staff Country Report No. 60. 35-47.

Brook, A. M. and D. Hargreaves. 2001. PPP-based Analysis of New Zealand's Equilibrium Exchange Rate. Reserve Bank of New Zealand Discussion Paper No. 1.

Bruno, M. 1993. Crisis, Stabilization, and Economic Reform-Therapy by Consensus, Oxford, Clarendon Press

Buliř A. and K. Šmidkova. 2005. Exchange Rates in the New EU Accession Countries: What Have We Learned from the Forerunners? Economic Systems. 29(2). 163-186.

Buiter, W. H. and C. Grafe. 2002. Anchor, Float or Abandon Ship: Exchange Rate Regimes for Accession Countries. CEPR Discussion Paper No. 3184.

Burgess, R., Fabrizio, S. and Y. Xiao. 2003. Competitiveness in the Baltics in the Run-Up to EU Accession. IMF Country Report No. 114. Pages

Bussière. M., Fratzscher, M. and G.J. Müller. 2004. Current account dynamics in OECD and EU acceding countries An intertemporal approach. ECB Working Paper No. 311.

Campos, N. and F. Coricelli. 2002. Growth in Transition: What We Know, What We Don't and What We Should. Journal of Economic Literature. 40(3). 793-836.

Canzoneri, M.B., R.E. Cumby and B. Diba. 1999. Relative Labour Productivity and the Real Exchange Rate in the Long-Run: Evidence for a Panel of OECD Countries. Journal of International Economics. 47. 245-266. !

Cassel, G. 1916a. The Present Situation of the Foreign Exchanges. Economic Journal 26(101). 62-65.

Cassel, G. 1916b. The Present Situation of the Foreign Exchanges. Economic Journal 26(103). 219-323.

Cassel, G. 1918. Abnormal Deviations in International Exchanges. Economic Journal 28(112). 413-415.

Chen, S-S. and Ch. Engel. 2004. Does “Aggregation Bias Explain the PPP Puzzle? NBER Working Paper No. 10304.

Čihák, M. and T. Holub. 2001. Convergence of Relative Prices and Inflation in Central and Eastern Europe. IMF Working Paper No. 124.

Čihák, M and T. Holub. 2003. Price Convergence to the EU: What Do the 1999 ICP Data Tell Us? Czech National Bank Working Paper Series No. 2.

Cincibuch, M. and J. Podpiera. 2004. Beyond Balassa-Samuelson: Real Appreciation in Tradables in Transition Economies. CERGE-EI Research Report. http://www.cerge-ei.cz/pdf/gdn/RRCIII 41 paper 01.pdf

Clarida, R. and J. Gali. 1994. Sources of Real Exchange Rate Fluctuations: How Important are Nominal Shocks? Carnegie-Rochester Series on Public Policy. 41. 1-56.

Clark, P. and R. MacDonald. 1999. Exchange Rates and Economic Fundamentals: A Methodological Comparison of BEERs and FEERs. In R. MacDonald and J. Stein (eds), Equilibrium Exchange Rates, Amsterdam: Kluwer. $285-322$. 
Clark, P. and R. MacDonald. 2000. Filtering the BEER - A Permanent and Transitory Decomposition. IMF Working Paper No. 144.

Coricelli, F. and B. Jazbec. 2004. Real Exchange Rate Dynamics in Transition Economies. Structural Change and Economic Dynamics, 15, 83-100.

Corsetti, G. and L. Dedola. 2004. Macroeconomics of International Price Discrimination. Mimeo.

Coudert, V. 1999. Comment définir un taux de change d'équilibre pour les pays émergents? Economie Internationale. 77. $1^{\mathrm{er}}$ trimestre. $45-65$

Coudert, V. and C. Couharde. 2003. Exchange Rate Regimes and Sustainable Parities for CEECs in the Run-up to EMU Membership. Revue Economique, 54(5): 983-1012

Crespo-Cuaresma, J., Fidrmuc, J. and R. MacDonald. 2005. The Monetary Approach to Exchange Rates in the CEECs. Economics of Transition, 13(2), 395-416.

Csajbók, A. 2003. The Equilibrium Real Exchange Rate in Hungary: Results from Alternative Approaches. Paper presented at the $2^{\text {nd }}$ Workshop on Macroecomic Policy Research. National Bank of Hungary. October 2-3.

Csajbók, A. and M. A. Kovács. 2002. FEER Enough? National Bank of Hungary. Mimeo.

Cumby, R. and J. Huizinga. 1990. The Predictability of Real Exchange Rate Changes in the Short Run and in the Long Run. Japan and the World Economy. 3. 17-38.

Darvas, Zs. 2001. Exchange Rate Pass-Through and Real Exchange Rate in EU Candidate Countries. Economic Research Centre of the Deutsche Bundesbank Discussion Paper No. 10.

De Broeck, M. and T. Sløk. 2001. Interpreting Real Exchange Rate Movements in Transition Countries. IMF Working Paper No. 56.

Detken, C., A. Dieppe, J. Henry, C. Marin and F. Smets. 2002. Model Uncertainty and the Equilibrium Value of the Real Effective Euro Exchange Rate. ECB Working Paper No. 160.

Dixit, A.K. and J. Stiglitz. 1977. Monopolistic Competition and Optimum Product Diversity. American Economic Review. 67(3). 297-308.

Djankov, S. and P. Murrell. 2002. Enterprise Restructuring in Transition: A Quantitative Survey. Journal of Economic Literature. 40(3). 739-792.

Dobrinsky, R. 2003. Convergence in Per Capita Income Levels, Productivity Dynamics and Real Exchange Rates in the EU Acceding Countries. Empirica. 30(3). 305-334.

Doisy M. and A. Hervé. 2003. Les déficits courants des PECO: quelles implications pour leur entrée dans l’Union européenne et la zone euro? Economie Internationale. 93. $1^{\mathrm{er}}$ trimestre. 59-88.

Driver, R. and S. Wren-Lewis (1998), Real Exchange Rates for the Year 2000, Washington: Institute for International Economics.

Driver, R. and S. Wren-Lewis. 1999. FEERS: A Sensitivity Analysis. in R. MacDonald and J. Stein (eds). Equilibrium Exchange Rates. Amsterdam: Kluwer. 135-62.

Driver, R. L. and P. F. Westaway. 2005. Concepts of Equilibrium Real Exchange Rates. Bank of England Working Paper No. 248.

Durlauf, S., P. Johnson and J. Temple. 2005. Growth Econometrics. in P. Aghion and S. Durlauf (eds.) Handbook of Economic Growth. Amsterdam: North Holland. forthcoming

EBRD. 2003. Transition Report 2003.

Égert, B. 2002. Investigating the Balassa-Samuelson Hypothesis in the Transition: Do We Understand What We See? A Panel Study. Economics of Transition 10(2). 273-309.

Égert, B. 2005a. The Balassa-Samuelson Hypothesis in Estonia: Oil Shale, Tradable Goods, Regulated Prices and Other Culprits.The World Economy, 28 (2), 259-286.

Égert, B. 2005b. Equilibrium Exchange Rates in South-Eastern Europe, Russia, Ukraine and Turkey: Healthy or (Dutch) Diseased? Economic Systems, 29(2), 205-241.

Égert, B. and A. Lahrèche-Révil. 2003. Estimating the Equilibrium Exchange Rate of the Central and Eastern European Acceding Countries: The Challenge of Euro Adoption. Weltwirtschaftliches Archiv. 139(4). 683-708

Égert, B. and K. Lommatzsch. 2003. Equilibrium Exchange Rates in Acceding Countries: How Large Is Our Confidence (Interval)? Oesterreichische Nationalbank. Focus on Transition. 2. 107-37. 
Égert, B. and L. Halpern. 2005. Equilibrium Exchange Rates in Central and Eastern Europe: A Meta-Regression Analysis. CEPR Discussion Paper 4869 and Journal of Banking and Finance (forthcoming).

Égert, B., A. Lahrèche-Révil and K. Lommatzsch. 2004. The Stock-Flow Approach to the Real Exchange Rate of Transition Economies, CEPII Working Paper No. 14.

Égert, B., I. Drine, K. Lommatzsch and Ch. Rault. 2003. The Balassa-Samuelson Effect in Central and Eastern Europe: Myth or Reality? Journal of Comparative Economics 31(3). 552-572.

Engel, Ch. 1993. Exchange Rates and Relative Prices: An Empirical Investigation. Journal of Monetary Economics. 32(1). 32-50.

Engel, Ch. 1999. Accounting for US Real Exchange Rate Changes. Journal of Political Economy. 107(3). 507-38.

European Central Bank. 2002. Economic Fundamentals and the Exchange Rate of the Euro, Monthly Bulletin. January. $41-53$.

Faruqee, H. 1995. Long-Run Determinants of the Real Exchange Rate: A Stock-Flow Perspective. IMF Staff Papers. 42(1). 80-107.

Filer, R. K. and J. Hanousek. 2000. Output Changes and Inflationary Bias in Transition. Economic Systems. 24(3). 285294.

Filipozzi, F. 2000. Equilibrium Exchange Rate of the Estonian Kroon, Its Dynamics and Its Impacts of Deviations. Bank of Estonia Working Paper No. 3.

Fischer, Ch. 2004. Real Currency Appreciation in Accession Countries: Balassa-Samuelson and Investment Demand. Weltwirtschaftliches Archiv, 140(2). 179-210.

Flek, V., L. Marková and J. Podpiera. 2002. Sectoral Productivity and Real Exchange Rate Appreciation: Much Ado About Nothing? Czech National Bank Working Paper Series No. 4.

Frait, J. and L. Komárek. 1999. Dlouhodobý rovnovážný re álný měnový kurz koruny a jeho determinanty. Czech National Bank Monetary Policy Division Working Paper No. 9.

Froot, K. A. and K. Rogoff. 1994. Perspectives on PPP and Long-Run Real Exchange Rates. NBER Working Paper No. 4952.

Froot, K. A., M. Kim and K. Rogoff. 1995.: The Law of One Price Over 700 Years, NBER Working Paper No. 5132.

Genorio, H. and D. Kozamernik. 2004. FEER Estimates - The Slovenian Case. Bank of Slovenia. Prikazi in analize 12(1). Bank of Slovenia.

Goldstein, M. and M. S. Khan. 1985. Income and Price Effects in Foreign Trade. Chapter 20 in Handbook of International Economics. Vol. 2. ed. by Ronald W. Jones and Peter B. Kenen. Amsterdam: Elsevier. 1985, pp. 1041105.

Golinelli, R. and R. Orsi. 2002. Modelling Inflation in EU Accession Countries: The Case of the Czech Republic, Hungary and Poland. In: Charemza, W. W. and K. Strzala. (eds.). East European Transition and EU Enlargement: A Quantitative Approach. Berlin: Springer Verlag. 267-290.

Gonzalo, J. and C.W.J. Granger. 1995. Estimation of Common Long-Memory Components in Cointegrated Systems. Journal of Business \& Economic Statistics. 13(1). 27-36.

Gordon, R. J. 2000. The Boskin Commission Report and Its Aftermath. NBER Working Paper No. 7759.

Gylfason, T., 2002, Natural resources and economic growth: What is the connection? University of Iceland.

Halpern, L. and Ch. Wyplosz. 1997. Equilibrium Exchange Rates in Transition Countries. IMF Staff Papers 44(4). 430461.

Halpern, L. and Ch. Wyplosz. 2001. Economic Transformation and Real Exchange Rates in the 2000s: The BalassaSamuelson Connection. UNO Economic Survey of Europe. 227-239.

Hanousek, J. and R. K. Filer. 2001a. Consumers' Opinion of Inflation Bias Due to Quality Improvements in Transition in the Czech Republic. CERGE-EI Working Paper 184.

Hanousek, J. and R. K. Filer. 2001b. Evaluating Imperfections and Biases in Price Indexes during Transition. CERGEEI Working Paper No. 186.

Haskel, J. and H. Wolf. 2001. The Law of One Price: A Case Study. Scandinavian Journal of Economics, 103(4), 54558. 
Hinnosar, M., R. Juks, H. Kaadu and L. Uusküla. 2003. Estimating the Equilibrium Exchange Rate of the Estonian Kroon. Bank of Estonia. Mimeo.

Huizinga. J 1987. An Empirical Investigation of the Long-run Behaviour of Real Exchange Rates. Carnegie-Rochester Series on Public Policy. 27. 149-214.

Imbs, J., H. Mumtaz, M.O. Ravn and H. Rey. 2002. PPP Strikes Back: Aggregation and the Real Exchange Rate. NBER Working Paper No. 9372.

Isard, P., H. Faruquee, G. R. Kincaid and M. Fetherston. 2001. Methodology for Current Account and Exchange Rate Assessments. IMF Occasional Papers No. 209.

Ito, T., P. Isard and S. Symansky. 1997. Economic Growth and Real Exchange Rate: An Overview of the BalassaSamuelson Hypothesis in Asia. NBER Working Paper No. 5979.

Jazbec, B. 2002. Balassa-Samuelson Effect in Transition Economies: The Case of Slovenia. William Davidson Working Paper No. 507.

Johansen, S and K. Juselius. 1992. Testing Structural Hypothesis in a Multivariate Cointegration Analysis of the PPP and the UIP for the UK. Journal of Econometrics. 53. pp 211-244.

Juselius, K. 1991. Long-run relations in a well defined statistical model for the data generating process: Cointegration analysis of the PPP and UIP relations between Denmark and Germany. in J. Gruber (ed.). Econometric decision models: New methods of modeling and applications. Springer Verlag. New York, NY.

Juselius, K. 1995. Do purchasing power parity and uncovered interest rate parity hold in the long run? An example of likelihood inference in a multivariate time-series model. Journal of Econometrics. 69(1). 211-240.

Juselius, K. and R. MacDonald. 2000. International parity relationships between Germany and the United States. Unpublished report. European University Institute.

Kao, C. 1999. Spurious Regression and Residual-Based Tests for Cointegration in Panel Data. Journal of Econometrics. 90(1). 1-44.

Karádi, P. 2003. Structural and Single Equation Estimation of the NATREX Equilibrium Real Exchange Rate of the Hungarian Forint. National Bank of Hungary. Mimeo.

Kazaks, M. 2000. Real exchange rate appreciation and loss of competitiveness. The case of Latvia. Presented at the Second Seminar of Managing Economic Transition in Eastern Europe. May 24, 2000. University College London. School of Slavonic and East European Studies.

Kazaks, M. 2005. Essays on the dynamics of the exchange rate of the Latvian Lats. PhD Thesis. Queen Mary. University of London.

Kemme, D. M. and W. Teng. 2000. Determinants of the Real Exchange Rate, Misalignment and Implications for Growth in Poland. Economic Systems 24(2). 171-205.

Kim, B. Y. and I. Korhonen. 2005. Equilibrium Exchange Rates in Transition Countries: Evidence from Dynamic Heterogeneous Panel Models. Economic Systems, 29(2), 144-162.

Kohler, M. 2000. The Balassa-Samuelson Effect and Monetary Targets. In: Mahadeva, L. and G. Sterne (eds.). Monetary Policy Frameworks in a Global Context. London and New York: Routledge. 354-389.

Kornai, J., E. Maskin and G. Roland. 2003. Understanding the Soft Budget Constraint. Journal of Economic Literature. 41(4). 1095-1136.

Kovács, M. A. (ed.). 2002. On the Estimated Size of the Balassa-Samuelson Effect in Five Central and Eastern European Countries. National Bank of Hungary Working Paper No. 5.

Kovács, M. A. 2001. The Equilibrium Exchange Rate in Hungary. National Bank of Hungary Background Study 3. Budapest.

Kovács, M. A. 2003. How Real Is the Fear? Investigating the Balassa-Samuelson Effect in CEC5 Countries in the Prospect of EMU Enlargement. Presented at "Monetary Strategies for Accession Countries". Budapest. 27 - 28 February.

Kovács, M. A. and A. Simon. 1998. Components of the Real Exchange Rate in Hungary. National Bank of Hungary Working Paper No. 3.

Kozamernik, D. 2003. Long-Run Growth and Price Convergence: Implications of a Two-Sector Neoclassical Growth Model and Application to the Slovenian Case. Prikazi in analize 11(2). Bank of Slovenia 
Krajnyák, K. and J. Zettelmeyer. 1998. Competitiveness in Transition Economies: What Scope for Real Appreciation? IMF Staff Papers 45. 309-362.

Kronenberg, T., 2004, The curse of natural resources in the transition economies, Economics of Transition 12(3), 399426.

Kutan, A. M. and M. L. Wyzan. 2005. Explaining the Real Exchange Rate in Kazakhstan, 1996-2003: Is Kazakhstan Vulnerable to the Dutch Disease? Economic Systems. 29(2). Forthcoming.

Lee, J. and M. K. Tang. 2003. Does Productivity Growth Lead to Appreciation of the Real Exchange Rate? IMF Working Paper 154.

Lojschova, A. 2003. Estimating the Impact of the Balassa-Samuelson Effect in Transition Economies. Institute for Advanced Studies Working Paper No. 140.

Lommatzsch, K. and S. Tober. 2002. Monetary Policy Aspects of the Enlargement of the Euro Area. Deutsche Bank Research Working Paper No. 4.

Lommatzsch, K. and S. Tober. 2004. What Is behind the Real Appreciation of the Accession Countries' Currencies? An Investigation of the PPI-Based Real Exchange Rate. Economic Systems, 28(4), 383-403.

Lommatzsch, K. and S. Tober. 2003. The inflation target of the ECB: Does the Balassa-Samuelson effect matter? DIWBerlin. Mimeo.

MacDonald R. and P. Swagel. 2000. Business Cycle Influences on Exchange Rates: Survey and Evidence, World Economic Outlook Supporting Studies. IMF.

MacDonald, R. 1995. Long-run Exchange Rate Modeling: A Survey of the Recent Literature. IMF Staff Papers. 42 (3). 437-489.

MacDonald, R. 1998a. What Determines Real Exchange Rates? The Long and Short of It. Journal of International Financial Markets, Institutions and Money. 8(2). 117-53

MacDonald, R. 1998b. What Do We Really Know About Real Exchange Rates? Oesterreichische Nationalbank Working Paper No. 28.

MacDonald, R. 2000. Concepts to Calculate Equilibrium Exchange Rates: An Overview. Deutsche Bundesbank Discussion Paper No 3.

MacDonald, R. 2005. Exchange Rate Economics: Theories and Evidence. Taylor and Francis. forthcoming.

MacDonald, R. and C. Wójcik (2004) Catching Up: The Role of Demand, Supply and Regulated Price Effects on the Real Exchange Rates of Four Accession Countries. Economics of Transition. 12(1). 153-179.

MacDonald, R. and I.W. Marsh. 1997. On Fundamentals and Exchange Rates: A Casselian Perspective. Review of Economics and Statistics. 79(4). 655-64.

MacDonald, R. and I.W. Marsh. 1999. Exchange Rate Modelling, Amsterdam: Kluwer.

MacDonald, R. and L. Ricci. 2001. PPP and the Balassa Samuelson Effect: The Role of the Distribution Sector. IMF Working Paper No. 38.

MacDonald, R. and L. Ricci. 2002. Purchasing Power Parity and New Trade Theory. IMF Working Paper No. 32.

Maeso-Fernandez, F., Ch. Osbat and B. Schnatz (2004) Towards the Estimation of Equilibrium Exchange Rates for CEE Acceding Countries: Methodological Issues and a Panel Cointegration Perspective, European Central Bank Working Paper No. 353.

Maeso-Fernandez, F., Ch. Osbat and B. Schnatz (2005a) Pitfalls in Estimating Equilibrium Exchange Rates for Transition Economies, Economic Systems, 29(2), 130-143

Maeso-Fernandez, F., Ch. Osbat and B. Schnatz (2005b) Estimating Equilibrium Exchange Rates for New EU Member States: Overcoming Econometric Pitfalls Using Panel Cointegration, mimeo.

Maurin, L. 2001. Fundamental Determinants of RER for Transition Countries. In: Stierle, M. H. and T. Birringer (eds.). Economics of Transition: Theory, Experiences and EU-Enlargement. Berlin: Verlag für Wissenschaft und Forschung. $427-442$.

Mihaljek, D. and M. Klau. 2004. The Balassa-Samuelson Effect in Central Europe: A Disaggregated Analysis. Comparative Economic Studies, 46(1): 63-94

Monacelli, T. 2004. Into the Mussa Puzzle: Monetary Policy Regimes and the Real Exchange Rate in a Small Open Economy. Journal of International Economics. 62. 191-217. 
Mussa, M. 1986. Nominal Exchange Rate Regimes and the Behavior of Real Exchange Rates: Evidence and Implications. Carnegie-Rochester Conference Series on Public Policy. 25. 117-214.!

Nenovsky, N. and K. Dimitrova, 2002, Dual Inflation under the Currency Board: The Challenges of Bulgarian EU Accession, William Davidson Working Paper No. 487.

Nurkse, R. 1945. Conditions of International Monetary Equilibrium. Essays in International Finance. Princeton: International Finance Section. Princeton University. Republished in the Theory of International Trade. Philadelphia: Blackiston. 1949. 3-34.

Obstfeld, M. and K. Rogoff. 2001. Perspectives on OECD Economic Integration: Implications for US Current Account Adjustment, paper presented at the Jackson Hole Conference, Federal Reserve Bank of Kansas.

Oomes, N. 2005. Maintaining Competitiveness Under Equilibrium Real Appreciation: The Case of Slovakia. Economic Systems. 29(2). 187-204.

Ostry, J. and C. Reinhart. 1992. Private Savins and Terms of Trade Shocks, International Monetary Fund Staff Papers.

Papyrakis, E. and R. Gerlagh, 2004, The resource curse hypothesis and its transmission channels, Journal of Comparative Economics 32(1), 181-193.

Pedroni, P. 1999. Critical Values for Cointegration Tests in Heterogeneous Panels with Multiple Regressors. Oxford Bulletin of Economics and Statistics. 61. Supplement 1. 653-670.

Pelkmans, J., Gros, D. and J. N. Perrer. 2000. Long-Run Economic Aspects of the European Union's Eastern Enlargement. The Netherlands Scientific Council for Government Policy Working Document 109.

Rahn, J. 2003. Bilateral Equilibrium Exchange Rates of the EU Accession Countries Against the Euro. BOFIT Discussion Paper No. 11.

Randveer, M. and M. Rell. 2002. The Relationship Between Competitiveness and Real Exchange Rate in Estonia. Bank of Estonia Research Paper.

Rautava, J., 2004, The role of oil prices and the real exchange rate in Russia's economy: a cointegration approach, Journal of Comparative Economics 32, 315-27.

Rawdanowicz, Ł. W. 2003. Poland's Accession to EMU: Choosing the Exchange Rate Parity. CASE Studies\&Analyses 247. December 2002, and forthcoming in: De Souza, L.V. and B. Van Aarle (eds.). The Euro Area and the New EU Member States. New York: Palgrave Macmillan.

Rawdanowicz, Ł. W. 2004. Panel Estimations of PPP and Relative Price Models for CEECs: Lessons for Real Exchange Rate Modelling. CASE Studies\&Analyses No. 276.

Rogoff, K. 1996. The Purchasing Power Parity Puzzle. Journal of Economic Literature. 34(2). 647-668.

Rosati, D. 1994. Output decline during transition. Economics of Transition. 2(4). 419-441.

Rosati, D. 1996. Exchange rate policies during transition from plan to market. Economics of Transition. 4(1). 159-186.

Rosati, D. K. 2002. The Balassa-Samuelson Effect in the EU Candidate Countries. In: Roger, G. and A. Inotai (eds.). Trade, Integration and Transition. Budapest: The World Bank and Institute for World Economics. Hungarian Academy of Sciences. 58-77.

Rother, C. P. 2000. The Impact of Productivity Differentials on Inflation and the Real Exchange Rate: An Estimation of the Balassa-Samuelson Effect in Slovenia. IMF Country Report. Republic of Slovenia: Selected Issues 56. April. $26-39$.

Rubaszek, M. 2003. The Optimal ERM II Central Parity for the Polish Zloty. National Bank of Poland. mimeo

Rubaszek, M. 2004. A Model of Balance of Payments Equilibrium Exchange Rate: Application to the Zloty. Eastern European Economics. 2004. 42(3). 5-22.

Saal, D. and D. Parker. 2001. Productivity and Price Performance in the Privatised Water and Sewerage Companies of England and Wales. Journal of Regulatory Economics 20(1). 61-90.

Sachs, J. and A. Warner, 1995, Natural resource abundance and economic growth, NBER Working Paper No. 5398.

Samuelson, P. 1964. Theoretical Notes on Trade Problems. Review of Economics and Statistics 46(2). 145-154.

Sinn, H. W. and M. Reutter. 2001. The Minimum Inflation Rate for Euroland. NBER Working Paper No. 8085.

Šmídková, K. 1999. Estimating the FEER for the Czech Economy. Prague Economic Papers. 8(1): 53-67

Šmídková, K., R. Barrell and D. Holland. 2003. Estimates of Fundamental Real Exchange Rates for the Five EU PreAccession Countries. Prague Economic Papers. 12(4): 291-316 
Sosunov, K. and O. Zamulin, 2004, What stands behind the real appreciation of the Russian Rouble in 1998-2003? Paper presented at the BOFIT Workshop. Helsinki. April 2-3.

Spilimbergo, A., 1999, Copper and the Chilean Economy: 1960-98, IMF Working Paper No. 57.

Stapafora, N. and E. Stavrev, 2003, The Equilibrium Real Exchange Rate in a Commodity Exporting Country: The Case of Russia, IMF Working Paper No. 93.

Stein, J. L. 1994. The Natural Real Exchange Rate of the US dollar and Determinants of Capital Flows. in J. Williamson (ed.). Estimating Equilibrium Exchange Rates. Institute for International Economics. 133-176.

Stein, J. L. 1995. The Fundamental Determinants of the Real Exchange Rate of the U.S. Dollar Relative to Other G-7 Countries. IMF Working Paper No. 81.

Stein, J. L. 2002. The Equilibrium Real Exchange Rate of the Euro: An Evaluation of Research. CESifo Economic Studies. Zeitschrift für empirische Wirtschaftsforschung. 43(3). 349-381.

Stein, J. L. and G. C. Lim. 2002. Introduction to "Exchange rates in Europe and Australasia: Fundamental determinant, adjustments and policy implications." Australian Economic Papers 41(4). 329-341.

Szapáry, Gy. 2003. Les critères de Maastricht sont-ils trop sévères? (Is Maastricht Too Tough?), Revue d'Economie Financière. No. 71. 225-44

Vetlov, I. 2002. Analysis of the Real Exchange Rate and Competitiveness in Lithuania. Bank of Estonia Research Paper.

Világi, B. 2004. Dual Inflation and Real Exchange Rate in New Open Economy Macroeconomics. National Bank of Hungary Working Paper No. 5.

Wagner, M. and J. Hlouskova. 2004. What is really the story with this Balassa-Samuelson effect in the CEECs. University of Bern. Mimeo.

Williamson, J. 1994. Estimates of FEERs. In: Williamson, J. (ed.). Estimating Equilibrium Exchange Rates. Washington D.C.: Institute for International Economics. 177-244.

Wren-Lewis, S. 1992. On the Analytical Foundations of the Fundamental Equilibrium Exchange Rate, in Macroeconomic Modelling of the Long Run (ed.) Colin P. Hargreaves, Edward Elgar.

Zavoico, B. 1995. A Brief Note on the Inflationary Process in Transition Economies. IMF. Mimeo.

Žumer, T. 2002 Estimation of the Balassa-Samuelson effect in Slovenia. Bank of Slovenia. Prikazi in analize X/1. September 


\section{DAVIDSON INSTITUTE WORKING PAPER SERIES - Most Recent Papers}

The entire Working Paper Series may be downloaded free of charge at: www.wdi.bus.umich.edu

CURRENT AS OF 11/04//05

\begin{tabular}{|c|c|c|}
\hline Publication & Authors & Date \\
\hline $\begin{array}{l}\text { No. 793: Equilibrium Exchange Rates in Transition Economies: } \\
\text { Taking Stock of the Issues }\end{array}$ & Balázs Égert & Oct. 2005 \\
\hline No. 792: Bribery: Who Pays, Who Refuses, What Are The Payoffs? & Jennifer Hunt and Sonia Laszlo & Sept. 2005 \\
\hline $\begin{array}{l}\text { No. 791: Gender Differences In Personality and Earnings: Evidence from } \\
\text { Russia }\end{array}$ & $\begin{array}{l}\text { Susan Linz and Anastasia } \\
\text { Semykina }\end{array}$ & Apr. 2005 \\
\hline No. 790: Why Are Some Public Officials More Corrupt Than Others? & Jennifer Hunt & Sept. 2005 \\
\hline No. 789: Disinflation and Monetary Policy Arrangements in Romania & Daniel Daianu and Ella Kalai & Nov. 2004 \\
\hline $\begin{array}{l}\text { No. 788: Does Economic Uncertainty Affect the Decision to Bear } \\
\text { Children? Evidence from East and West Germany }\end{array}$ & $\begin{array}{l}\text { Sumon Kumar Bhaumik and } \\
\text { Jeffrey B. Nugent }\end{array}$ & Aug. 2005 \\
\hline $\begin{array}{l}\text { No. 787: Economic Reform and Changing Patterns of Labor Force } \\
\text { Participation in Urban and Rural China }\end{array}$ & $\begin{array}{l}\text { Margaret Maurer-Fazio and James } \\
\text { W. Hughes }\end{array}$ & Aug. 2005 \\
\hline $\begin{array}{l}\text { No. 786: The Determinants of Asset Stripping: Theory and Evidence } \\
\text { From the Transition Economies }\end{array}$ & $\begin{array}{l}\text { Nauro F. Campos and Francesco } \\
\text { Giovannoni }\end{array}$ & Aug. 2005 \\
\hline $\begin{array}{l}\text { No. 785: How to Catch Foreign Fish? FDI and Privatization in EU } \\
\text { Accession Countries }\end{array}$ & $\begin{array}{l}\text { Bruno Merlevede and Koen } \\
\text { Schoors }\end{array}$ & Aug. 2005 \\
\hline $\begin{array}{l}\text { No. 784: Does the World Bank have any impact on human development } \\
\text { of the poorest countries? Some preliminary evidence from Africa }\end{array}$ & Sumon Kumar Bhaumik & Aug. 2005 \\
\hline $\begin{array}{l}\text { No. 783: Comparative social capital: Networks of entrepreneurs and } \\
\text { investors in China and Russia }\end{array}$ & Bat Batjargal & July 2005 \\
\hline $\begin{array}{l}\text { No. 782: Exchange Rate Regimes, Foreign Exchange Volatility and } \\
\text { Export Performance in Central and Eastern Europe: Just Another Blur } \\
\text { Project? }\end{array}$ & $\begin{array}{l}\text { Balázs Égert and Amalia Morales- } \\
\text { Zumaquero }\end{array}$ & July 2005 \\
\hline $\begin{array}{l}\text { No. 781: Equilibrium Exchange Rate in the Czech Republic: How Good } \\
\text { is the Czech BEER? }\end{array}$ & Ian Babetskii and Balázs Égert & July 2005 \\
\hline $\begin{array}{l}\text { No. 780: Autonomy and Performance of Foreign Subsidiaries in five } \\
\text { Transition Countries }\end{array}$ & $\begin{array}{l}\text { Urmas Varblane, Katrin Männik, } \\
\text { and Helena Hannula }\end{array}$ & July 2005 \\
\hline $\begin{array}{l}\text { No. 779: The Political Economy of Industrial Policy in China: The Case } \\
\text { of Aircraft Manufacturing }\end{array}$ & Andrea Goldstein & July 2005 \\
\hline $\begin{array}{l}\text { No. 778: Bank Supervision Russian style: Rules versus Enforcement and } \\
\text { Tacit Objectives }\end{array}$ & $\begin{array}{l}\text { Sophie Claeys, Gleb Lanine and } \\
\text { Koen Schoors }\end{array}$ & June 2005 \\
\hline No. 777: Labor Market Trends and Institutions in Belarus & $\begin{array}{l}\text { Zuzana Brixiova and Vera } \\
\text { Volchok }\end{array}$ & June 2005 \\
\hline $\begin{array}{l}\text { No. 776: Can Vietnam Achieve One of its Millennium Development } \\
\text { Goals? An analysis of schooling dropouts of children }\end{array}$ & $\begin{array}{l}\text { Vo Tri Thanh And Trinh Quang } \\
\text { Long }\end{array}$ & June 2005 \\
\hline $\begin{array}{l}\text { No. 775: Is The Link Between Reforms And Growth Spurious? A } \\
\text { Comment }\end{array}$ & Tomasz Mickiewicz & May 2005 \\
\hline $\begin{array}{l}\text { No. 774: The Risk Aversion of Banks in Emerging Credit markets: } \\
\text { Evidence from India }\end{array}$ & $\begin{array}{l}\text { Sumon Kumar Bhaumik and } \\
\text { Jenifer Piesse }\end{array}$ & May 2005 \\
\hline $\begin{array}{l}\text { No. 773: Organized Labor and Restructuring: Coal Mines in the Czech } \\
\text { Republic and Romania }\end{array}$ & $\begin{array}{l}\text { Jan Bruha, Delia Ionascu, and } \\
\text { Byeongju Jeong }\end{array}$ & May 2005 \\
\hline $\begin{array}{l}\text { No. 772: Is Political Risk Company-Specific? The Market Side of the } \\
\text { Yukos Affair }\end{array}$ & $\begin{array}{l}\text { Alexei Goriaev and Konstantin } \\
\text { Sonin }\end{array}$ & May 2005 \\
\hline $\begin{array}{l}\text { No. 771: Non-Linear Exchange Rate Dynamics in Target Zones: A } \\
\text { Bumpy Road Towards A Honeymoon }\end{array}$ & $\begin{array}{l}\text { Jesús Crespo-Cuaresma, Balázs } \\
\text { Égert, and Ronald MacDonald }\end{array}$ & May 2005 \\
\hline $\begin{array}{l}\text { No. 770: Equilibrium Exchange Rates in Southeastern Europe, Russia, } \\
\text { Ukraine and Turkey: Healthy or (Dutch) Diseased? }\end{array}$ & Balázs Égert & May 2005 \\
\hline $\begin{array}{l}\text { No. 769: Equilibrium Exchange Rates in Central and Eastern Europe: A } \\
\text { Meta-Regression Analysis }\end{array}$ & Balázs Égert and László Halpern & May 2005 \\
\hline $\begin{array}{l}\text { No. 768: Testing for inflation convergence between the Euro Zone } \\
\text { and its CEE partners }\end{array}$ & Imed Drine and Christophe Rault & Apr. 2005 \\
\hline
\end{tabular}

